\title{
O efeito da eliminação de doenças crônicas na população idosa: a compressão e a expansão da morbidade
}

Alessandro Gonçalves Campolina

Tese apresentada ao Programa de Pós Graduação da Faculdade de Saúde Pública da Universidade de São Paulo para obtenção do título de Doutor em Saúde Pública.

Área de Concentração: Epidemiologia

Orientadora: Prof ${ }^{\mathrm{a}}$. Dra . Maria Lúcia Lebrão

São Paulo

2011 


\section{Dedicatória}

Aos que, com alegria, fazem da vida uma escultura de tempo e, esquecendo do medo da morte, encontram a criança que persiste em cada idade. 


\section{Agradecimentos}

À Professora Doutora Maria Lúcia Lebrão, pelo apoio e orientação recebidos ao longo dos últimos anos.

Aos professores: Dr. Wilson Jacob Filho, Dra. Margareth Crisóstomo Portela, Dr. Ruy Laurenti e Dr. Jair Licio Ferreira Santos, pelas sugestões e críticas que qualificaram este trabalho.

A todo corpo docente, discente e funcionários do Departamento de Epidemiologia da Faculdade de Saúde Pública da Universidade de São Paulo.

Aos meus pais, familiares e amigos que apoiaram meus estudos e trabalhos.

Em especial, ao Prof. Dr. James F. Fries, pelas contribuições científicas, à Fernando Adami, pela amizade sincera, e à Patrícia Skolaude Dini, pelo amor e alegria compartilhados durante a execução deste trabalho. 
"É impossível meditar sobre o tempo e o mistério da passagem criativa da natureza sem uma avassaladora comoção ante as limitações da inteligência humana”.

Alfred North Whitehead 


\section{Resumo}

Introdução: No contexto do envelhecimento populacional, uma questão fundamental é avaliar se as estratégias de prevenção de doenças crônicas poderiam contribuir para o aumento dos anos vividos em boas condições de saúde, pela população idosa. Objetivo: Avaliar se a eliminação de determinadas doenças crônicas é capaz de levar à compressão da morbidade em indivíduos idosos. Métodos: Estudo transversal analítico, de base populacional, utilizando dados oficiais secundários para o Município de São Paulo, em 2000, e dados obtidos a partir do estudo SABE. O método de Sullivan foi utilizado para o cálculo de expectativas de vida livre de incapacidade (E.V.L.I.). O impacto da eliminação de uma doença na prevalência de incapacidade foi estimado com um modelo de regressão logística múltipla. Tábuas de vida de eliminação de causas foram utilizadas para calcular as probabilidades de morte com a eliminação de doenças. O efeito da eliminação das doenças crônicas foi avaliado, considerando a teoria de riscos competitivos e a abordagem proposta por Nusselder e colaboradores. Resultados: Os maiores ganhos em E.V.L.I., com a eliminação de doenças crônicas, ocorreram no sexo feminino, levando a um processo de compressão absoluta da morbidade. Nos indivíduos de idade mais avançada, os ganhos em E.V.L.I., ocorreram em função de um processo de compressão relativa da morbidade. Nos homens com idade de 75 anos, todas as doenças estudadas, com exceção da doença cardíaca e da hipertensão arterial sistêmica, levaram a um processo de expansão absoluta da morbidade, mas simultaneamente a um processo de compressão relativa da morbidade, ao serem eliminadas. A doença cardíaca apresentou-se como aquela que mais promoveria a compressão da morbidade, caso fosse eliminada, em ambos os sexos. Conclusão: A eliminação de doenças crônicas na população idosa poderia levar a uma compressão da morbidade em homens e mulheres, tanto na idade de 60 anos, quanto na de 75 anos.

Descritores: Transição Epidemiológica; Doença Crônica; Esperança de Vida; Expectativa de Vida Ativa; Tábuas de Vida; Morbidade; Longevidade; Prevenção de Doenças; Saúde do Idoso; Idoso. 


\begin{abstract}
Introduction: In the context of the aging process, a key issue is to assess whether strategies to prevent chronic diseases may contribute to the increase in years lived in good health among elderly individuals. Objective: To evaluate whether elimination of certain chronic diseases can lead to the compression of morbidity, in the elderly. Methods: Analytical cross-sectional survey, based on official data for the city of São Paulo, in 2000, and data obtained from the SABE study. Sullivan's method was used for the calculation of disability-free life expectancy (DFLE). Cause-deleted disability prevalence was estimated using multiple logistic regression model. Cause-deleted probabilities of dying were derived with the cause-elimination life-table technique, considering the independence of the causes of based on the approach proposed by Nusselder and co-workers. Results: The greatest gains in DFLE, with the elimination of chronic diseases, occurred in women, leading to a process of absolute compression of morbidity. Among individuals of a more advanced age, gains in DFLE occurred due to a relative compression of morbidity process. Among men aged 75 years, all diseases eliminated, except heart disease and hypertension, led to a process of absolute expansion of morbidity, but simultaneously, to a relative compression of morbidity. If eliminated, heart disease was the condition that would most lead to the compression of morbidity in both genders. Conclusion: The elimination of chronic diseases in the elderly population could lead to the compression of morbidity in men and women at both 60 years of age and in 75 years of age or older.
\end{abstract}

Keywords: Health Transition; Chronic Disease; Life Expectancy; Active Life Expectancy; Life Tables; Morbidity; Longevity; Disease Prevention; Health of the Elderly; Aged. 


\section{Índice}

\section{Introdução}

1.1 Longevidade, transição demográfica e epidemiológica

1.1.1 A conquista do tempo e revolução demográfica

1.1.2 A multimorbidade e os vetores de complexidade de uma transformação emergente

1.1.3 Doenças crônicas: "o desafio do século XXI" ............................................19

1.2 A compressão da morbidade e a prevenção de doenças crônicas ........................21

1.3 Perspectivas para as políticas de saúde: o Envelhecimento Ativo ........................25

\section{Objetivos}

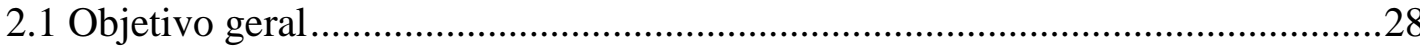

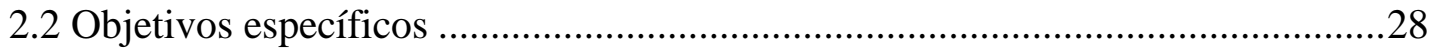

\section{Métodos}

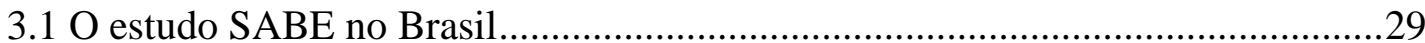

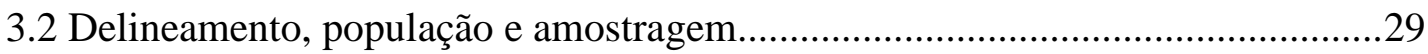

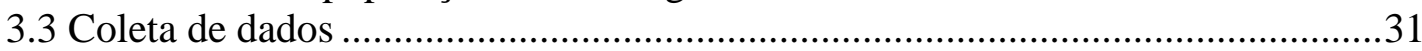

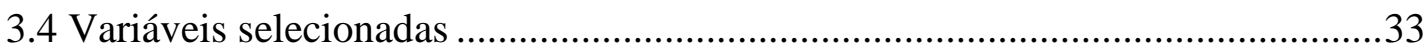

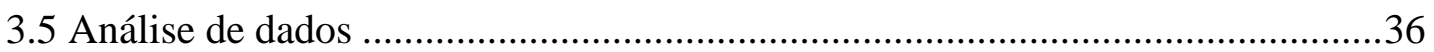

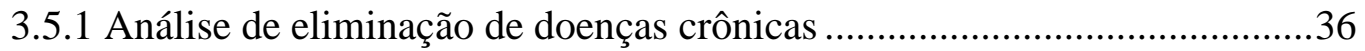

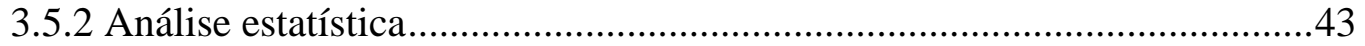

3.6 Medidas de desfecho e interpretação dos resultados............................................43

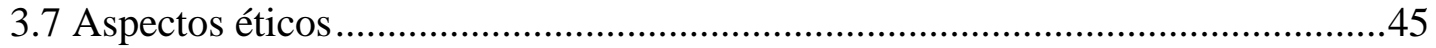

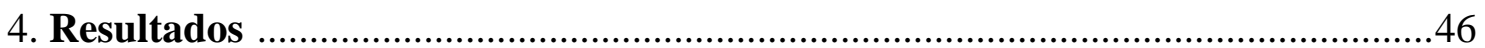

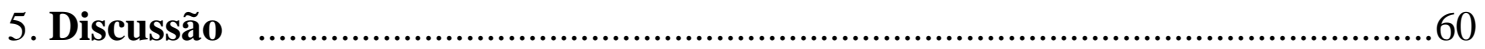

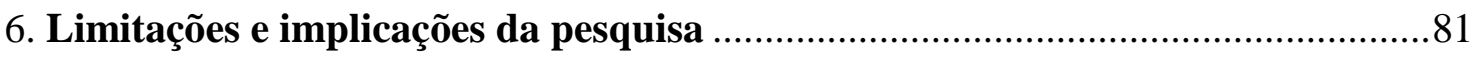

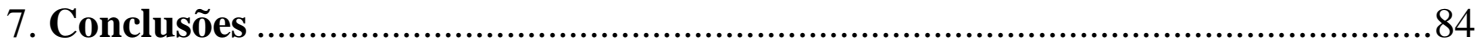

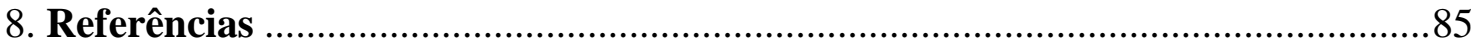

Anexos

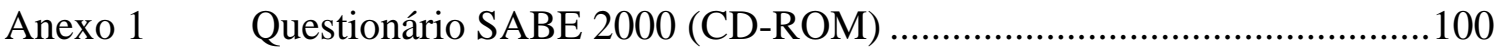

Anexo 2 Tábuas de Vida (CD-ROM) ……............................................................

Anexo 3 Pareceres do Comitê de Ética em Pesquisa..............................................102

\section{Currículo Lattes}




\section{Lista de Siglas e Abreviaturas}

$\begin{array}{ll}\text { ABVD } & \text { Atividades Básicas de Vida Diária } \\ \text { AIDS } & \text { Síndrome da Imunodeficiência Adquirida } \\ \text { BRAZOS } & \text { Brazilian Osteoporosis Study } \\ \text { CID-10 } & \text { Classificação Internacional de Doenças (10 Revisão) } \\ \text { COEP } & \text { Comitê de Ética } \\ \text { CONEP } & \text { Comitê Nacional de Ética em Pesquisa } \\ \text { DALE } & \text { Disability-adjusted Life Expectancy } \\ \text { DALY } & \text { Disability-adjusted Life Years } \\ \text { DCNT } & \text { Doenças Crônicas Não Transmissíveis } \\ \text { DPOC } & \text { Doença Pulmonar Obstrutiva Crônica } \\ \text { EPIDOSO } & \text { Epidemiologia do Idoso } \\ \text { EUA } & \text { Estados Unidos da América } \\ \text { E.V. } & \text { Expectativa de Vida } \\ \text { E.V.C.I. } & \text { Expectativa de Vida com Incapacidade } \\ \text { E.V.L.I. } & \text { Expectativa de Vida Livre de Incapacidade } \\ \text { FAPESP } & \text { Fundação de Amparo à Pesquisa do Estado de São Paulo } \\ \text { FSP/USP } & \text { Faculdade de Saúde Pública da Universidade de São Paulo } \\ \text { HAS } & \text { Hipertensão Arterial Sistêmica } \\ \text { IBGE } & \text { Instituto Brasileiro de Geografia e Estatística } \\ \text { IC } & \text { Intervalo de Confiança } \\ \text { INCA } & \text { Instituto Nacional do Câncer } \\ \text { OMS } & \text { Organização Mundial da Saúde } \\ \text { OPAS } & \text { Organização Pan-Americana da Saúde } \\ \text { PLATINO } & \text { Latin American Project for the Investigation of } \\ & \text { Obstructive Lung Disease } \\ \text { PNAD } & \text { Pesquisa Nacional por Amostra de Domicílios } \\ \text { REVES } & \text { Réseau Esperance de Vie en Santé } \\ \text { SABE } & \text { Saúde, Bem-Estar e Envelhecimento } \\ \text { SAMU } & \text { Serviço de Atendimento Móvel de Urgência } \\ \text { SEADE } & \text { Fundação Sistema Estadual de Análise de Dados } \\ \text { SES-SP } & \text { Secretaria de Estado da Saúde de São Paulo } \\ \text { SUS } & \text { Sistema Único de Saúde } \\ \text { VIGITEL } & \text { Sistema de Vigilância de Fatores de Risco e Proteção } \\ & \text { para Doenças Crônicas por Inquérito Telefônico } \\ & \end{array}$




\section{Lista de tabelas, figuras e quadros}

Tabela 1 Distribuição dos idosos por sexo segundo grupo etário, cor da pele, escolaridade, estado marital, estado laboral e arranjo domiciliar. Estudo SABE, município de São Paulo, Brasil, 2000.

Tabela 2

Prevalência de dificuldade em atividade básica de vida diária segundo sexo e idade. Estudo SABE, município de São Paulo, Brasil, 2000.

Tabela 3

Prevalência de dificuldades no desempenho das ABVD segundo sexo e grupo etário. Estudo SABE, município de São Paulo, Brasil, 2000.

Tabela 4 Auto-percepção de saúde segundo sexo e grupo etário.

Tabela 5 Estudo SABE, município de São Paulo, Brasil, 2000.

Prevalência de doenças crônicas auto-referidas segundo 50 sexo e idade. Estudo SABE, município de São Paulo, Brasil, 2000.

Tabela 6

Número de doenças crônicas auto-referidas pelos idosos segundo sexo e grupo etário. Estudo SABE, município de São Paulo, Brasil, 2000.

Tabela 7

Probabilidade de morrer segundo grupo etário (em anos) dos homens idosos. Município de São Paulo, Brasil, 2000.

Tabela 8

Probabilidade de morrer segundo grupo etário (em anos) das mulheres idosas. Município de São Paulo, Brasil, 2000.

Tabela 9

E.V., E.V.L.I. e proporção de anos a serem vividos livres de incapacidade segundo sexo e grupo etário. Município de São Paulo, Brasil, 2000.

Tabela 10 Número de óbitos segundo sexo, grupo etário (em anos) e causa básica de morte pelo CID-10. Município de São Paulo, Brasil, 2000.

Tabela 11

Prevalência de doenças crônicas e razão de chances para a presença de incapacidade em pelo menos uma ABVD segundo sexo, conforme a análise de regressão logística múltipla. Estudo SABE, município de São Paulo, 2000.

Tabela 12

Parâmetros estimados ( $\beta$ s) pela regressão logística múltipla para a presença de incapacidade em pelo menos uma ABVD segundo o sexo, em idosos. Estudo SABE, município de São Paulo, 2000.

Tabela 13 E.V., E.V.L.I., E.V.C.I. e proporção (\%) dos anos a 55 serem vividos livres de incapacidade, no sexo feminino, segundo faixa etária e eliminação de doenças crônicas. Município de São Paulo, Brasil, 2000.

Tabela 14 E.V., E.V.L.I., E.V.C.I. e proporção (\%) dos anos a 56 


\section{Tabela 15}

Tabela 16

Figura 1

Figura 2

Quadro 1

Quadro 2

Quadro 3 serem vividos livres de incapacidade, no sexo masculino, segundo faixa etária e eliminação de doenças crônicas. Município de São Paulo, Brasil, 2000.

Mudança na E.V., E.V.L.I., E.V.C.I. e na proporção

(\%) dos anos a serem vividos livres de incapacidade, no sexo feminino, segundo faixa etária, em função da eliminação de doenças crônicas. Município de São Paulo, Brasil, 2000.

Mudança na E.V., E.V.L.I., E.V.C.I. e na proporção 58 (\%) dos anos a serem vividos livres de incapacidade, no sexo masculino, segundo faixa etária, em função da eliminação de doenças crônicas. Município de São Paulo, Brasil, 2000.

Mudança na E.V., E.V.L.I., E.V.C.I. e na proporção

(\%) dos anos a serem vividos livres de incapacidade, no sexo masculino, segundo faixa etária, em função da eliminação de doenças crônicas. Município de São Paulo, Brasil, 2000.

Proporção (\%) dos anos a serem vividos livres de incapacidade, no sexo masculino, segundo idade e doença crônica eliminada. Município de São Paulo, Brasil, 2000.

Classificação das doenças auto-referidas segundo o 35 CID-10.

Definição dos blocos temáticos de acordo com as 36 variáveis utilizadas neste estudo e os códigos das questões do questionário SABE, São Paulo, 2000.

Descrição das variáveis categóricas utilizadas na 42 análise de regressão logística múltipla. 


\section{INTRODUÇÃ̃o}

\subsection{LONGEVIDADE, TRANSIÇÃO DEMOGRÁFICA E EPIDEMIOLÓGICA}

\subsubsection{A conquista do tempo e a revolução demográfica}

Se a busca da longevidade parece ser um dos valores mais cultuados em toda a história, o crescimento rápido e progressivo na proporção de idosos em uma população pode ser visto como um grande triunfo da humanidade (PACHOAL, 1996; LITVOC \& BRITO, 2004).

Mesmo diante de uma realidade aparentemente tão desejada e, das inúmeras evidências que afirmam as possibilidades de um envelhecimento saudável, participativo e criativo (OMS, 2005), é notório que muitos ainda vivam atormentados pelo grande paradoxo da longevidade, que faz com que "a ideia de ter uma vida longa agrade a todos e a ideia de envelhecer não agrade a ninguém" (LEBRÃO et al., 2008).

Fazer do aumento do tempo vivido uma conquista de independência e autonomia, talvez seja, assim, o que há de mais esperado pela maior parte dos indivíduos.

Nesse sentido, o conceito de uma velhice bem-sucedida surge no debate gerontológico, a partir da década de 60 , dissociando envelhecimento de doença e destacando os aspectos singulares da longevidade, em especial a heterogeneidade, a multidimensionalidade e a multicausalidade, associadas a esse processo (NERI \& CACHIONI, 1999; ALBUQUERQUE, 2005).

O envelhecimento, visto como um processo positivo em que é possível uma "otimização seletiva com compensação", não se separa de um mecanismo geral de adaptação no qual os indivíduos se engajam ao longo de sua vida. O bem-estar na velhice seria, então, o resultado de uma relação entre as limitações e as potencialidades dos idosos permitindo que, com diferentes graus de eficácia, as perdas ocorridas possam ser superadas ao longo da existência (NERI, 2006). 
Numa perspectiva evolucionista, uma das observações de importância fundamental é a de que a força de seleção natural enfraquece com o envelhecimento e que, portanto, os seres não estariam necessariamente programados para morrer (KIRKWOOD, 2003). Assim, uma força vital poderia estar regulando positivamente o curso de vida, abrindo novas possibilidades especulativas para o longo debate entre as teorias estocásticas e programadas do envelhecimento (BERGSON, 2005).

A visão de um envelhecimento "positivo" também encontra ressonância no termo "envelhecimento ativo", adotado pela Organização Mundial de Saúde (OMS) no final dos anos 90. Este conceito procura transmitir uma mensagem mais abrangente do que "envelhecimento saudável", e reconhecer, para além da dimensão da saúde, outros fatores que afetam o modo como os indivíduos e as populações envelhecem (OMS, 2005).

Envelhecimento ativo, enquanto política de saúde, é entendido como "o processo de otimização das oportunidades para a saúde, a participação e a segurança, com o objetivo de melhorar a qualidade de vida à medida que as pessoas envelhecem" (OMS, 2005). Nesta perspectiva, muitos estudos têm mostrado que o bem-estar ou a qualidade de vida na velhice não depende exclusivamente da presença ou ausência de doenças, mas, talvez, de forma mais expressiva, da manutenção da independência e da autonomia (OMS, 2005; BRASIL. MINISTÉRIO DA SAÚDE, 2006).

Assim, a funcionalidade aparece como um conceito central para uma política de envelhecimento ativo, articulando funções e estruturas do corpo, atividades e participação das pessoas idosas; além de indicar os aspectos positivos da interação contínua entre um indivíduo (com ou sem comprometimentos de saúde), e os fatores contextuais, com os quais se encontra implicado, sejam eles ambientais ou pessoais (OMS, 2003a).

Já de um ponto de vista demográfico, o envelhecimento populacional pode ser visto como um fenômeno recente, que contribui para uma das transformações mais importantes das condições de saúde das populações humanas, fazendo com que o que era no passado privilégio de alguns poucos, passasse a ser uma experiência duradoura de um número crescente de pessoas em todo o mundo (CHAIMOWICZ, 1997; WALDMAN, 2000). 
De uma maneira geral, o envelhecimento de uma população relaciona-se à redução do número de crianças e de jovens e ao aumento na proporção de pessoas com 60 anos ou mais (OMS, 2005). A literatura científica tem destacado, como determinantes demográficos do tamanho e da estrutura etária de uma população, a fecundidade, a mortalidade e a migração. Destes, a fecundidade tem sido considerada como o fator mais importante, principalmente em populações com altas taxas de mortalidade (GRUNDY, 2003). Assim, a redução da fecundidade produz o envelhecimento da população pela diminuição da proporção de crianças e o declínio da mortalidade contribui, simultaneamente, para o processo, pelo aumento da proporção de idosos (LAURENTI et al., 2005a).

A sequência típica das mudanças na distribuição etária de uma população é comumente descrita por um modelo de quatro estágios:

“ $1^{\circ}$ estágio - trata-se de uma etapa estacionária anterior à transição demográfica. Em princípio, a expectativa de vida ao nascer é de 20 a 30 anos. A fecundidade não é controlada, com isso o número médio de filhos por mulheres, durante sua vida é igual a 6,7 ou 8 . A combinação de altos níveis de fecundidade e de mortalidade faz com que a estrutura etária seja do tipo muito jovem, permanecendo relativamente estável, exceto por perturbações esporádicas causadas por calamidades como fome, epidemia e conflitos internos.

$2^{\circ}$ estágio - apesar de algumas exceções, o processo normal da transição demográfica é caracterizado por uma queda sensível da mortalidade, antes mesmo que diminua a fecundidade. Na presença de uma alta mortalidade, o declínio é maior nas idades mais jovens. Assim, apesar de a queda da mortalidade levar a um crescimento da população em todas as idades, há um aumento pronunciado no número de crianças, fazendo com que a estrutura jovem torne-se mais jovem. Outro fato decorrente dessas mudanças é um aumento da fecundidade, que age no mesmo sentido, contribuindo para torná-la ainda mais jovem. Com isso, o crescimento populacional concentra-se inicialmente, nas primeiras idades e, depois, espalha-se para as mais velhas.

$3^{\circ}$ estágio - geralmente, várias décadas depois do início da queda da mortalidade, ocorre um significante declínio da fecundidade. Isso faz com que diminuam o crescimento do número de crianças e a sua proporção na população, acarretando o aumento da proporção de idosos. Esse estágio, portanto, pode ser referido como o de envelhecimento em função da fecundidade. O início de um declínio significante da fecundidade marca a passagem de uma estrutura etária cada vez mais jovem, para outra, cada vez mais velha, e a mudança do aumento para a diminuição da taxa de crescimento da população global.

$4^{\circ}$ estágio - quando o coeficiente de fecundidade total atinge nível próximo ao de reposição (em torno de 2,1 filhos por mulher), o declínio da mortalidade vai substituir, gradualmente, a importância da queda da fecundidade como força motriz do envelhecimento da população. Tem sido mostrado que o envelhecimento populacional na França, Itália e Japão, em anos recentes, é muito mais atribuível ao declínio da mortalidade do que ao da fecundidade" (LAURENTI et al., 2005b). 
A partir desse modelo de transição demográfica, os países podem ser agrupados em três categorias em termos de momento da queda da fecundidade, a saber: os que não a iniciaram até em torno de 1990, os que a iniciaram entre 1950 e 1990 e os que começaram a queda antes de 1950. Esses três grupos são chamados, respectivamente, países de pré-iniciação, iniciação tardia e iniciação precoce do processo de envelhecimento (LAURENTI et al., 2005b).

Pode-se, assim, reconhecer que a transição de uma população jovem para uma envelhecida aconteceu originalmente na Europa, onde a fecundidade declinou marcadamente, muito antes da disponibilidade dos métodos anticoncepcionais científicos. Os países europeus, tidos como de iniciação precoce, em função do desenvolvimento social gerado pela Revolução Industrial, apresentaram inicialmente uma queda gradual na mortalidade e, em seguida, uma queda da fecundidade que, consequentemente, culminou com o envelhecimento da população (RAMOS, 2002).

Toda essa transformação resultou de uma interação complexa de fatores, dentre os quais merecem destaque: a industrialização; os modelos de desenvolvimento econômico com repercussões nos processos migratórios; a ampliação do acesso à água para abastecimento público; a expansão da educação e da rede de serviços de saúde; o aumento da renda com melhora das condições habitacionais e da disponibilidade de alimentos; as mudanças no estilo de vida, com o homem adotando hábitos mais sedentários, submetendo-se a situações de maior estresse; o ingresso da mulher no mercado de trabalho e maior acesso a métodos de contracepção; o aprimoramento das técnicas de preservação de alimentos e a incorporação de novas tecnologias médicas (WALDMAN, 2000).

Paralelamente às transformações demográficas, à medida que os países se industrializaram, mudanças nos padrões de vida e trabalho foram inevitavelmente acompanhadas por uma modificação nos padrões de adoecimento. Essas mudanças fizeram com que o perfil de morbimortalidade, baseado em doenças transmissíveis, fosse modificado para um perfil baseado em doenças crônicas não transmissíveis (DCNT), em que diagnósticos como as doenças cardiovasculares, o câncer e a depressão tornaram-se cada vez mais importantes como causas de morte e invalidez (OMS, 2005). 
Na América Latina, em particular, e nos países em desenvolvimento, em geral, observa-se hoje uma transição demográfica conceitualmente idêntica à verificada na Europa no início do século XX, porém com aspectos práticos diferentes e com implicações aparentemente mais desfavoráveis (RAMOS, 2002).

No caso brasileiro, por exemplo, pode-se observar, a partir do final dos anos 60, uma rapidíssima e generalizada queda da fecundidade e, consequentemente, um acelerado processo de envelhecimento da população. Esse processo apresenta-se mais rápido e com mudanças demográficas mais profundas do que nos países do Primeiro Mundo por duas razões: o declínio da fecundidade deu-se em um ritmo maior e originou-se de uma população mais jovem do que aquela dos países desenvolvidos (RAMOS et al., 1987; CARVALHO \& GARCIA, 2003).

Num contexto de desigualdade social e de alta velocidade com que esses processos vem acontecendo, o que se espera é uma complexidade cada vez maior das necessidades dessa população envelhecida que emerge no Brasil (CHAIMOWICZ, 1997).

Considerando-se ainda o exemplo brasileiro, no início do século passado a expectativa de vida ao nascimento era de 33,7 anos, tendo atingido 43,2 anos em 1950. No decorrer da década imediatamente posterior, a expectativa de vida havia aumentado em quase oito anos (55,9 em 1960). Na década seguinte a expectativa de vida ao nascimento já havia passado a 57,1 e em 1980, atingiu 63,5 anos (KALACHE et al., 1987). Levando em consideração a fecundidade apresentada pelo Brasil nos anos de 1950 a 2000, o país enquadra-se, conforme a classificação apresentada, no estágio de iniciação tardia, com uma fecundidade de 6,2 filhos/mulher em 1950 e de 3,4 filhos/mulher em 1985 (LAURENTI et al., 2005b).

Com uma queda da fecundidade de 2,8 filhos/mulher entre 1950 e 1985, o que chama a atenção no crescimento da população de idosos no Brasil é, portanto, a expectativa da rapidez com que ele se dará até meados do século XXI. Espera-se que o país chegue ao ano 2025 com uma população de cerca de 34 milhões de pessoas acima de 60 anos, uma população maior do que a de qualquer estado brasileiro na atualidade. 
A tendência é haver, assim, transformações drásticas na estrutura etária do país, em tempo relativamente curto, sem que as conquistas sociais tenham se processado devidamente para a maioria da população (RAMOS et al., 1987).

Por fim, pode-se dizer que, no mundo inteiro, os ganhos em expectativa de vida das populações decorreram, portanto, de processos históricos de transformação na estrutura populacional e nos padrões culturais e de morbi-mortalidade, que passaram a ser conhecidos como transição demográfica e transição epidemiológica (OMRAN, 1971; OMRAN, 1983).

Diante de uma revolução sem precedentes, entre 1970 e 2025, espera-se estar diante de um crescimento mundial de $223 \%$, ou em torno de 694 milhões, no número de pessoas com 60 anos ou mais (OMS, 2005).

\subsubsection{A multimorbidade e os vetores de complexidade de uma transformação emergente}

O aumento da prevalência das DCNT é uma das principais características relacionadas ao fenômeno das transições demográfica e epidemiológica, ocorridas, primeiramente, nos países desenvolvidos e que vem ocorrendo de maneira rápida no Brasil, a partir da década de 1960.

As DCNT caracterizam-se por terem uma etiologia incerta, múltiplos fatores de risco, longos períodos de latência, curso prolongado, origem não-infecciosa e por estarem associadas a deficiências e incapacidades funcionais. As causas do surgimento das DCNT são objeto de muitas teorias e envolvem determinantes de natureza biológica, comportamental, política, econômica e social (BRASIL. MINISTÉRIO DA SAÚDE, 2005).

Mais recentemente, o termo "condições crônicas de saúde" tem sido empregado para definir os problemas que persistem no tempo e que requerem algum nível de gerenciamento pelo sistema de saúde, visto que muitas entidades mórbidas, em especial no idoso, não podem ser definidas como doenças (como, por exemplo, algumas das chamadas síndromes geriátricas). Além disso, algumas das doenças transmissíveis incuráveis, como a Síndrome da Imunodeficiência Adquirida (AIDS) 
e as hepatites virais tem apresentado comportamento similar às demais doenças crônicas, a partir do surgimento dos tratamentos modernos (OMS, 2003b).

As condições crônicas de saúde abrangem, portanto, doenças nãotransmissíveis ou transmissíveis persistentes, além de distúrbios mentais e deficiências físicas irreversíveis.

Dentre as principais DCNT que acometem a saúde do idoso podem ser citadas: as doenças osteoarticulares, a hipertensão arterial sistêmica (HAS), as doenças cardiovasculares, o diabetes mellitus, as doenças respiratórias crônicas e o câncer. A prevalência de algumas dessas doenças eleva-se a partir dos 60 anos, em especial as cardiovasculares e as osteoarticulares. Outras condições, apesar de igualmente importantes nessa faixa etária, raramente aparecem nas estatísticas usuais, como: a incontinência urinária e fecal, a instabilidade e quedas, as síndromes de imobilidade e as demências (GRUNDY, 2003).

Em países em desenvolvimento, 50\% de toda a carga de doença está associada às DCNT. Nesses países, a maior parte das mortes é relacionada à doença cardiovascular, câncer, doença pulmonar crônica e diabetes, sendo que, na vigência desse quadro, estima-se a perda de 84 bilhões de dólares, apenas em função da doença cardíaca, doença cerebrovascular e diabetes, entre 2006 e 2015 (STRONG et al., 2005; ABEGUNDE et al., 2007; BEAGLEHOLE et al., 2007).

De especial interesse para a população idosa é o reconhecimento crescente na literatura científica de que a presença da multimorbidade - ou a existência simultânea em um mesmo indivíduo de mais de uma doença crônica - tem se comportado como a regra e não a exceção, nos serviços de atenção primária à saúde (FORTIN et al., 2005; GLYNN et al., 2008). A partir das informações disponíveis, estima-se que nos Estados Unidos da América (EUA), aproximadamente 57 milhões de indivíduos eram portadores de múltiplas doenças crônicas em 2000, sendo que este número poderia chegar a 81 milhões em 2020 (FORTIN et al., 2004).

Essas alterações epidemiológicas trazem profundas implicações para o sistema de saúde na medida em que indivíduos com duas ou mais doenças crônicas apresentam necessidades especiais que demandam processos de atenção orientados para situações complexas, que podem ocasionar um maior número de atendimentos 
médicos e hospitalizações, com custos assistenciais mais elevados (BAYLISS et al., 2008).

Estudos recentes têm revelado, entretanto, que a multimorbidade isoladamente não é capaz de refletir de modo integral a complexidade dos pacientes em acompanhamento clínico, principalmente quando se trata da população idosa. Aspectos socioeconômicos, culturais, comportamentais e ambientais são igualmente importantes, apesar de não receberem uma atenção similar, no contexto clínico. A mudança dos sistemas de gerenciamento, baseados em uma lógica financeira e administrativa, para sistemas baseados em processos clínicos custo-efetivos tem sido apontada como possibilidade de exercício de uma prática médica, com dimensões antropológicas e holísticas, mais adequada ao manejo da complexidade do idoso (NARDI, 2007; SAFFORD, 2007).

Diante dessa nova realidade epidemiológica, o estudo longitudinal EPIDOSO, realizado em São Paulo, foi um dos pioneiros a mostrar que poucas variáveis mantiveram um efeito independente e significante no risco de morte da população idosa, a saber: sexo (masculino), idade (avançada), auto-avaliação subjetiva de saúde (negativa), hospitalização (nos últimos seis meses) e positividade nos rastreamentos para déficit cognitivo e dependência no dia-a-dia (RAMOS, 2002).

Na prática, os únicos fatores de risco de morte mutáveis encontrados nesse estudo foram o estado cognitivo e o grau de dependência no dia-a-dia, demonstrando a importância da funcionalidade para a saúde do idoso e sua associação com a expectativa de vida na velhice (RAMOS, 2003).

Nesta mesma vertente, a Organização Pan-Americana de Saúde (OPAS) durante o período de outubro de 1999 a dezembro de 2000 conduziu e coordenou um estudo multicêntrico denominado Saúde, Bem-estar e Envelhecimento (SABE), em sete centros urbanos da América Latina e Caribe com o objetivo de traçar o perfil das condições de vida e saúde dos idosos residentes nessa região, buscando identificar as demandas associadas ao acelerado processo de envelhecimento observado, de forma a contribuir para o planejamento de ações baseadas na prevenção e diminuição das consequências advindas desse processo (ALBALA et al., 2005; LEBRÃO \& DUARTE, 2008). 
$\mathrm{O}$ estudo SABE mostrou que as doenças crônicas apresentam uma forte influência na capacidade funcional e na auto-percepção de saúde do idoso. A presença de hipertensão arterial aumenta em 39\% a chance de os indivíduos serem dependentes nas atividades instrumentais de vida diária, a doença cardíaca aumenta em $82 \%$, a artropatia em 59\% e a doença pulmonar em 50\%. Para a dependência nas atividades instrumentais e básicas de vida diária, a chance mais do que dobrou para a presença de cada uma dessas doenças crônicas (ALVES \& RODRIGUES, 2005; ALVES et al., 2007).

O relatório mundial publicado em 2003 pela Organização Mundial da Saúde (OMS, 2003b) estabelece que as DCNT devem ser vistas como o "desafio da saúde no século XXI".

Neste sentido, a compreensão do impacto causado por essas doenças na qualidade e na expectativa de vida da população idosa torna-se fundamental.

\subsubsection{Doenças crônicas: "o desafio da saúde no século XXI"}

As DCNT, principalmente as doenças cardiovasculares, o câncer, as doenças respiratórias crônicas e o diabetes, apesar de serem as principais causas de morte e incapacidade, são amplamente negligenciadas nas agendas globais de saúde (BEAGLEHOLE et al., 2007; DAAR, et al., 2007). Equivocadamente consideradas como problemas de sociedades desenvolvidas e de populações envelhecidas, as doenças crônicas constituem uma problemática emergente em países em desenvolvimento, principalmente para aqueles que carecem de recursos para investir em “opções de vida saudáveis” (STRONG et al., 2005).

Aproximadamente $80 \%$ das mortes por doenças crônicas ocorrem em países de baixa e média renda. Mais de $80 \%$ das mortes prematuras por doença cardíaca, acidente vascular encefálico e diabetes poderiam ser evitadas com intervenções comportamentais e farmacológicas conhecidas (ABDALLA et al., 2007), sendo que a redução das taxas de mortalidade por doenças crônicas em $2 \%$ poderia evitar 36 milhões de mortes entre 2005 e 2015 (STRONG et al., 2005). 
Em um relatório de 2007, a OPAS apontava um panorama alarmante para os próximos 10 anos: as mortes por doenças crônicas aumentariam em 17\%, tornandose o principal desafio da área da saúde nas Américas (OPAS, 2007). Da mesma forma, a OMS estima que, até 2020, as DCNT serão responsáveis por $78 \%$ da carga global de doenças nos países em desenvolvimento (OMS, 2003).

Em um estudo comparativo realizado pela OMS (SZWARCWALD \& VIACAVA, 2005; ABEGUNDE et al., 2007), as estimativas de mortalidade para o Brasil em 2005 sugeriam como os principais fatores de risco de morte: a hipertensão arterial sistêmica (20\% de todas as mortes), o colesterol elevado (11\%), o tabaco (7$6 \%$ ) e o sobrepeso e a obesidade (6-5\%).

No Brasil, o estudo de carga de doença mostrou que as DCNT responderam por $66,3 \%$ da carga de doença, as doenças infecciosas por $23,5 \%$ e as causas externas por 10,2\%, uma vez mais, confirmando o processo de transição epidemiológica em curso no país (SCHRAMM et al., 2004).

Também nessa direção, a análise das causas de óbitos entre idosos brasileiros, em 2006, revela as doenças do aparelho circulatório como as principais $(37,8 \%)$, tendo as cerebrovasculares como a mais importante dentre elas. As doenças do aparelho circulatório são seguidas, em importância, pelas neoplasias (16,4\%) e pelas doenças do aparelho respiratório $(13,0 \%)$, com as doenças crônicas das vias aéreas inferiores (incluindo as asmas) como as mais significativas dentro desse grupo (BRASIL. MINISTÉRIO DA SAÚDE, 2005).

No estudo SABE, dentre as doenças crônicas referidas, destacam-se as do aparelho circulatório, as neoplasias e as do aparelho respiratório, como as que proporcionaram as maiores incidências de óbitos (MAIA et al., 2006a).

Intrinsecamente ligado a esse perfil de morbidade da população de mais de 60 anos de idade, as características dos processos de atenção necessários tornam-se diferentes daqueles praticados para o resto da sociedade, em função da incapacidade e da cronicidade que requerem investimentos consideráveis em recursos físicos, medicamentos, pessoal capacitado e procedimentos tecnológicos (WALDMAN, 2000; MURRAY et al., 2000). Nesse sentido, o maior impacto das doenças crônicas na saúde do idoso, provavelmente, esteja relacionado ao prejuízo funcional para a realização de atividades da vida diária (OMS, 2003b). 
Num contexto de envelhecimento populacional, pode se considerar, portanto, que a magnitude do aumento de demanda por assistência à saúde é dada, portanto, pelo número de idosos com problemas crônicos de saúde, ou seja, que apresentam necessidades permanentes de atenção à saúde (LAURENTI et al., 2005a).

Se considerarmos também o aumento progressivo da multimorbidade na população idosa, a demanda por serviços de saúde pode ser ainda maior, acompanhando uma piora da qualidade de vida dessa população, mesmo naqueles indivíduos que sofrem de doenças estáveis e com sintomas controlados (NÓBREGA et al., 2009).

\subsection{A COMPRESSÃO DA MORBIDADE E A PREVENÇÃO DE DOENÇAS CRÔNICAS}

Segundo um estudo realizado no Brasil, pode-se considerar a existência de um grande espaço para a continuação da queda da mortalidade da população brasileira e, se as condições de vida da população sobrevivente não melhorarem, pode-se também prognosticar um aumento do tempo vivido em uma situação precária de saúde (CAMARANO et al., 2004). Nesse caso, uma questão fundamental é avaliar as chances de uma queda progressiva da mortalidade ser acompanhada de uma redução do tempo vivido em más condições de saúde, pela população brasileira, em idades mais avançadas.

O surgimento das DCNT ao longo do curso de vida impõe, portanto, um grande desafio para o "envelhecimento ativo": adiar o surgimento das doenças crônicas e, principalmente, suas sequelas e prejuízos funcionais, mantendo-se fixa a expectativa de vida, e reduzindo, assim, o intervalo de tempo vivido entre o início das doenças e a morte (FRIES, 1980).

Diante das enormes dúvidas que este desafio contemporâneo estabelece, três hipóteses principais têm sido formuladas para investigar a evolução da saúde populacional em países em que as taxas de natalidade e mortalidade são baixas e a mortalidade continua a cair, em especial nas idades mais avançadas. 
A primeira hipótese é conhecida como compressão da morbidade e foi proposta por Fries (1980), sugerindo que a expectativa de vida do adulto tem chegado a seus limites biológicos. Como resultado, se a incidência de doenças incapacitantes puder ser prorrogada, a morbidade será então comprimida em um período de vida menor. Esta hipótese propõe, portanto, que a duração da vida humana é fixa, que a expectativa de vida está chegando a seus limites e que as doenças crônicas e as incapacidades a elas relacionadas podem ser prorrogadas para idades mais avançadas, a partir de modificações no estilo de vida e alterações nos processos fisiológicos e psicológicos do envelhecimento (FRIES, 1980; FRIES, 1992; FRIES, et al., 2011).

A segunda hipótese, proposta por Gruenberg (1977) e Kramer (1980), propõe que o declínio da mortalidade resulta de uma redução das taxas de letalidade das doenças e não da redução de suas incidências ou progressões. Consequentemente, o declínio da mortalidade é acompanhado por um aumento das doenças crônicas e da incapacidade. Para esta hipótese, a expansão da morbidade é resultado de dois processos concomitantes. Primeiramente, a sobrevivência de pessoas com doenças crônicas, em função das intervenções médicas, poderia prolongar a vida de indivíduos seriamente acometidos por essas doenças. Em segundo lugar, o aumento da sobrevida deve empurrar as populações para as idades chamadas de "muito idosos", para além dos 75 anos, quando o risco de doenças nãofatais associadas ao envelhecimento é maior (GRUEMBERG, 1977; KRAMER, 1980).

A terceira hipótese foi proposta por Manton (1982) que sugeriu que o declínio da mortalidade deve-se parcialmente à queda nas taxas de letalidade, mas ao mesmo tempo a incidência e a progressão das doenças crônicas devem estar reduzindo, levando a um equilíbrio dinâmico. De acordo com essa hipótese, os anos com morbidade grave e incapacidade permanecem relativamente constantes, porque as intervenções médicas e as mudanças de estilo de vida também reduzem a taxa de progressão das doenças crônicas (MANTON, 1982).

O que se encontra na literatura científica atualmente são evidências sobre a continuação da queda da mortalidade, mas não há consenso sobre até quando e como ela poderá cair (CAMARANO et al., 2004). 
Como consequência da queda da fecundidade, o processo de envelhecimento populacional brasileiro tem se acentuado, inclusive com um crescimento expressivo da proporção dos "muito idosos". No Brasil, o número de centenários dobrou entre 1980 e 2000, passando de 12.225 para 24.576 (CAMARANO et al., 2004).

Vários demógrafos já falam, inclusive, da quarta fase da transição demográfica e epidemiológica, em que a geração mais velha, particularmente nos países desenvolvidos, vivenciará declínios expressivos na mortalidade e ganhos na expectativa de vida (CAMARANO et al., 2004). O crescimento da expectativa de vida coloca, portanto, uma questão importante para as políticas públicas: em que condições viverão os longevos?

Para Fries, uma vez que a expectativa de vida chegue bem próxima do limite biológico, dever-se-á alcançar a compressão da morbidade, ou seja, a qualidade de vida na ampliação da expectativa de vida (FRIES, 1980).

Visões negativas a respeito do aumento da expectativa de vida associado a um aumento na prevalência de distúrbios mentais e doenças crônicas em idosos, pautaram, entretanto, o discurso de vários pesquisadores do envelhecimento e da qualidade de vida nos anos de 1960 e 1970, num discurso que ficou conhecido como a "falência do sucesso" (GRUEMBERG, 1977).

Na realidade, parece não existir uma associação clara entre o tempo de vida e o seu estado de saúde correspondente, conforme ilustrado pela comparação, por exemplo, das expectativas de saúde de diferentes grupos raciais norte-americanos. Para os descendentes de asiáticos, uma vida mais longa esteve associada a um tempo de vida menor e em um estado de saúde pior. Para os nativos americanos, uma maior extensão do tempo de vida foi associada com a expansão do período de morbidade. Os negros americanos são os que tiveram os menores períodos de vida, e, ainda assim, com uma grande proporção desse período acometido por doenças crônicas. Já os de descendência hispânica, apesar de viverem menores períodos de vida, apresentaram uma compressão relativa da morbidade (NUSSELDER, 2003).

Em uma perspectiva mais ampla, as tendências demográficas têm se mostrado contrárias às proposições de Fries, com o aumento progressivo da população de muito idosos e com a ausência de dados consistentes que sustentem a 
hipótese de compressão de morbidade nos países em desenvolvimento (KALACHE et al., 2002).

Entretanto, as doenças crônicas podem ser adiadas ou mesmo prevenidas com a adoção de um estilo de vida saudável, como, por exemplo, evitando o sobrepeso, o tabagismo, e o sedentarismo. Uma estratégia ativa para a manutenção da saúde e do bem-estar nas idades avançadas parece envolver uma perspectiva preventiva de compromisso pessoal com um estilo de vida promotor de nutrição adequada, aptidão física, conexões sociais e uso preventivo de serviços de saúde (FRIES, 1992; PHELAN et al., 2003).

Dentre os hábitos saudáveis que não só permitem que os indivíduos sobrevivam por mais tempo, mas, também, prorroguem o aparecimento da incapacidade e comprimam a perda funcional para os últimos anos de vida, grande destaque tem sido dado à qualidade nutricional, à cessação do tabagismo e à prática regular de atividade física (PHELAN et al., 2003; TAKAHASHI et al., 2004).

Conforme o modelo de Fries resta, portanto, sustentar um processo de avaliação contínua das intervenções preventivas, visando estabelecer se o controle de doenças crônicas em populações idosas mórbidas, poderia contribuir para uma compressão da incapacidade em países em desenvolvimento, onde a transição epidemiológica ainda se encontra em uma fase intermediária, em que as taxas de mortalidade tendem a cair progressivamente nos próximos anos.

Com este propósito, em uma perspectiva de prevenção de doenças crônicas, será utilizado neste projeto um indicador específico de expectativa de saúde: a expectativa de vida livre de incapacidade, conforme proposto pela Réseau Esperance de Vie en Santé (REVES), uma rede de estudos constituída na década de 80 (ROBINE et al., 1999) que vem divulgando a implementação de indicadores que combinam dados de morbidade e mortalidade em uma mesma medida (medidasresumo) para fins de planejamento em saúde (CRIMMINS, 2002; MATHERS, 2002; MYERS et al., 2003; MCDOWELL et al., 2004).

Com a finalidade de testar a hipótese de Fries, a relação entre a expectativa de vida e a expectativa de vida livre de incapacidade pode ser usada para avaliar a ocorrência de compressão de morbidade (NUSSELDER, 2003). Nesse sentido, quando apenas 2 estados de saúde são considerados (como por exemplo, com ou sem 
incapacidade) ou quando estados dicotômicos baseados em uma série de estados de saúde são construídos, as mudanças nas medidas de expectativa de saúde de uma população podem ser classificadas em termos de compressão (e expansão) da morbidade (NUSSELDER, 2003).

\subsection{PERSPECTIVAS PARA AS POLÍTICAS DE SAÚDE: O ENVELHECIMENTO ATIVO}

No documento "Envelhecimento Ativo: uma política de saúde", a OMS chama a atenção de legisladores e tomadores de decisão quanto ao impacto econômico e social de uma perspectiva preventiva de envelhecimento ativo (OMS, 2005).

\footnotetext{
“Em relação aos crescentes gastos públicos com assistência médica, alguns dados disponíveis indicam que a velhice em si não está associada ao aumento das despesas médicas. O que encarece os gastos são as deficiências e a saúde precária - frequentemente associados à velhice. Se as pessoas envelhecerem com uma saúde melhor, as despesas médicas, provavelmente, não aumentarão tão rapidamente... Por fim, é, frequentemente, menos dispendioso prevenir a doença do que tratá-la. Por exemplo, estimou-se que para cada dólar investido em medidas para encorajar a atividade física moderada houve uma economia de 3,2 dólares em despesas médicas" (OMS, 2005).
}

Se o envelhecimento ativo tem por objetivo "melhorar a qualidade de vida à medida que as pessoas ficam mais velhas”, é necessário, também, reconhecer que "para promover o envelhecimento ativo, os sistemas de saúde necessitam ter uma perspectiva de curso de vida que vise à promoção da saúde, prevenção de doenças e acesso equitativo a cuidado primário e de longo prazo com qualidade" (OMS, 2005).

$\mathrm{Na}$ tentativa de dar conta da nova realidade epidemiológica que acompanha o envelhecimento populacional, num contexto em que os custos do setor saúde tornam-se crescentes com a rapidez das inovações tecnológicas incorporadas, os modelos tecno-assistenciais de gerenciamento de doenças crônicas têm se multiplicado em diversas partes do mundo, com uma necessidade clara de evidências científicas que sustentem uma perspectiva preventiva de atenção à saúde (ASSIS et al., 2004). 
Nos EUA, o Chronic Care Model talvez seja um dos mais conhecidos desses modelos, estando na base da política de "Cuidados Inovadores em Doenças Crônicas", proposta pela OMS (BONDENHEIMER et al., 2002a). Focando na criação de um ambiente favorável para a relação triádica entre a comunidade, a organização de saúde e os pacientes, o Chronic Care Model busca obter resultados favoráveis no tratamento das condições crônicas de saúde. Dentre as estratégias preconizadas pelo modelo figuram a utilização de sistemas informatizados de monitoramento clínico, o treinamento das equipes de saúde com o uso de suportes de decisão, do tipo diretrizes terapêuticas, e a motivação dos pacientes com suporte para o auto-cuidado (BONDENHEIMER et al., 2002b).

Já o Guided Care, também desenvolvido nos EUA e conhecido como "modelo da Johns Hopkins", tem um direcionamento maior para indivíduos multimórbidos, sendo por vezes chamado de "Chronic Care Ampliado". A ideia central nesse modelo é trabalhar com guias ou planos terapêuticos, sendo que algumas inovações facilitam a assistência, num enfoque mais direcionado ao idoso, como: a utilização de dispositivos organizacionais de cuidado intermediário, a ênfase na educação dos cuidadores e a implementação de avaliações geriátricas amplas (BOYD et al., 2007).

No Canadá, um modelo proposto por pesquisadores do campo da multimorbidade, tem focado mais no trabalho de equipe, acreditando no potencial dos relacionamentos e na aprendizagem colaborativa, ao longo do trabalho multiprofissional. A utilização de ferramentas inovadoras para facilitar o trabalho coletivo é uma característica desse modelo em que se encontra o desenvolvimento de estudos de caso via internet e a utilização de tecnologias ativas de aprendizagem, como norteadores dos processos de trabalho em saúde (SOUBHI et al., 2010).

No Brasil, esforços nessa direção também não deixam de acontecer a partir da Política Nacional de Saúde do Idoso e da elaboração das linhas de cuidado para doenças crônicas (SES-SP, 2010).

De uma maneira geral, segundo o relatório da OMS de 2002, todos esses modelos tecno-assistenciais para doenças crônicas baseiam-se em alguns princípios fundamentais: tomada de decisão com base em evidências científicas, enfoque na 
população, enfoque na prevenção, enfoque na qualidade, integração entre os níveis de atenção, flexibilidade e adaptabilidade com vigilância permanente (OMS, 2003).

De acordo essas propostas, a Política de Envelhecimento Ativo da OMS também reconhece a necessidade de interação constante entre a dimensão individual e contextual para a conquista de uma velhice ativa:

"Programas e políticas de envelhecimento ativo reconhecem a necessidade de incentivar e equilibrar responsabilidade pessoal (cuidado consigo mesmo), ambientes amistosos para a faixa etária e solidariedade entre gerações. As famílias e os indivíduos precisam se planejar e se preparar para a velhice e precisam se esforçar pessoalmente para adotar uma postura de práticas saudáveis em todas as fases da vida. Ao mesmo tempo, é necessário que os ambientes de apoio façam com que as opções saudáveis sejam as mais fáceis" (OMS, 2005).

O objetivo de uma política de envelhecimento ativo é, portanto, "aumentar a expectativa de vida saudável, inclusive dos mais frágeis, fisicamente incapacitados e que requerem cuidados" (OMS, 2005).

Para este trabalho, parte-se de uma perspectiva processual de envelhecimento ativo, intrinsecamente ligada à capacidade de prevenir doenças e, principalmente, as incapacidades relacionadas a elas; e, ao mesmo tempo, de manter um alto nível de funcionamento físico, mental e de engajamento com a vida, o que significa manter relacionamentos sociais e atividades produtivas (LUPIEN \& WAN, 2004).

Assim, buscar-se-á contribuir para o entendimento sobre as possibilidades da prevenção das doenças crônicas em uma população idosa, em termos de compressão ou expansão da morbidade, numa perspectiva de produção de conhecimentos estratégicos para o planejamento dos modelos de gerenciamento de casos e de doenças, focados na atenção à saúde do idoso. 


\section{OBJETIVOS}

\subsection{OBJETIVO GERAL}

Avaliar se a eliminação de determinadas doenças crônicas é capaz de levar à compressão da morbidade em indivíduos idosos.

\subsection{OBJETIVOS ESPECÍFICOS}

2.2.1 Calcular a expectativa de vida livre de incapacidade, com eliminação de causas, segundo o sexo, para a população idosa do município de São Paulo, em 2000.

2.2.2 Analisar o efeito da eliminação de doenças crônicas na expectativa de vida, expectativa de vida livre de incapacidade e expectativa de vida com incapacidade, da população idosa do município de São Paulo, em 2000.

2.2.3 Comparar o efeito da eliminação de diferentes doenças crônicas, em termos de compressão e expansão da morbidade, na população idosa.

2.2.4 Verificar se a eliminação de doenças crônicas comprime o tempo de incapacidade, ou seja, diminui a proporção do tempo de expectativa de vida que seria vivido com incapacidade, pela população idosa. 


\section{MÉTODOS}

\subsection{O ESTUDO SABE NO BRASIL}

O estudo SABE é uma pesquisa epidemiológica, de base populacional, que se constitui em um dos primeiros esforços para coletar sistematicamente informações sobre as condições de vida do idoso em sete cidades da América Latina e Caribe (Argentina, Barbados, Brasil, Chile, Cuba, México e Uruguai) (LEBRÃO \& LAURENTI, 2005).

No Brasil, o SABE foi desenvolvido na área urbana do município de São Paulo, tendo se iniciado no ano de 2000, coordenado pela Faculdade de Saúde Pública da Universidade de São Paulo (FSP/USP) e financiado pela Fundação de Amparo à Pesquisa do Estado de São Paulo (FAPESP) e pelo Ministério da Saúde (LEBRÃO \& DUARTE, 2003; PALLONI \& PELAÉZ, 2003). Passados seis anos da primeira coleta de dados deste estudo, sua continuidade foi proposta em 2006, transformando-o em um estudo longitudinal. Assim as pessoas que haviam sido entrevistadas em 2000 foram reavaliadas, constituindo um conjunto de participantes de 1115 pessoas com 65 anos e mais. Paralelamente à pesquisa com esta coorte, introduziu-se uma nova coorte de 60 a 64 anos, composta por 400 indivíduos.

\subsection{DELINEAMENTO, POPULAÇÃO E AMOSTRAGEM}

Este projeto é parte do estudo SABE e adotou um delineamento do tipo observacional, transversal e analítico, baseado no banco de dados do SABE, elaborado no ano 2000, e em informações de mortalidade do município de São Paulo.

No Brasil, participaram do estudo 2143 indivíduos, com idades de 60 anos ou mais, de ambos os sexos. A amostragem foi probabilística, de acordo com a população idosa do município de São Paulo em 1996, sendo representativa dessa população. Nesse ano, o número de idosos do município era 836.223, conforme o IBGE, correspondendo a 8,1\% da população total (IBGE, 2001). 
A amostra foi composta inicialmente por 1568 idosos e, posteriormente, ampliada para 2143 para complementar o número de idosos com idade $\geq 75$ anos e do sexo masculino, em função da maior taxa de mortalidade desse grupo etário e sexo (SILVA, 2003).

Para a obtenção da quantidade de idosos desejados, foi definido o número mínimo de 5882 domicílios a serem sorteados, pela expressão [d=(1500*10/3)/0,85], sendo d, o número mínimo de domicílios a serem sorteados; 1500, o número mínimo de idosos para possibilitar as análises desejadas; a razão 10/3, referente a 3 idosos para cada 10 domicílios; e 0,85, a taxa de sucesso esperada para localização e realização das entrevistas nos domicílios sorteados (SILVA, 2003).

Para o sorteio dos domicílios, foi utilizada a amostragem por conglomerados, em dois estágios, selecionados por critério de partilha proporcional ao tamanho:

Primeiro estágio - para a amostragem deste estágio, foi utilizado o cadastro permanente de 72 setores censitários da Pesquisa Nacional por Amostra de Domicílios (PNAD) de 1995 e calculado por $\mathrm{f}_{1}=\left(72 * \mathrm{D}_{\mathrm{i}}\right) / \mathrm{D}$, sendo $\mathrm{f}_{1}$, a fração de amostragem deste estágio, $\mathrm{D}_{\mathrm{i}}$, o número de domicílios de cada setor; e, $\mathrm{D}$, o total de domicílios existentes no município de São Paulo.

Segundo estágio - para a amostragem deste estágio, foi calculado o número de domicílios a serem sorteados, segundo o número de setores censitários $(5882 / 72=81,69$, aproximado para 90$)$, definido por $\mathrm{f}_{2}=90 / \mathrm{D}_{\mathrm{i}}$, a partir da utilização dos endereços, segundo a PNAD de 1998 (SILVA, 2003).

A probabilidade de um domicílio pertencer à amostra sorteada foi definida por $\mathrm{f}=\mathrm{f} 1 * \mathrm{f} 2$. Nos domicílios sorteados, foram identificados 1852 idosos elegíveis, dos quais 1568 concordaram em participar do estudo (84,67\%).

A complementação da amostra de idosos com idade $\geq 75$ anos e do sexo masculino foi realizada pela localização de moradias próximas aos setores selecionados ou, no máximo, dentro dos limites dos distritos dos setores sorteados (SILVA, 2003).

Para ajustar a distribuição da amostra à composição da população, foram calculados pesos para cada sexo e grupo etário. Para compensar probabilidades desiguais de sorteio do segundo estágio, devido à atualização das listas de endereço 
pela PNAD de 1998 foram calculados pesos para cada setor censitário (SILVA, 2003).

A descrição detalhada dos métodos empregados no estudo SABE pode ser encontrada no livro "O Projeto SABE no Município de São Paulo: uma abordagem inicial" [disponível em www.opas.org.br/publicac.cfm].

\subsection{COLETA DE DADOS}

Os dados para o estudo $\mathrm{SABE}$, foram obtidos por meio de um questionário elaborado por um comitê regional, composto pelos principais pesquisadores de cada país participante e por especialistas em temas específicos da pesquisa. O instrumento era composto por onze seções que abrangiam vários aspectos da vida do idoso, tais como: dados pessoais, avaliação cognitiva, estado de saúde, estado funcional, medicamentos, uso e acesso aos serviços, rede de apoio familiar e social, história laboral e fontes de ingresso, características da moradia, antropometria, flexibilidade e mobilidade. As variáveis incluídas em cada seção foram:

\section{Seção A - Dados Pessoais}

Ano e país de nascimento; local de residência durante os primeiros quinze anos de vida; local de residência durante os últimos cinco anos de vida e, onde, fosse aplicável, razões para a mudança de residência; história e estado marital; número de filhos; sobrevivência dos pais e, se não, a idade em que faleceram; escolaridade.

\section{Seção B - Avaliação Cognitiva}

Auto-avaliação da memória; avaliação da memória pelo teste mini-mental modificado e validado no Chile para realização do estudo. Para os que obtivessem escore igual ou inferior a 12 pontos, uma escala de desempenho funcional era administrada a um proxi-respondente (informante substituto) a partir da questão "é capaz de...".

\section{Seção C - Estado de saúde}

Auto-avaliação de saúde atual e comparativa ao ano anterior, bem como da saúde na infância; doenças referidas, considerando nove das doenças crônicas mais prevalentes na população idosa e incluindo seu tratamento; hábitos, condições 
sensoriais; saúde reprodutiva; saúde bucal; ocorrência de quedas; escala de avaliação de depressão geriátrica e mini screening nutricional.

\section{Seção D - Estado Funcional}

Avaliação do desempenho funcional e da ajuda recebida, quando necessário, nas atividades básicas e instrumentais da vida diária e identificação e caracterização dos cuidadores principais.

\section{Seção E - Medicamentos}

Terapêutica medicamentosa utilizada, incluindo indicação, tempo de uso, forma de utilização, obtenção e pagamento; gastos mensais com medicamentos e motivos referidos para a não utilização dos medicamentos prescritos.

\section{Seção F - Uso e acesso a serviços}

Serviços de saúde utilizados, públicos ou privados, nos últimos meses e ocorrência de hospitalização, atendimento ambulatorial, exames nos últimos quatro meses, bem como tempo de espera para atendimento, terapêutica prescrita e gastos relacionados.

\section{Seção G - Rede de apoio familiar e social}

Número e características de pessoas que vivem com o idoso no mesmo domicílio (sexo, parentesco, estado marital, idade, escolaridade e condição de trabalho); assistência prestada ao idoso e fornecida por ele referente a cada membro citado; tempo gasto na ajuda ao idoso. As mesmas perguntas foram feitas em relação aos irmãos e filhos que não vivem no mesmo domicílio, bem como a outros familiares e que, de alguma forma, fornecem ou recebem ajuda do/ao idoso; assistência recebida ou fornecida nos últimos 12 meses de alguma instituição ou organização; participação do idoso em algum serviço voluntário ou organização comunitária.

\section{Seção H - História laboral e fontes de renda}

Trabalho atual (tipo, renda, razões para continuar trabalhando); caso não trabalhasse mais, porque não o fazia, ocupação que teve durante o maior período de sua vida, horas trabalhadas, razões para mudar de atividade, aposentadoria, pensões, benefícios, outras fontes de renda, renda total pessoal e número de dependentes dessa renda; gastos pessoais (moradia, transporte, alimentação, vestimenta, saúde) e autoavaliação de seu bem estar econômico. 


\section{Seção J - Características da moradia}

Tipo e propriedade da moradia, condições de habitação (saneamento básico, luz, número de cômodos, bens presentes).

\section{Seção K - Antropometria}

Altura do joelho, circunferência do braço, cintura, quadril, prega triciptal, peso, circunferência da panturrilha, largura do punho e força da mão.

\section{Seção L - Flexibilidade e Mobilidade}

Provas de equilíbrio, mobilidade e flexibilidade.

As entrevistas foram realizadas em domicílio, sendo a maior parte delas, feitas diretamente com os idosos (88\%). Nos casos em que havia dificuldade ou impossibilidade de o idoso responder aos questionamentos (por problemas físicos ou cognitivos), foi solicitado que uma pessoa próxima a ele o fizesse (NAZÁRIO, 2003).

A primeira coleta dos dados ocorreu de janeiro de 2000 a março de $2001 \mathrm{em}$ duas fases: na primeira, foram realizadas as seções de A a J, por equipe de 25 profissionais de saúde, incluindo enfermeiras e assistentes sociais, que atuavam individualmente e, na segunda etapa, as seções L e K, por equipe de 12 estudantes de nutrição, que trabalhavam em dupla, devido às características das questões dessas seções que incluíam mensurações antropométricas e testes de mobilidade e flexibilidade.

O questionário empregado no estudo SABE pode ser obtido na íntegra no CD que acompanha este volume (Anexo I) ou em http://www.fsp.usp.br/sabe.

\subsection{VARIÁVEIS SELECIONADAS}

Para este projeto, as variáveis foram selecionadas, entre as disponíveis, quanto às características sócio-demográficas, doenças auto-referidas e capacidade funcional.

As seguintes variáveis sócio-demográficas foram consideradas para descrição e análise: idade, sexo, arranjo familiar, estado marital, cor da pele, escolaridade e renda, com base em literatura científica pertinente (GUTIÉRREZ- 
FISAC et al., 2000; NUSSELDER et al., 2000; KONDO et al., 2005; MATHEWS et al., 2006; JAGGER et al., 2007b; MACIEL \& GUERRA, 2007; FIEDLER \& PERES, 2008).

A idade foi avaliada como variável contínua e categorizada em: 60-74 anos e 75 anos e mais. O arranjo familiar foi dicotomizado em: vive sozinho (a), vive acompanhado (a). Com relação à escolaridade, os idosos foram categorizados em: sem educação formal, ensino fundamental, ensino médio e ensino superior ou mais. O estado marital foi categorizado em: solteiro, casado/amasiado, viúvo e divorciado/separado. O estado laboral foi dicotomizado em: trabalha atualmente e não trabalha atualmente.

As doenças crônicas foram mensuradas com base nas respostas afirmativas (auto-referidas) relativas à presença de nove doenças crônicas: hipertensão arterial sistêmica, diabetes mellitus, doença cardíaca, doença pulmonar crônica, neoplasia, doença articular, doença cerebrovascular, queda no último ano e problema nervoso ou psiquiátrico. Em função da alta prevalência na população idosa e do grande impacto em termos de morbi-mortalidade, optamos por tratar o evento queda como doença crônica, para fins de análise neste estudo.

A doença cardíaca foi definida como: ataque cardíaco, doença coronariana, angina, doença congestiva ou outros problemas cardíacos. A doença pulmonar como: asma, bronquite ou enfisema. A artropatia como: artrite, reumatismo ou artrose. O câncer excluía somente os tumores menores de pele.

A capacidade funcional foi avaliada detalhadamente, no estudo SABE, por meio de três componentes (BARBOSA et al., 2005): atividades básicas de vida diária (seis itens), atividades instrumentais de vida diária (nove itens) e mobilidade (12 itens).

A incapacidade funcional foi definida, para este projeto, como a dificuldade em realizar uma ou mais atividades básicas de vida diária, baseado em vários estudos que têm utilizado esta mesma opção metodológica, recomendando o uso de indicadores de incapacidade que mensuram a disfunção em si e não a necessidade de intervenções para reduzir as disfunções, como, por exemplo, a assistência prestada por cuidadores (DEGG et al., 2003). 
As atividades básicas de vida diária contempladas no questionário do SABE e empregadas na presente análise foram: vestir-se, comer, tomar banho, ir ao banheiro, locomover-se (deitar-se, levantar da cama e atravessar um cômodo da casa), incontinência fecal e incontinência urinária (DUARTE et al., 2007). A presença de dificuldade para a realização de uma ou mais destas atividades, ou presença de incontinências, foi considerada como incapacidade para fins de cálculo das expectativas de vida livre de incapacidade.

As questões referentes às doenças auto-referidas do questionário SABE foram classificadas segundo a Classificação Internacional das Doenças - $10^{\mathrm{a}}$ Revisão (CID-10), conforme apresentado nos Quadro 1 e 2:

Quadro 1 - Classificação das doenças auto-referidas, segundo o CID-10¹.

\begin{tabular}{|l|l|}
\hline Doença segundo o questionário SABE & Doença segundo o CID-10 \\
\hline Pressão sanguínea alta / hipertensão & I10 - Hipertensão essencial primária \\
\hline Diabetes/níveis altos de açúcar no sangue & E14 - Diabetes mellitus não especificado \\
\hline Câncer ou tumor maligno & $\begin{array}{l}\text { C80- Neoplasia maligna, sem } \\
\text { especificação de localização }\end{array}$ \\
\hline $\begin{array}{l}\text { Doença crônica do pulmão (asma, bronquite ou } \\
\text { enfisema) }\end{array}$ & $\begin{array}{l}\text { J44.9 - Doença pulmonar obstrutiva } \\
\text { crônica não especificada }\end{array}$ \\
\hline Problema nervoso ou psiquiátrico & $\begin{array}{l}\text { F00-99 - Transtornos mentais e } \\
\text { comportamentais }\end{array}$ \\
\hline $\begin{array}{l}\text { Ataque do coração/doença coronária/angina/ } \\
\text { doença congestiva / ou outros problemas cardíacos }\end{array}$ & $\begin{array}{l}\text { I51.9 - Doença não especificada do } \\
\text { coração }\end{array}$ \\
\hline Embolia/derrame/ataque/isquemia/trombose cerebral & $\begin{array}{l}\text { I67.9 - Doença cerebrovascular não } \\
\text { especificada }\end{array}$ \\
\hline Artrite/reumatismo/artrose & M00-25 - Artropatias \\
\hline Queda no último ano & W00-19 - Quedas \\
\hline Classificação Internacional de Doenças (10 ${ }^{\text {a Revisão) }}$ & \\
\hline
\end{tabular}

Classificação Internacional de Doenças (10 a Revisão). 
Quadro 2 - Definição dos blocos temáticos, de acordo com as variáveis utilizadas neste estudo e os códigos das questões do questionário SABE, São Paulo, 2000.

\begin{tabular}{|c|c|}
\hline Bloco & Variáveis - Definição \\
\hline \multirow[t]{6}{*}{ Informações Pessoais } & Idade em anos - A01b \\
\hline & Última série da escola frequentada - A06 \\
\hline & Número de filhos - A18 \\
\hline & Arranjo familiar - A07 \\
\hline & Estado marital - A13a \\
\hline & Cor da pele $-\mathrm{A} 12$ \\
\hline \multirow[t]{13}{*}{ Estado de Saúde } & Auto-avaliação de saúde - C01 \\
\hline & Sexo-C18 \\
\hline & Hipertensão Arterial - C04 \\
\hline & Diabetes - C05 \\
\hline & Neoplasias - C06 \\
\hline & Doença Pulmonar Crônica - C07 \\
\hline & Problema Nervoso ou Psiquiátrico - C20 \\
\hline & Doença Cardíaca - C08 \\
\hline & Doença Cerebrovascular - C09 \\
\hline & Doença Articular - C10 \\
\hline & Queda no último ano - C11 \\
\hline & Continência urinária $-\mathrm{C} 12$ \\
\hline & Continência fecal - C12b \\
\hline \multirow[t]{5}{*}{ Estado Funcional } & Banhar-se - D14a \\
\hline & Locomover-se - D16a \\
\hline & Vestir-se - D13a \\
\hline & Usar o banheiro - D17a \\
\hline & Alimentar-se - D15a \\
\hline \multirow[t]{2}{*}{ História de trabalho e fontes de receita } & Quantia que recebe de receita $-\mathrm{H} 27$ \\
\hline & Trabalha atualmente $-\mathrm{H} 21$ \\
\hline
\end{tabular}




\subsection{ANÁLISE DE DADOS}

\subsubsection{Análise de eliminação de doenças crônicas}

As medidas-resumo de saúde populacional (dentre elas, as expectativas de saúde) tem sido utilizadas recentemente para estimar a carga de determinadas condições e doenças, através dos ganhos esperados com sua redução ou eliminação (MATHERS et al., 2002). Essas abordagens podem permitir que os benefícios de intervenções possam ser estimados para utilização em análises de custo-efetividade, contribuir para o planejamento das políticas públicas e dos programas em saúde e prover informações sobre necessidades de pesquisa e desenvolvimento (MANUEL et al., 2002).

Assim, investigadores de diversas disciplinas tem levantado questões sobre a relação entre diversos fatores causais e as condições de saúde da população. Para o estudo das relações entre os determinantes de saúde (doenças, lesões e fatores de risco) e as expectativas de saúde de uma população, duas abordagens tem sido comumente descritas na literatura científica: a atribuição categórica e a "análise contra-fatual" (do inglês, counterfactual analysis) (MATHERS, 2002).

$\mathrm{Na}$ atribuição categórica, um evento como morte ou o início de um estado de saúde pode ser categoricamente atribuído a uma única causa de acordo com um conjunto de regras definidas. Nas tabulações de causa de morte, por exemplo, cada morte é atribuída a uma única causa de acordo com as regras da Classificação Internacional de Doenças (CID) da OMS, mesmo em casos de multicausalidade. Essa abordagem categórica foi utilizada pelo Global Burden of Disease Project em 1990 (MURRAY \& LOPEZ, 1997; MATHERS et al., 2001a; MURRAY et al., 2000).

$\mathrm{Na}$ "análise contra-fatual", a contribuição de uma doença, lesão ou fator de risco pode ser estimada comparando o nível real e os futuros níveis de uma medida de expectativa de saúde com os níveis que seriam esperados em um cenário alternativo como, por exemplo, uma diferente distribuição de riscos ou de extensão das doenças e lesões. Dentre os tipos de "análise contra-fatual", um que tem ganho bastante interesse recentemente é o que avalia a mudança esperada em uma medida de expectativa de saúde com a completa eliminação de uma doença (MURRAY et 
al., 2000). Vários estudos tem apresentado resultados com essa abordagem que passou a ser conhecida como "expectativas de saúde com causa eliminada" (do inglês, cause-deleted heath expectancies) (NUSSELDER et al., 1996; MANUEL et al., 2002; MANUEL et al., 2003a; MANUEL et al., 2003b).

A abordagem por "análise contra-fatual" tem vantagens que são importantes para o estudo do impacto de doenças, lesões e fatores de risco na população idosa: o método apresenta uma concepção clara, resolve problemas de multicausalidade e é consistente com as abordagens de avaliação de benefícios de intervenções em saúde (MURRAY et al., 2000).

As "expectativas de saúde com causa eliminada" (cause-deleted health expectancies) estimam a contribuição de doenças específicas ou de um grupo de doenças para o risco de morte e para a prevalência de incapacidade. A eliminação de uma doença, portanto, reduz a prevalência global de incapacidade e as taxas de mortalidade, resultando em um aumento da expectativa de vida livre ou ajustada para incapacidades (MATHERS et al., 2002).

Neste projeto, com base na classificação da REVES, serão utilizados dois tipos específicos de expectativas de saúde, a expectativa de vida livre de incapacidade (E.V.L.I.) e a expectativa de vida com incapacidade (E.V.C.I.); e a expectativa de vida (E.V.), para fins de análises e interpretações.

O efeito da eliminação de uma doença crônica nas expectativas de saúde e na expectativa de vida foi avaliado, em alguns passos, conforme a abordagem desenvolvida por Nusselder e colaboradores em 1996 (NUSSELDER et al., 1996).

Com base na proposta desses autores, hipoteticamente, se uma doença é eliminada, os indivíduos não serão acometidos por incapacidade ou óbito decorrente dela. Assim, assumindo a independência entre as causas de óbito e de incapacidade, a eliminação de uma doença levará a um declínio nas probabilidades de morte específicas para a idade e na prevalência de incapacidade específica para a idade.

O efeito da eliminação de uma doença na expectativa de saúde é frequentemente calculado assumindo as seguintes independências entre causas de morte e incapacidade: 
1 - As probabilidades de morte com causa eliminada são estimadas com tábuas de vida de eliminação de causas, assumindo independência entre as causas de morte.

2 - As prevalências de incapacidade com causa eliminada são calculadas diretamente subtraindo as prevalências de incapacidade por causa específica das prevalências totais.

3 - As "expectativas de saúde com causa eliminada" são calculadas pelo "método de Sullivan" usando as prevalências com causa eliminada em tábuas de vida de eliminação de causas.

Assim, baseado nesses pressupostos, pode-se considerar algumas etapas para a implementação da abordagem de Nusselder e colaboradores, conforme apresentado a seguir.

\section{1- Cálculo da Expectativa de Vida Livre de Incapacidade}

A idéia de combinar dados sobre a prevalência de estados de saúde com dados de mortalidade, em uma tábua de vida, para gerar estimativas de expectativa de vida em vários estados de saúde, foi proposta inicialmente na década de 60 por Saunders (MATHERS, 2002). Ao longo dos anos 70, com base nessa idéia, Sullivan desenvolveu um indicador interessante que fornece uma medida sensível das variações temporais verificadas na saúde da população de um país, através de um processo eminentemente estatístico que utiliza uma técnica na qual combina os dados de mortalidade e morbidade em uma única medida (SULLIVAN, 1971).

Os métodos de construção de tábuas de vida constituem a base para a obtenção das expectativas de vida e passaram a ser utilizados por Sullivan para o cálculo de expectativas de vida livre de incapacidade (E.V.L.I.), através de um método que ficou conhecido como "método de Sullivan" (MATHERS et al., 2001b).

As informações necessárias para a aplicação do método de Sullivan são: as taxas de mortalidade específica para uma determinada população que permitam a construção de uma tábua de vida e a prevalência dos estados de saúde de acordo com a idade (ROMERO et al., 2005). 
A tábua de vida, elaborada de maneira tradicional, é o instrumento básico para a construção do indicador: do total de anos vividos, em cada idade, é subtraído, por exemplo, o tempo de incapacidade por doenças, lesões, traumatismos e outros agravos à saúde, obtendo-se como consequência a "vida média sem incapacidade".

Para o cálculo da expectativa de vida livre de incapacidade (E.V.L.I.) poderse-ia empregar, portanto, a seguinte fórmula:

$$
E V L I x=\frac{\sum_{i=x}^{w} Y W D_{i}}{l_{x}}
$$

As abreviações, seguindo a notação internacional, têm o seguinte significado:

$1_{\mathrm{x}}=$ número de sobreviventes na idade $\mathrm{x}$ na coorte hipotética da tábua; YWD = número de anos vividos sem incapacidade; $\mathrm{EVLI}_{\mathrm{x}}=$ soma dos anos vividos sem incapacidade para as idades $\mathrm{x}$ e mais, dividido por $1_{\mathrm{x}}$.

No presente estudo, tábuas de vida abreviadas, a partir da idade de 60 anos, cobrindo o ano de 2000, foram calculadas com base nas informações de mortalidade e morbidade, através do método de Sullivan descrito anteriormente (SULLIVAN, 1971), seguindo uma série de etapas (Anexo II), conforme descrito detalhadamente em outras publicações (LAURENTI et al., 2005a; JAGGER et al., 2006).

A população idosa estimada para o meio do ano de 2000 foi obtida a partir dos censos demográficos de 2000 (IBGE, 2001; BRASIL. MINISTÉRIO DA SAÚDE, 2010) e as informações sobre óbitos na população idosa provieram da Fundação Sistema Estadual de Análise de Dados (SEADE, 2000; BRASIL. MINISTÉRIO DA SAÚDE, 2010).

\section{2 - Cálculo das probabilidades de incapacidade}

A Análise Multivariada, através de Regressão Logística, foi utilizada para estimar a probabilidade de incapacidade com a eliminação de uma causa (doença crônica), controlada para a idade. A ocorrência (versus a não ocorrência) de uma ou 
mais incapacidades foi utilizada como variável dependente. A idade e a doença selecionada foram utilizadas como variáveis independentes.

Para tanto, todas as variáveis independentes foram consideradas dicotômicas, com valores 0 e 1 . As definiçõos e categorias dessas variáveis constam do Quadro 3, onde também se especificam as categorias usadas como referência e como contraste na análise multivariada. A variável dependente foi definida igualmente de forma binomial, com as categorias $0=$ não possui dificuldades nas ABVD e 1= possui uma ou mais dificuldades nas ABVD. A idade foi incluída como variável contínua no modelo. O elemento de comparação escolhido foi a Razão de Chances.

A probabilidade de uma pessoa ter uma ou mais incapacidades foi computada substituindo os coeficientes da regressão e os escores dos respondentes nas variáveis independentes da equação de regressão:

$$
P=\frac{\varepsilon^{\beta x}}{1+\varepsilon^{\beta x}}
$$

Onde: $\mathrm{P}=$ probabilidade de uma pessoa ter pelo menos uma incapacidade, $\varepsilon=$ base do logaritmo natural e $\beta x=\alpha+\beta 1 x 1+\beta 2 x 2+\cdots$, um vetor de coeficientes de regressão, sendo que os dados (x), foram incluídos no modelo como variáveis independentes (a idade e as nove doenças crônicas avaliadas).

O efeito da eliminação da doença na prevalência de incapacidade foi simulado eliminando a doença da equação de regressão obtida conforme a etapa anterior, de acordo com a proposta de Nusselder e colaboradores.

As informações correspondentes a "não sabe" e "não responde" foram desconsideradas, assim como as informações não preenchidas ("missing values"). 
Quadro 3 - Descrição das variáveis categóricas utilizadas na análise de regressão logística múltipla.

\begin{tabular}{|l|c|c|}
\hline \multicolumn{1}{|c|}{ Variáveis } & $\begin{array}{c}\text { Categoria de } \\
\text { Referência (RC } \mathbf{1} \text { ) }\end{array}$ & Categoria de Contraste \\
\hline Pressão sanguínea alta / hipertensão & Não & Sim \\
\hline Diabetes / níveis altos de açúcar no sangue & Não \\
\hline Câncer ou tumor maligno & Não & Sim \\
\hline $\begin{array}{l}\text { Doença crônica do pulmão (asma, bronquite ou } \\
\text { enfisema) }\end{array}$ & Não & Sim \\
\hline Problema nervoso ou psiquiátrico & Não \\
\hline $\begin{array}{l}\text { Ataque do coração / doença coronária/angina/ } \\
\text { doença congestiva / ou outros problemas } \\
\text { cardíacos }\end{array}$ & Não & Sim \\
\hline $\begin{array}{l}\text { Embolia / derrame / ataque / isquemia / trombose } \\
\text { cerebral }\end{array}$ & Não & Sim \\
\hline Artrite / reumatismo / artrose & Não & \\
\hline Queda no último ano & & \\
\hline
\end{tabular}

${ }^{1}$ Razão de Chances

\section{3 - Construção das tábuas de eliminação de causas}

As probabilidades de morte com a eliminação de uma causa específica (doença crônica) foram estimadas com base nas técnicas de tábua de vida de eliminação de causas (GOTLIEB, 1981; MATHERS et al., 2002; MATHERS, 2003; BARBONI \& GOTILIEB, 2004).

A seguinte fórmula foi usada para avaliar o efeito da eliminação de uma fração de mortes pela causa $\mathrm{k}$ na probabilidade de morte $\mathrm{q}_{\mathrm{i}}$ no intervalo etário $\left(\mathrm{x}_{\mathrm{i}}\right.$, $\mathrm{X}_{\mathrm{i}+1}$ ) da tábua de vida (TSAI et al., 1978):

$$
q_{i}^{\prime}=1-\left(1-q_{i}\right)^{\left(d_{i}-\pi_{i k} D_{i k}\right)} / d_{i}
$$

onde $\mathrm{d}_{\mathrm{i}}$ é o total do número de mortes no intervalo etário $\left(\mathrm{x}_{\mathrm{i}}, \mathrm{x}_{\mathrm{i}+1}\right), \pi_{i k}$ é a proporção de mortes pela causa k que são eliminadas $\left(0 \leq \pi_{i k} \leq 1\right)$ e $\mathrm{D}_{\mathrm{ik}}$ é o total do número de mortes pela causa $\mathrm{k}$ no intervalo etário $\left(\mathrm{x}_{\mathrm{i}}, \mathrm{x}_{\mathrm{i}+1}\right)$.

Se a prevalência de incapacidade observada no intervalo etário $\left(x_{i}, x_{i+1}\right)$ é $d_{i}$, e $\mathrm{d}_{\mathrm{ik}}$ é a prevalência de incapacidade atribuível à causa $\mathrm{k}$, então a expectativa de vida 
livre de incapacidade média na idade $x_{i}$, após a eliminação da proporção $\pi_{i k}$ da causa k, pode ser calculada usando o método de Sullivan como:

$$
E V L I_{x}=\frac{\sum_{i=x}^{w}\left(1-d_{i}+\pi_{i k} d_{i k}\right) L_{i}}{l_{x}}
$$

Finalmente, as probabilidades de morte estimadas com eliminação de uma causa específica e a prevalência de incapacidade, estimada com eliminação causal através do modelo de regressão logística, foram combinadas em expectativas de vida total e expectativas de vida livre de incapacidade pelo método de Sullivan (SULLIVAN, 1971; NUSSELDER et al., 1996; MATHERS, 2003).

\subsubsection{Análise Estatística}

Tendo em vista que o SABE é um estudo com amostragem complexa, a princípio, considerou-se a ponderação dos dados em todas as análises.

Estatísticas descritivas foram utilizadas para a caracterização da população por meio do cálculo de frequências relativas (\%) para as variáveis do estudo. Para verificar a associação entre variáveis categóricas foi empregado o teste de Rao-Scott, considerando que a amostra foi ponderada (RAO \& SCOTT, 1984).

A análise multivariada, por regressão logística, descrita anteriormente, também foi realizada considerando a ponderação dos dados.

Foram fixados valores de confiança de 95\% (alfa de 0,05), considerados estatisticamente significativos. As análises foram realizadas a partir dos softwares Microsoft Excel 2007 e Pacote Estatístico Stata, versão 11.1. Neste último caso, levou-se em consideração o efeito do desenho amostral complexo no processo de estimação dos parâmetros estudados (comando svy do Stata).

Nas análises que envolveram inferência a partir da amostra as informações de cada indivíduo foram ponderadas pelo inverso de fração amostral, correções para estratificação e não resposta. 


\subsection{MEDIDAS DE DESFECHO E INTERPRETAÇÃO DOS RESULTADOS}

Em uma classificação ajustada por Nusselder em 1997, na distinção entre compressão absoluta e expansão absoluta da morbidade, a mudança no número de anos com incapacidade (ou a diferença entre a expectativa de vida e a expectativa de vida livre de incapacidade) é decisiva (NUSSELDER, 2003).

A redução do número de anos com incapacidade expressa uma compressão absoluta, enquanto um aumento expressa uma expansão absoluta. Entretanto, distinguir apenas entre compressão e expansão absoluta, na maioria das vezes, pode se constituir em uma avaliação muito grosseira. Por exemplo, seria importante distinguir entre uma situação de leve expansão absoluta da morbidade, acompanhada de um ganho substancial de anos de vida livre de incapacidade, em comparação a uma situação de aumento substancial de anos de vida com incapacidade, acompanhada de apenas um leve aumento da expectativa de vida livre de incapacidade.

A mudança na porcentagem dos anos de vida com incapacidade proporciona informações sobre a distribuição entre anos com e sem incapacidade, no total de anos ganhos, em relação a uma situação inicial. Assim, para determinar se uma expansão relativa ocorreu, a mudança na porcentagem dos anos com incapacidade é utilizada, com um aumento dessa porcentagem indicando expansão relativa da morbidade. Qualquer situação em particular pode ser classificada como uma combinação de compressão ou expansão absoluta e compressão ou expansão relativa.

Portanto, neste projeto, as mudanças nas expectativas de saúde, conforme a eliminação de doenças, foram classificadas em quatro situações possíveis, para fins de interpretação dos resultados:

1- Compressão absoluta e compressão relativa da morbidade: situação em que ocorre uma diminuição da expectativa de vida com incapacidade (E.V.C.I.) e um aumento da porcentagem da expectativa de vida livre de incapacidade (E.V.L.I.) na expectativa de vida (E.V.).

2 - Compressão absoluta e expansão relativa da morbidade: situação em que ocorre uma diminuição da expectativa de vida com incapacidade (E.V.C.I.) e uma 
diminuição da porcentagem da expectativa de vida livre de incapacidade (E.V.L.I.) na expectativa de vida (E.V.).

3 - Expansão absoluta e compressão relativa da morbidade: situação em que ocorre um aumento da expectativa de vida com incapacidade (E.V.C.I.) e um aumento da porcentagem da expectativa de vida livre de incapacidade (E.V.L.I.) na expectativa de vida (E.V.).

4 - Expansão absoluta e expansão relativa da morbidade: situação em que ocorre um aumento da expectativa de vida com incapacidade (E.V.C.I.) e uma diminuição da porcentagem da expectativa de vida livre de incapacidade (E.V.L.I.) na expectativa de vida (E.V.).

\subsection{ASPECTOS ÉTICOS}

O projeto de pesquisa SABE foi submetido aos respectivos Comitês de Ética dos países envolvidos. No Brasil, o mesmo foi aprovado pelo Comitê de Ética (COEP) da Faculdade de Saúde Pública (FSP) da Universidade de São Paulo, em 19 de maio de 1999, oficio no 83/06 (Anexo III), e pelo Comitê Nacional de Ética em Pesquisa (CONEP), em 17 de junho de 1999, ofício no 67/99 (Anexo III). 


\section{RESULTADOS}

No ano de 2000, o estudo SABE avaliou um total de 2143 idosos, sendo 1256 pertencentes ao sexo feminino $(58,6 \%)$ e 897 pertencentes ao sexo masculino $(41,4 \%)$.

A tabela 1 apresenta a distribuição desses idosos por sexo, segundo grupo etário, cor da pele, escolaridade, estado marital, estado laboral e arranjo domiciliar.

Em relação ao grupo etário (tabela 1), observa-se uma maior porcentagem de mulheres $(24,2 \%)$ no grupo etário de idade mais avançada (75 anos e mais), em comparação com os homens $(19,2 \%)$.

Em relação à cor da pele (tabela 1), as distribuições não variaram de modo estatisticamente significativo ( $p=0,9535)$.

Em relação à escolaridade (tabela 1), nota-se uma maior porcentagem de homens com maior grau de escolaridade. Assim, 8,9\% dos homens concluíram o ensino médio, em comparação com 6,8\% das mulheres; e 8,3\% dos homens concluíram o ensino superior (ou mais) em comparação com 3,7\% das mulheres.

Em relação ao estado marital (tabela 1), observa-se uma maior porcentagem de viuvez entre as mulheres (43,2\%), em comparação com os homens $(14,5 \%)$; e uma maior porcentagem de indivíduos solteiros, também entre as mulheres $(52,4 \%)$, em comparação com os homens $(4,4 \%)$.

Em relação ao estado laboral (tabela 1), uma maior porcentagem dos homens trabalhava na ocasião do estudo $(40,5 \%)$ em comparação com as mulheres $(19,1 \%)$.

Em relação ao arranjo domiciliar (tabela 1), 17,1\% das mulheres vivia sozinha, em comparação com $7,7 \%$ dos homens. 
Tabela 1 - Distribuição dos idosos por sexo segundo grupo etário, cor da pele, escolaridade, estado marital, estado laboral e arranjo domiciliar. Estudo SABE, município de São Paulo, Brasil, 2000.

\begin{tabular}{|c|c|c|c|}
\hline Variável & Feminino (\%) & Masculino (\%) & $p^{1}$ \\
\hline \multicolumn{4}{|l|}{ Grupo etário (anos) } \\
\hline $60-74$ & 75,8 & 80,8 & \\
\hline 75 e mais & 24,2 & 19,2 & \\
\hline Total & 100,00 & 100,00 & 0,0030 \\
\hline \multicolumn{4}{|l|}{ Cor da pele } \\
\hline Branca & 76,7 & 76,6 & \\
\hline Parda & 14,0 & 14,2 & \\
\hline Preta & 4,4 & 4,1 & \\
\hline Amarela / outras & 4,9 & 5,1 & \\
\hline Total & 100,00 & 100,00 & 0,9535 \\
\hline \multicolumn{4}{|l|}{ Escolaridade } \\
\hline Sem educação formal & 23,4 & 18,3 & \\
\hline Ensino fundamental & 66,1 & 64,5 & \\
\hline Ensino médio & 6,8 & 8,9 & \\
\hline Ensino superior ou + & 3,7 & 8,3 & \\
\hline Total & 100,00 & 100,00 & 0,0002 \\
\hline \multicolumn{4}{|l|}{ Estado Marital } \\
\hline Solteiro & 52,5 & 4,4 & \\
\hline Casado & 37,5 & 70,4 & \\
\hline Viúvo & 43,2 & 14,5 & \\
\hline Divorciado / separado & 14,0 & 10,7 & \\
\hline Total & 100,00 & 100,00 & $<0,0000$ \\
\hline \multicolumn{4}{|l|}{ Estado Laboral } \\
\hline Trabalha atualmente & 19,1 & 40,5 & \\
\hline Não trabalha atualmente & 80,9 & 59,5 & \\
\hline Total & 100,00 & 100,00 & $<0,0000$ \\
\hline \multicolumn{4}{|l|}{ Arranjo Domiciliar } \\
\hline Vive sozinho & 17,1 & 7,7 & \\
\hline Vive acompanhado & 82,9 & 92,3 & \\
\hline Total & 100,00 & 100,00 & $<0,0000$ \\
\hline
\end{tabular}

Observa-se que para todas as ABVD, a maior prevalência de dificuldade ocorre nas faixas etárias mais avançadas, tanto para o sexo feminino, quanto para o masculino; sendo que, para ambos os sexos, a incontinência urinária apresenta-se como a dificuldade mais prevalente, seguida pela dificuldade para vestir-se (tabela 2).

Comparando os grupos etários, nota-se que, no sexo feminino, a dificuldade para ABVD mais prevalente é a incontinência urinária, seguida pela dificuldade para vestir-se e pela dificuldade para locomoção. Já no sexo masculino, a dificuldade para ABVD mais prevalente, na faixa etária de 60-74 anos, é a incontinência urinária, seguida pela dificuldade para vestir-se e pela dificuldade para locomoção. Já na faixa 
Tabela 2 - Prevalência de dificuldade em atividade básica de vida diária segundo sexo e idade. Estudo SABE, município de São Paulo, Brasil, 2000.

\begin{tabular}{|c|c|c|c|c|c|c|c|}
\hline \multirow[t]{2}{*}{$\mathrm{ABVD}^{1}$} & \multicolumn{3}{|c|}{$\begin{array}{c}\text { Feminino } \\
(\%)\end{array}$} & \multicolumn{3}{|c|}{$\begin{array}{c}\text { Masculino } \\
(\%)\end{array}$} & \multirow[t]{2}{*}{$\begin{array}{c}\text { Total } \\
(\%)\end{array}$} \\
\hline & $\begin{array}{c}60-74 \\
\text { anos }\end{array}$ & $\begin{array}{c}75 \text { anos ou } \\
\text { mais }\end{array}$ & $\mathrm{p}^{2}$ & $\begin{array}{c}60-74 \\
\text { anos }\end{array}$ & $\begin{array}{c}75 \text { anos ou } \\
\text { mais }\end{array}$ & $\mathrm{p}^{2}$ & \\
\hline Vestir-se ${ }^{3}$ & 12,8 & 22,8 & $<0,000$ & 8,2 & 23,4 & $<0,000$ & 13,5 \\
\hline Banho & 5,1 & 16,2 & $<0,000$ & 3,9 & 12,5 & $<0,000$ & 6,9 \\
\hline Locomoção $^{4}$ & 10,5 & 17,0 & 0,0019 & 5,0 & 10,3 & 0,0041 & 9,6 \\
\hline Sanitário & 3,9 & 11,2 & $<0,000$ & 2,3 & 9,8 & $<0,000$ & 4,9 \\
\hline Comer & 1,1 & 5,9 & 0,0001 & 2,1 & 6,8 & 0,0005 & 2,6 \\
\hline I. $\mathrm{Fecal}^{5}$ & 3,8 & 10,2 & 0,0002 & 3,4 & 6,7 & 0,0262 & 4,8 \\
\hline I. Urinária ${ }^{6}$ & 22,3 & 38,6 & $<0,000$ & 8,9 & 23,8 & $<0,000$ & 20,3 \\
\hline
\end{tabular}

${ }^{1}$ Atividade Básica de Vida Diária; ${ }^{2}$ teste de Rao-Scott; ${ }^{3}$ inclusive calçar sapatos e meias; ${ }^{4}$ atravessar um cômodo caminhando, ${ }^{5}$ incontinência fecal; ${ }^{6}$ incontinência urinária.

etária de 75 anos ou mais, a incontinência urinária é seguida pela dificuldade para vestir-se e pela dificuldade para banho, em termos de prevalência (tabela 2).

Do total, 31,9\% dos indivíduos referiam apresentar pelo menos uma dificuldade para $A B V D$, sendo que as porcentagens de dificuldade foram maiores no sexo feminino e no grupo etário de idades mais avançadas (tabela 3 ).

Tabela 3 - Prevalência de dificuldades no desempenho das ABVD segundo sexo e grupo etário. Estudo SABE, município de São Paulo, Brasil, 2000.

\begin{tabular}{|c|c|c|c|c|c|c|c|}
\hline \multirow[t]{2}{*}{$\begin{array}{c}\mathrm{ABVD}^{1} \\
\text { (dificuldades) }^{\text {and }}\end{array}$} & \multicolumn{3}{|c|}{$\begin{array}{c}\text { Feminino } \\
(\%)\end{array}$} & \multicolumn{3}{|c|}{$\begin{array}{c}\text { Masculino } \\
(\%)\end{array}$} & \multirow[t]{2}{*}{$\begin{array}{c}\text { Total } \\
(\%)\end{array}$} \\
\hline & $\begin{array}{c}60-74 \\
\text { anos }\end{array}$ & $\begin{array}{c}\text { 75anos ou } \\
\text { mais }\end{array}$ & $\mathrm{p}^{2}$ & $\begin{array}{c}60-74 \\
\text { anos }\end{array}$ & $\begin{array}{c}\text { 75anos ou } \\
\text { mais }\end{array}$ & $\mathrm{p}^{2}$ & \\
\hline Nenhuma & 65,0 & 48,2 & & 82,0 & 62,3 & & 68,1 \\
\hline Uma ou + & 35,0 & 51,8 & $<0,000$ & 18,0 & 37,7 & $<0,000$ & 31,9 \\
\hline
\end{tabular}

${ }^{1}$ Atividade Básica de Vida Diária; ${ }^{2}$ teste de Rao-Scott.

A maior parte dos indivíduos referia saúde de regular a má $(53,9 \%)$, sendo que a distribuição da auto-percepção de saúde, conforme as faixas etárias, não apresentou diferenças significativas, em ambos os sexos (tabela 4). 
Tabela 4 - Auto-percepção de saúde segundo sexo e grupo etário. Estudo SABE, município de São Paulo, Brasil, 2000.

\begin{tabular}{|c|c|c|c|c|c|c|c|}
\hline \multirow{2}{*}{$\begin{array}{c}\text { Auto- } \\
\text { percepção } \\
\text { de saúde }\end{array}$} & \multicolumn{3}{|c|}{$\begin{array}{c}\text { Feminino } \\
(\%)\end{array}$} & \multicolumn{3}{|c|}{$\begin{array}{c}\text { Masculino } \\
(\%)\end{array}$} & \multirow[t]{2}{*}{$\begin{array}{l}\text { Total } \\
(\%)\end{array}$} \\
\hline & $\begin{array}{c}60-74 \\
\text { anos }\end{array}$ & $\begin{array}{c}75 \text { anos ou } \\
\text { mais }\end{array}$ & $p^{1}$ & $\begin{array}{c}60-74 \\
\text { anos }\end{array}$ & $\begin{array}{c}75 \text { anos ou } \\
\text { mais }\end{array}$ & $p^{1}$ & \\
\hline $\begin{array}{l}\text { Excelente / } \\
\text { muito boa }\end{array}$ & 11,0 & 9,6 & & 10,4 & 12,1 & & 10,7 \\
\hline Boa & 33,9 & 33,3 & & 39,1 & 31,7 & & 35,4 \\
\hline Regular/má & 55,1 & 57,0 & 0,6637 & 50,4 & 56,2 & 0,0860 & 53,9 \\
\hline
\end{tabular}

A doença crônica auto-referida mais prevalente foi a hipertensão arterial, seguida pela doença articular e pela queda no último ano. No sexo feminino, tanto na faixa etária de 60-74 anos, quanto na de 75 anos ou mais, as doenças crônicas mais prevalentes foram, em ordem decrescente: a hipertensão arterial, a doença articular e a queda no último ano. No sexo masculino, na faixa de 60-74 anos, as doenças crônicas mais prevalentes foram, do mesmo modo: a hipertensão arterial, a doença articular e a queda no último ano. Já na faixa de 75 anos ou mais, as doenças mais prevalentes foram: a hipertensão arterial, a queda no último ano e a doença articular, também em ordem decrescente (tabela 5).

Comparando os grupos etários, nota-se que no sexo feminino, apenas para a doença articular, a queda no último ano, a doença cardíaca e a doença mental, observam-se diferenças significativas. Já no sexo masculino, o único agravo que apresentou diferença de prevalência significativa entre os grupos etários foi a queda no último ano (tabela 5). 
Tabela 5 - Prevalência de doenças crônicas auto-referidas segundo sexo e idade. Estudo SABE, município de São Paulo, Brasil, 2000.

\begin{tabular}{|c|c|c|c|c|c|c|c|}
\hline & $\begin{array}{c}60-74 \\
\text { anos }\end{array}$ & $\begin{array}{c}\text { Feminino } \\
(\%) \\
75 \text { anos ou } \\
\text { mais }\end{array}$ & $\mathrm{p}^{9}$ & $\begin{array}{c}60-74 \\
\text { anos }\end{array}$ & $\begin{array}{c}\text { Masculino } \\
(\%) \\
75 \text { anos ou } \\
\text { mais }\end{array}$ & $\mathrm{p}^{9}$ & $\begin{array}{c}\text { Total } \\
(\%)\end{array}$ \\
\hline Hipertensão $^{1}$ & 55,3 & 60,8 & 0,0837 & 50,2 & 46,5 & 0,3156 & 53,7 \\
\hline Articular $^{2}$ & 39,2 & 44,1 & 0,0362 & 20,2 & 23,3 & 0,3145 & 32,2 \\
\hline Queda $^{3}$ & 30,8 & 39,9 & 0,0037 & 20,1 & 31,6 & 0,0002 & 28,6 \\
\hline Cardíaca ${ }^{4}$ & 17,2 & 24,2 & 0,0092 & 19,5 & 24,8 & 0,0280 & 19,6 \\
\hline Diabetes $^{5}$ & 19,2 & 17,2 & 0,3138 & 17,5 & 15,0 & 0,4090 & 18,0 \\
\hline Mental $^{6}$ & 19,5 & 12,3 & 0,0026 & 12,9 & 10,7 & 0,2881 & 15,6 \\
\hline Pulmonar $^{7}$ & 10,7 & 10,7 & 0,9883 & 13,9 & 16,5 & 0,2697 & 12,2 \\
\hline Cerebrovascular $^{8}$ & 5,7 & 6,9 & 0,4549 & 8,6 & 10,6 & 0,3461 & 7,2 \\
\hline Neoplasia & 3,0 & 5,0 & 0,0653 & 2,9 & 4,0 & 0,2830 & 3,3 \\
\hline
\end{tabular}

A maior parte dos indivíduos (62,3\%) apresentava duas ou mais doenças crônicas. Tanto no sexo feminino, quanto no masculino, não se nota diferença significativa na distribuição dos indivíduos conforme o número de doenças crônicas auto-referidas (tabela 6).

Tabela 6 - Número de doenças crônicas auto-referidas pelos idosos segundo sexo e grupo etário. Estudo SABE, município de São Paulo, Brasil, 2000.

\begin{tabular}{|c|c|c|c|c|c|c|c|}
\hline & \multicolumn{3}{|c|}{$\begin{array}{c}\text { Feminino } \\
(\%)\end{array}$} & \multicolumn{3}{|c|}{$\begin{array}{c}\text { Masculino } \\
(\%)\end{array}$} & \multirow[t]{2}{*}{$\begin{array}{l}\text { Total } \\
(\%)\end{array}$} \\
\hline & $\begin{array}{c}60-74 \\
\text { anos }\end{array}$ & $\begin{array}{c}75 \text { anos ou } \\
\text { mais }\end{array}$ & $\mathrm{p}^{1}$ & $\begin{array}{c}60-74 \\
\text { anos }\end{array}$ & $\begin{array}{c}75 \text { anos ou } \\
\text { mais }\end{array}$ & $\mathrm{p}^{1}$ & \\
\hline Nenhuma & 11,1 & 8,1 & & 18,3 & 15,5 & & 13,4 \\
\hline Uma & 21,4 & 18,3 & & 29,8 & 27,1 & & 24,2 \\
\hline Duas ou + & 67,6 & 73,5 & 0,1022 & 51,9 & 57,4 & 0,3054 & 62,3 \\
\hline
\end{tabular}

'teste de Rao-Scott.

A tabela 7 apresenta as probabilidades de morrer, segundo a faixa etária, em homens, com base na população do município de São Paulo, em 2000, e no número de óbitos naquele ano. 
Tabela 7 - Probabilidade de morrer segundo grupo etário (em anos) dos homens idosos. Município de São Paulo, Brasil, 2000.

\begin{tabular}{cccccc}
\hline $\begin{array}{c}\text { Grupo } \\
\text { etário } \\
(\mathbf{x}, \mathbf{x}+\mathbf{n})\end{array}$ & $\begin{array}{c}\text { População } \\
\mathbf{1 / 7 / 2 0 0 0} \\
(\mathbf{n P x})\end{array}$ & Óbitos & $\begin{array}{c}\text { Óbitos } \\
\text { Espearados } \\
(\mathbf{n O x})\end{array}$ & $\begin{array}{c}\text { População } \\
\text { Exposta } \\
(\mathbf{n E x})\end{array}$ & Probabilidade \\
$60-64$ & 131589 & 3128 & 15640 & 139409 & 0,112188 \\
$65-69$ & 100545 & 3502 & 17510 & 109300 & 0,160201 \\
$70-74$ & 77589 & 3769 & 18845 & 87011,5 & 0,216581 \\
$75-79$ & 46718 & 3361 & 16805 & 55120,5 & 0,304877 \\
80 e mais & 37920 & 5054 & - & - & 1 \\
\hline
\end{tabular}

Fonte: IBGE, 2000; SEADE, 2001.

A tabela 8 apresenta as probabilidades de morrer, segundo a faixa etária, em mulheres, com base na população do município de São Paulo, em 2000, e no número de óbitos naquele ano.

Tabela 8 - Probabilidade de morrer segundo grupo etário (em anos) das mulheres idosas. Município de São Paulo, Brasil, 2000.

\begin{tabular}{cccccc}
\hline $\begin{array}{c}\text { Grupo } \\
\text { etário } \\
(\mathbf{x}, \mathbf{x}+\mathbf{n})\end{array}$ & $\begin{array}{c}\text { População } \\
\mathbf{1 / 7 / 2 0 0 0} \\
(\mathbf{n P x})\end{array}$ & Óbitos & $\begin{array}{c}\text { Óbitos } \\
\text { Espearados } \\
(\mathbf{n D O x})\end{array}$ & $\begin{array}{c}\text { População } \\
\text { Exposta } \\
(\mathbf{n E x})\end{array}$ & Probabilidade \\
\hline $60-64$ & 169830 & 2024 & 10120 & 174890 & 0,057865 \\
$65-69$ & 137889 & 2453 & 12265 & 144021,5 & 0,085161 \\
$70-74$ & 115950 & 3153 & 15765 & 123832,5 & 0,127309 \\
$75-79$ & 75527 & 3299 & 16495 & 83774,5 & 0,196898 \\
80 e mais & 78642 & 8391 & - & - & 1 \\
\hline
\end{tabular}

Fonte: IBGE, 2000; SEADE, 2001.

A tabela 9 apresenta a expectativa de vida, a expectativa de vida livre de incapacidade e a proporção de anos a serem vividos livres de incapacidade para o sexo feminino e masculino. 
Tabela 9 - E.V., E.V.L.I. e proporção de anos a serem vividos livres de incapacidade segundo sexo e grupo etário. Município de São Paulo, Brasil, 2000.

\begin{tabular}{lccc}
\hline \multicolumn{1}{c}{ Sexo e grupo etário (anos) } & $\begin{array}{c}\text { E.V. } \\
\text { (anos) }\end{array}$ & $\begin{array}{c}\text { E.V.L.I. } \\
\text { (anos) }\end{array}$ & $\begin{array}{c}\text { Proporção de anos a } \\
\text { serem vividos livres de } \\
\text { incapacidade (\%) }\end{array}$ \\
\hline Feminino & & & \\
$60-64$ & 22,45 & 13,01 & 57,94 \\
$65-69$ & 18,68 & 10,55 & 56,50 \\
$70-74$ & 15,18 & 7,92 & 52,18 \\
$75-79$ & 12,03 & 5,92 & 47,55 \\
80 e mais & 9,37 & 4,24 & 45,28 \\
Masculino & & & \\
60-64 & 17,65 & 13,30 & 75,34 \\
$65-69$ & 14,56 & 10,50 & 72,10 \\
$70-74$ & 11,86 & 8,01 & 67,53 \\
$75-79$ & 9,45 & 5,79 & 61,31 \\
80 e mais & 7,50 & 4,23 & 56,38 \\
\hline
\end{tabular}

${ }^{1}$ expectativa de vida; ${ }^{2}$ expectativa de vida livre de incapacidade.

A tabela 10 apresenta o número de óbitos segundo a causa básica de morte, registrados em 2000, no município de São Paulo, para o sexo feminino e masculino.

Tabela 10 - Número de óbitos segundo sexo, grupo etário (em anos) e causa básica de morte pelo CID-10 ${ }^{1}$. Município de São Paulo, Brasil, 2000.

\begin{tabular}{lcccc}
\hline Causa Básica de Óbito & \multicolumn{2}{c}{ Feminino (n) } & \multicolumn{2}{c}{ Masculino (n) } \\
& $\mathbf{6 0 - 6 4}$ & $\mathbf{7 5 - 7 9}$ & $\mathbf{6 0 - 6 4}$ & $\mathbf{7 5 - 7 9}$ \\
\hline Hipertensão $^{2}$ & 99 & 139 & 93 & 104 \\
Articular $^{3}$ & 7 & 7 & 2 & 4 \\
Queda $^{4}$ & 1 & 5 & 12 & 13 \\
Cardíaca $^{5}$ & 326 & 566 & 614 & 571 \\
Diabetes $^{6}$ & 119 & 230 & 127 & 156 \\
Mental $^{7}$ & 19 & 69 & 29 & 38 \\
Pulmonar $^{8}$ & 81 & 153 & 164 & 278 \\
Cerebrovascular $^{9}$ & 207 & 432 & 298 & 368 \\
Neoplasia & 578 & 656 & 740 & 781 \\
\hline
\end{tabular}

Fonte: SEADE, 2001.

${ }^{1}$ Classificação Internacional de Doenças $\left(10{ }^{a}\right.$ Revisão); ${ }^{2}$ hipertensão arterial sistêmica; ${ }^{3}$ doença articular; ${ }^{4}$ queda no último ano; ${ }^{5}$ doença cardíaca; ${ }^{6}$ diabetes mellitus tipo $2 ;{ }^{7}$ doença mental; ${ }^{8}$ doença pulmonar crônica; ${ }^{9}$ doença cerebrovascular.

A tabela 11 apresenta a prevalência de doenças crônicas (em porcentagens) e a Razão de Chances para incapacidade, para o sexo feminino e masculino, conforme o modelo de regressão logística elaborado. 
Tabela 11 - Prevalência de doenças crônicas e razão de chances para a presença de incapacidade em pelo menos uma ABVD, segundo sexo, conforme a análise de regressão logística múltipla. Estudo SABE, município de São Paulo, 2000.

\begin{tabular}{|c|c|c|c|c|}
\hline & $\begin{array}{c}\text { Prevalência da } \\
\text { Doença Crônica } \\
(\%)\end{array}$ & Razão de Chances & IC $95 \%^{9}$ & $\mathrm{p}$ \\
\hline \multicolumn{5}{|l|}{ Feminino } \\
\hline Hipertensão $^{1}$ & 56,60 & 1,47 & $1,09-1,98$ & 0,012 \\
\hline Articular ${ }^{2}$ & 40,40 & 2,06 & $1,63-2,60$ & $<0,000$ \\
\hline Queda $^{3}$ & 33,00 & 1,50 & $1,15-1,95$ & 0,003 \\
\hline Cardíaca ${ }^{4}$ & 18,90 & 1,35 & $0,90-2,01$ & 0,138 \\
\hline Diabetes $^{5}$ & 18,70 & 1,44 & $0,97-2,14$ & 0,068 \\
\hline Mental $^{6}$ & 17,70 & 2,35 & $1,62-3,41$ & $<0,000$ \\
\hline Pulmonar $^{7}$ & 10,70 & 1,70 & $1,10-2,63$ & 0,019 \\
\hline Cerebrovascular $^{8}$ & 6,00 & 2,72 & $1,50-4,93$ & 0,001 \\
\hline Neoplasia & 3,50 & 1,59 & $0,61-4,15$ & 0,337 \\
\hline \multicolumn{5}{|l|}{ Masculino } \\
\hline Hipertensão & 49,50 & 1,34 & $0,90-2,00$ & 0,143 \\
\hline Articular & 20,80 & 1,94 & $1,26-3,01$ & 0,003 \\
\hline Queda & 22,30 & 1,76 & $1,09-2,83$ & 0,022 \\
\hline Cardíaca & 20,50 & 0,86 & $0,53-1,42$ & 0,559 \\
\hline Diabetes & 17,00 & 2,12 & $1,34-3,35$ & 0,002 \\
\hline Mental & 12,50 & 1,90 & $1,03-3,48$ & 0,039 \\
\hline Pulmonar & 14,40 & 1,67 & $0,96-2,89$ & 0,067 \\
\hline Cerebrovascular & 8,90 & 3,97 & $2,08-7,57$ & $<0,000$ \\
\hline Neoplasia & 3,10 & 1,92 & $0,64-5,78$ & 0,240 \\
\hline
\end{tabular}

A tabela 12 apresenta os parâmetros estimados pela regressão logística para a presença de incapacidade em pelo menos uma ABVD, para o sexo feminino e masculino. 
Tabela 12 - Parâmetros estimados $(\beta s)$ pela regressão logística múltipla para a presença de incapacidade em pelo menos uma $\mathrm{ABVD}^{1}$ segundo o sexo, em idosos. Estudo SABE, município de São Paulo, 2000.

\begin{tabular}{lcc}
\hline & Feminino & Masculino \\
\hline Constante $\left(\beta_{0}\right)$ & $-4,42$ & $-6,81$ \\
Idade $\left(\beta_{1}\right)$ & 0,04 & 0,07 \\
Hipertensão $^{2}\left(\beta_{2}\right)$ & 0,39 & 0,29 \\
Articular $^{3}\left(\beta_{3}\right)$ & 0,72 & 0,66 \\
Queda $^{4}\left(\beta_{4}\right)$ & 0,40 & 0,56 \\
Cardíaca $^{5}\left(\beta_{5}\right)$ & 0,30 & $-0,15$ \\
Diabetes $^{6}\left(\beta_{6}\right)$ & 0,37 & 0,75 \\
Mental $^{7}\left(\beta_{7}\right)$ & 0,85 & 0,64 \\
Pulmonar $^{8}\left(\beta_{8}\right)$ & 0,53 & 0,51 \\
Cerebrovascular $^{9}\left(\beta_{9}\right)$ & 1,00 & 1,38 \\
Neoplasia $\left(\beta_{10}\right)$ & 0,46 & 0,65 \\
${ }^{1}$ Atividade Básica de Vida Diária; $^{2}$ hipertensão arterial sistêmica; ${ }^{3}$ doença articular; ${ }^{4}$ queda no \\
último ano; ${ }^{5}$ doença cardíaca; ${ }^{6}$ diabetes mellitus tipo $2 ;{ }^{7}$ doença mental; ${ }^{8}$ doença pulmonar crônica; \\
${ }^{9}$ doença cerebrovascular.
\end{tabular}

A tabela 13 apresenta: a expectativa de vida, a expectativa de vida livre de incapacidade, a expectativa de vida com incapacidade e a proporção de anos a serem vividos livres de incapacidade, no sexo feminino, conforme a eliminação de doenças crônicas. Observa-se que todas as doenças crônicas levaram a ganhos em expectativa de vida e expectativa de vida livre de incapacidade ao serem eliminadas, tanto aos 60 anos, quanto aos 75 anos (tabela 13 e tabela 15). 
Tabela 13 - E.V., E.V.L.I., E.V.C.I. e proporção (\%) dos anos a serem vividos livres de incapacidade, no sexo feminino, segundo faixa etária e eliminação de doenças crônicas. Município de São Paulo, Brasil, 2000.

\begin{tabular}{|c|c|c|c|c|}
\hline & E.V. ${ }^{1}$ & E.V.L.I. $^{2}$ & E.V.C.I. ${ }^{3}$ & $\begin{array}{c}\text { \% E.V.L.I. } \\
\text { na E.V. }\end{array}$ \\
\hline Mulheres aos 60 anos & 22,45 & 13,01 & 9,44 & 57,94 \\
\hline Hipertensão $^{4}$ & 24,60 & 20,91 & 3,69 & 84,99 \\
\hline Articular ${ }^{5}$ & 24,45 & 20,10 & 4,35 & 82,21 \\
\hline Queda $^{6}$ & 24,44 & 20,76 & 3,68 & 84,94 \\
\hline Cardíaca $^{7}$ & 25,17 & 21,56 & 3,61 & 85,64 \\
\hline Diabetes $^{8}$ & 24,71 & 21,04 & 3,67 & 85,14 \\
\hline Mental $^{9}$ & 24,49 & 19,86 & 4,63 & 81,09 \\
\hline Pulmonar $^{10}$ & 24,61 & 20,62 & 3,99 & 83,80 \\
\hline Cerebrovascular $^{11}$ & 24,89 & 19,84 & 5,05 & 79,13 \\
\hline Neoplasia & 25,49 & 21,47 & 4,02 & 84,23 \\
\hline Mulheres aos 75 anos & 12,03 & 5,72 & 6,31 & 47,55 \\
\hline Hipertensão & 13,07 & 10,44 & 2,63 & 79,88 \\
\hline Articular & 13,02 & 9,91 & 3,11 & 76,11 \\
\hline Queda & 13,02 & 10,39 & 2,63 & 79,77 \\
\hline Cardíaca & 13,23 & 10,70 & 2,53 & 80,87 \\
\hline Diabetes & 13,10 & 10,50 & 2,60 & 80,10 \\
\hline Mental & 13,04 & 9,73 & 3,31 & 74,63 \\
\hline Pulmonar & 13,08 & 10,24 & 2,84 & 78,29 \\
\hline Cerebrovascular & 13,18 & 9,61 & 3,57 & 72,92 \\
\hline Neoplasia & 13,27 & 10,49 & 2,78 & 79,06 \\
\hline
\end{tabular}

A tabela 14 apresenta a expectativa de vida, a expectativa de vida livre de incapacidade, a expectativa de vida com incapacidade e a proporção de anos a serem vividos livres de incapacidade, no sexo masculino, conforme a eliminação de doenças crônicas. Observa-se que todas as doenças crônicas levaram a ganhos em expectativa de vida e expectativa de vida livre de incapacidade ao serem eliminadas, tanto aos 60 anos, quanto aos 75 anos (tabela 14 e tabela 16). 
Tabela 14 - E.V., E.V.L.I., E.V.C.I. e proporção (\%) dos anos a serem vividos livres de incapacidade, no sexo masculino, segundo faixa etária e eliminação de doenças crônicas. Município de São Paulo, Brasil, 2000.

\begin{tabular}{|c|c|c|c|c|}
\hline & E.V. ${ }^{1}$ & E.V.L.I. $^{2}$ & E.V.C.I. ${ }^{3}$ & $\begin{array}{c}\text { \% E.V.L.I. } \\
\text { na E.V. }\end{array}$ \\
\hline Homens aos 60 anos & 17,65 & 13,30 & 4,35 & 75,34 \\
\hline Hipertensão ${ }^{4}$ & 24,60 & 20,01 & 4,59 & 81,36 \\
\hline Articular 5 & 24,44 & 19,68 & 4,76 & 80,52 \\
\hline Queda $^{6}$ & 24,45 & 19,74 & 4,71 & 80,74 \\
\hline Cardíaca $^{7}$ & 25,51 & 21,04 & 4,47 & 82,48 \\
\hline Diabetes $^{8}$ & 24,67 & 19,80 & 4,87 & 80,25 \\
\hline Mental $^{9}$ & 24,49 & 19,73 & 4,76 & 80,55 \\
\hline Pulmonar ${ }^{10}$ & 24,78 & 20,00 & 4,78 & 80,72 \\
\hline Cerebrovascular ${ }^{11}$ & 24,98 & 19,77 & 5,21 & 79,15 \\
\hline Neoplasia & 25,77 & 20,62 & 5,15 & 80,03 \\
\hline Homens aos 75 anos & 9,45 & 5,79 & 3,66 & 61,31 \\
\hline Hipertensão & 13,06 & 9,46 & 3,60 & 72,45 \\
\hline Articular & 13,02 & 9,26 & 3,76 & 71,14 \\
\hline Queda & 13,02 & 9,31 & 3,71 & 71,47 \\
\hline Cardíaca & 13,23 & 9,85 & 3,38 & 74,43 \\
\hline Diabetes & 13,08 & 9,26 & 3,82 & 70,83 \\
\hline Mental & 13,03 & 9,28 & 3,75 & 71,20 \\
\hline Pulmonar & 13,12 & 9,39 & 3,73 & 71,57 \\
\hline Cerebrovascular & 13,16 & 9,12 & 4,04 & 69,35 \\
\hline Neoplasia & 13,31 & 9,45 & 3,86 & 70,97 \\
\hline
\end{tabular}

A tabela 15 apresenta as mudanças na expectativa de vida, na expectativa de vida livre de incapacidade, na expectativa de vida com incapacidade e na proporção dos anos a serem vividos livres de incapacidade, no sexo feminino, conforme a eliminação de doenças crônicas. Em termos absolutos, nota-se que os maiores ganhos em expectativa de vida (E.V.) e expectativa de vida livre de incapacidade (E.V.L.I.) ocorreram na idade de 60 anos. Já em termos relativos (\% E.V.L.I. na E.V.), observase que os ganhos foram maiores na idade de 75 anos. 
Tabela 15 - Mudança na E.V., E.V.L.I., E.V.C.I. e na proporção (\%) dos anos a serem vividos livres de incapacidade, no sexo feminino, segundo faixa etária, em função da eliminação de doenças crônicas. Município de São Paulo, Brasil, 2000.

\begin{tabular}{|c|c|c|c|c|}
\hline & E.V. ${ }^{1}$ & E.V.L.I. ${ }^{2}$ & E.V.C.I. ${ }^{3}$ & $\begin{array}{c}\text { \% E.V.L.I. } \\
\text { na E.V. }\end{array}$ \\
\hline \multicolumn{5}{|l|}{ Mulheres - 60 anos } \\
\hline Hipertensão ${ }^{4}$ & 2,15 & 7,90 & $-5,75$ & 27,05 \\
\hline Articular ${ }^{5}$ & 2,00 & 7,09 & $-5,09$ & 24,27 \\
\hline Queda $^{6}$ & 1,99 & 7,75 & $-5,76$ & 27,00 \\
\hline Cardíaca $^{7}$ & 2,72 & 8,55 & $-5,83$ & 27,70 \\
\hline Diabetes $^{8}$ & 2,26 & 8,03 & $-5,77$ & 27,20 \\
\hline Mental $^{9}$ & 2,04 & 6,85 & $-4,81$ & 23,15 \\
\hline Pulmonar $^{10}$ & 2,16 & 7,61 & $-5,45$ & 25,86 \\
\hline Cerebrovascular $^{11}$ & 2,44 & 6,83 & $-4,39$ & 21,19 \\
\hline Neoplasia & 3,04 & 8,46 & $-5,42$ & 26,29 \\
\hline \multicolumn{5}{|l|}{ Mulheres - 75 anos } \\
\hline Hipertensão & 1,04 & 4,72 & $-3,68$ & 32,33 \\
\hline Articular & 0,99 & 4,19 & $-3,20$ & 28,56 \\
\hline Queda & 0,99 & 4,67 & $-3,68$ & 32,22 \\
\hline Cardíaca & 1,20 & 4,98 & $-3,78$ & 33,32 \\
\hline Diabetes & 1,07 & 4,78 & $-3,71$ & 32,55 \\
\hline Mental & 1,01 & 4,01 & $-3,00$ & 27,08 \\
\hline Pulmonar & 1,05 & 4,52 & $-3,47$ & 30,74 \\
\hline Cerebrovascular & 1,15 & 3,89 & $-2,74$ & 25,37 \\
\hline Neoplasia & 1,24 & 4,77 & $-3,53$ & 31,51 \\
\hline
\end{tabular}

A tabela 16 apresenta as mudanças na expectativa de vida, na expectativa de vida livre de incapacidade, na expectativa de vida com incapacidade e na proporção dos anos a serem vividos livres de incapacidade, no sexo masculino, conforme a eliminação de doenças crônicas. Em termos absolutos, nota-se que os maiores ganhos em expectativa de vida (E.V.) e expectativa de vida livre de incapacidade (E.V.L.I.) ocorreram na idade de 60 anos. Já em termos relativos (\% E.V.L.I. na E.V.), observase que os ganhos foram maiores na idade de 75 anos. 
Tabela 16 - Mudança na E.V., E.V.L.I., E.V.C.I. e na proporção (\%) dos anos a serem vividos livres de incapacidade, no sexo masculino, segundo faixa etária, em função da eliminação de doenças crônicas. Município de São Paulo, Brasil, 2000.

\begin{tabular}{|c|c|c|c|c|}
\hline & E.V. ${ }^{1}$ & E.V.L.I. $^{2}$ & E.V.C.I. ${ }^{3}$ & $\begin{array}{c}\text { \% E.V.L.I. na } \\
\text { E.V. }\end{array}$ \\
\hline \multicolumn{5}{|l|}{ Homens - 60 anos } \\
\hline Hipertensão $^{4}$ & 6,95 & 6,71 & 0,24 & 6,02 \\
\hline Articular ${ }^{5}$ & 6,79 & 6,38 & 0,41 & 5,18 \\
\hline Queda $^{6}$ & 6,80 & 6,44 & 0,36 & 5,40 \\
\hline Cardíaca $^{7}$ & 7,86 & 7,74 & 0,12 & 7,14 \\
\hline Diabetes $^{8}$ & 7,02 & 6,50 & 0,52 & 4,91 \\
\hline Mental $^{9}$ & 6,84 & 6,43 & 0,41 & 5,21 \\
\hline Pulmonar $^{10}$ & 7,13 & 6,70 & 0,43 & 5,38 \\
\hline Cerebrovascular $^{11}$ & 7,33 & 6,47 & 0,86 & 3,81 \\
\hline Neoplasia & 8,12 & 7,32 & 0,80 & 4,69 \\
\hline \multicolumn{5}{|l|}{ Homens - 75 anos } \\
\hline Hipertensão & 3,61 & 3,67 & $-0,06$ & 11,14 \\
\hline Articular & 3,57 & 3,47 & 0,10 & 9,83 \\
\hline Queda & 3,57 & 3,52 & 0,05 & 10,16 \\
\hline Cardíaca & 3,78 & 4,06 & $-0,28$ & 13,12 \\
\hline Diabetes & 3,63 & 3,47 & 0,16 & 9,52 \\
\hline Mental & 3,58 & 3,49 & 0,09 & 9,89 \\
\hline Pulmonar & 3,67 & 3,60 & 0,07 & 10,26 \\
\hline Cerebrovascular & 3,71 & 3,33 & 0,38 & 8,04 \\
\hline Neoplasia & 3,86 & 3,66 & 0,20 & 9,66 \\
\hline
\end{tabular}

Na figura 1 observa-se que, na idade de 60 anos, as doenças eliminadas que geraram a maior proporção de anos a serem vividos livres de incapacidade, para o sexo feminino, foram: a doença cardíaca (em $1^{\circ}$ lugar), o diabetes mellitus (em $2^{\circ}$ lugar) e a hipertensão arterial (em $3^{\circ}$ lugar). Já para o sexo masculino (figura 2), nesta mesma idade, as doenças eliminadas que geraram uma maior proporção de anos a serem vividos livres de incapacidade foram: a doença cardíaca (em $1^{\circ}$ lugar), a hipertensão arterial (em $2^{\circ}$ lugar) e a queda (em $3^{\circ}$ lugar). 


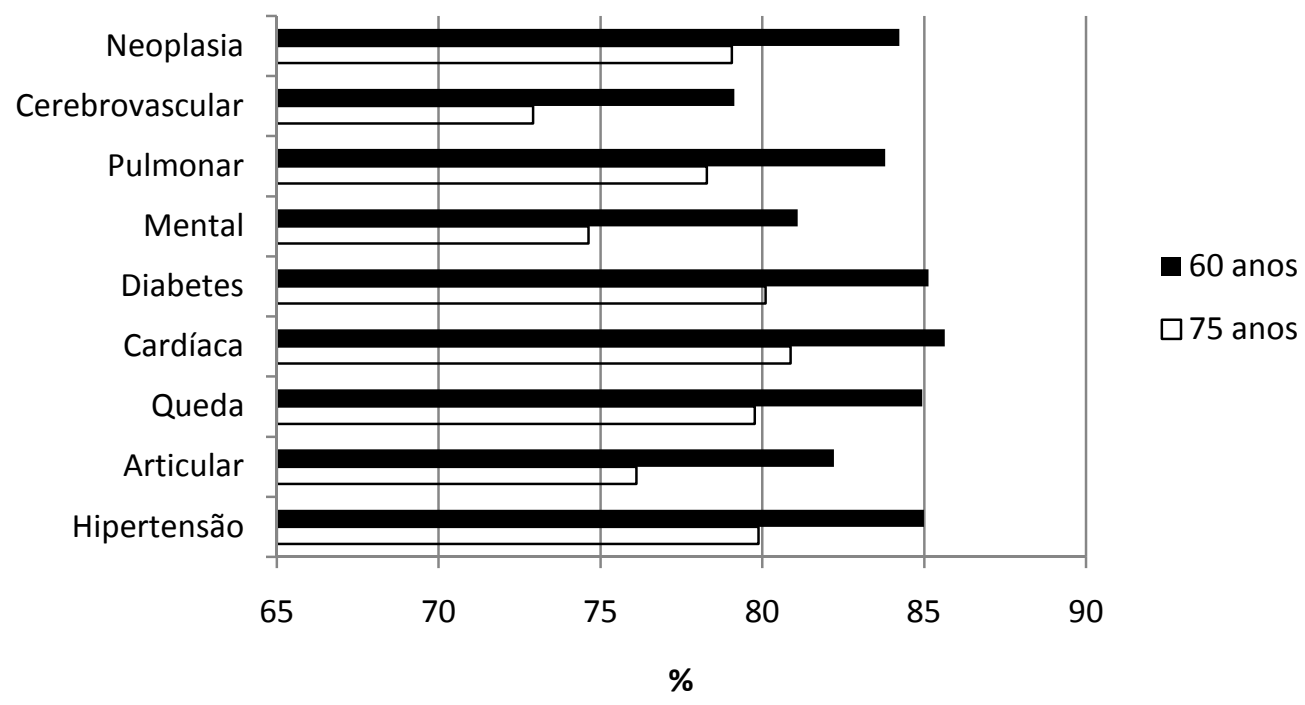

Figura 1 - Proporção (\%) dos anos a serem vividos livres de incapacidade, no sexo feminino, segundo idade e doença crônica eliminada. Município de São Paulo, Brasil, 2000.

Na figura 1, observa-se que, na idade de 75 anos, as doenças eliminadas que geraram a maior proporção de anos a serem vividos livres de incapacidade, para o sexo feminino, foram: a doença cardíaca (em $1^{\circ}$ lugar), o diabetes mellitus (em $2^{\circ}$ lugar) e a hipertensão arterial (em $3^{\circ}$ lugar). Já para o sexo masculino (figura 2), aos 75 anos, as doenças eliminadas que geraram uma maior proporção de anos a serem vividos livres de incapacidade foram: a doença cardíaca (em $1^{\circ}$ lugar), a hipertensão arterial (em $2^{\circ}$ lugar) e a doença pulmonar crônica (em $3^{\circ}$ lugar).

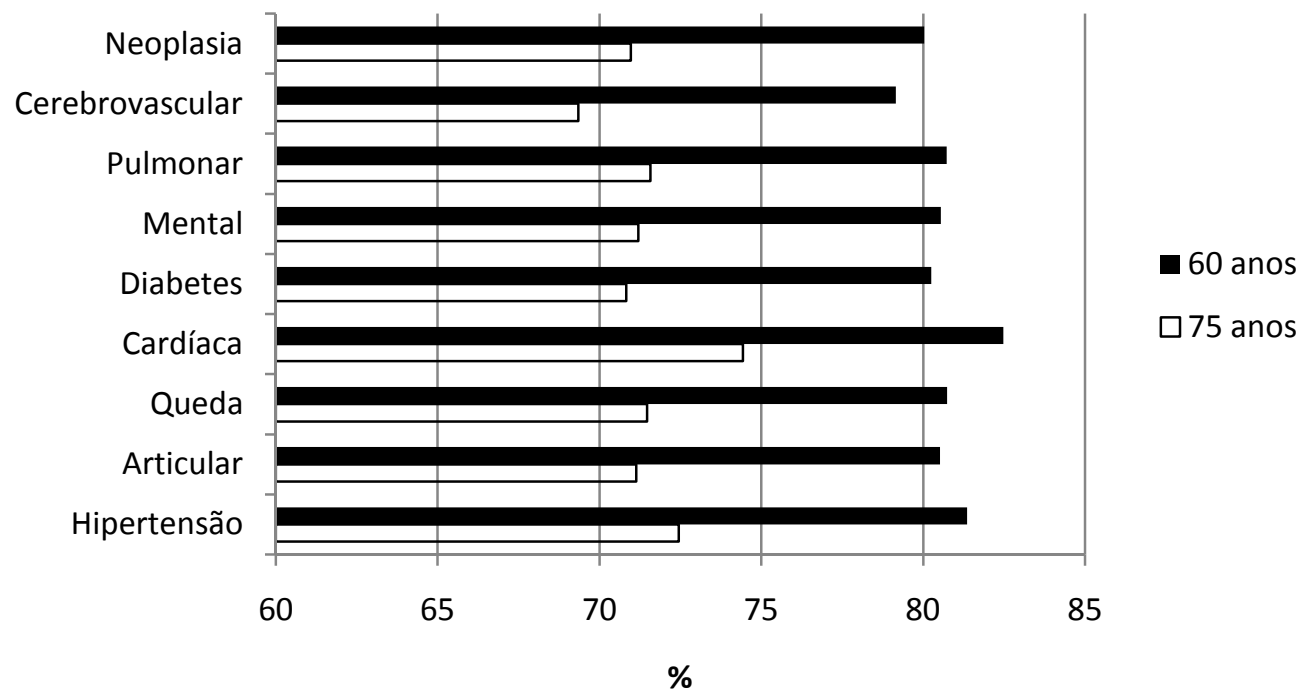

Figura 2 - Proporção (\%) dos anos a serem vividos livres de incapacidade, no sexo masculino, segundo idade e doença crônica eliminada. Município de São Paulo, Brasil, 2000. 


\section{DISCUSSÃO}

Ao longo do século XX, a população brasileira experimentou uma das mais rápidas e intensas transformações em sua estrutura e composição. A partir da segunda metade daquele século, a queda da taxa de fecundidade, mais acentuada que a verificada no coeficiente geral de mortalidade, provocou a diminuição progressiva das taxas de crescimento populacional no Brasil. Entre 1990 e 2005, a taxa de fecundidade caiu de 2,8 para 2,3 filhos por mulher e o coeficiente geral de mortalidade (ajustado por idade) de 7,7 para 6,8 por 1000 habitantes no mesmo período. Como consequência desse processo, a taxa de crescimento anual da população caiu de 1,7\% para 1,2\% de 1990 para 2008. Paralelamente, a expectativa de vida, ao nascimento, passou de 45,9 anos em 1950 para 66,3 anos em 1990 e 72,6 anos em 2008 (BARRETO et al., 2008).

Essas tendências destacam a diminuição da chance de morrer e o aumento da chance de sobreviver do cidadão brasileiro, refletindo no acelerado processo de envelhecimento populacional, com aumentos significativos da população de idosos.

Processos semelhantes foram experimentados por países que iniciaram a transição demográfica de suas populações em períodos anteriores, sendo que, atualmente, nas populações que evoluíram para baixas taxas de mortalidade, a continuidade do aumento da expectativa de vida deve-se, fundamentalmente, à redução da mortalidade por doenças crônicas nas idades mais avançadas (NUSSELDER, 2003). Se a população brasileira apresenta, na atualidade, tendências de evolução rápida para um cenário similar aos países desenvolvidos onde as baixas taxas de mortalidade já se constituem uma realidade epidemiológica, tornam-se cada vez mais urgentes os esforços que visam apoiar estratégias preventivas e de controle das doenças crônicas, especificamente na população idosa.

Entretanto, se tradicionalmente o declínio da mortalidade é considerado um reflexo do declínio da morbidade em uma população, quando esse processo passa a se concentrar especialmente em populações idosas, sérias dúvidas começam a existir sobre a possibilidade do prolongamento da vida vir a se constituir em melhores condições de saúde para a população sobrevivente (NUSSELDER, 2003). 
No caso do Brasil, a despeito das importantes mudanças demográficas e epidemiológicas, existem ainda percalços, desafios e problemas no campo da saúde que resistem e persistem no tempo, demonstrando que a sociedade brasileira ainda tem muito a avançar para alcançar padrões de saúde já conquistados por muitas sociedades desenvolvidas. Mesmo assim, a consolidação do SUS, nas últimas décadas, pode ser entendida como uma grande conquista do povo brasileiro, cujo contínuo desenvolvimento e aperfeiçoamento poderá trazer resultados positivos para toda a população, em especial para os indivíduos mais vulneráveis.

É fundamental lembrar que, no Brasil, a maioria dos idosos de hoje nasceu em áreas rurais, passando a viver em grandes centros urbanos. Essa geração enfrentou adversidades socioeconômicas significativas durante a vida, recebeu pouca ou nenhuma educação formal e trabalhou em ocupações mal remuneradas e não especializadas (SCHMIDT et al., 2011). Além disso, a diminuição do tamanho das famílias e o aumento do número de mulheres na força de trabalho remunerada reduziram as condições de suporte familiar a esses idosos (DUARTE et al., 2005).

É neste sentido, que a compressão da morbidade torna-se uma prioridade para as políticas públicas de envelhecimento ativo no século 21. Nos países em desenvolvimento, não se pode desconsiderar as condições sociais e econômicas precárias em que o processo de envelhecimento populacional se deu, nem mesmo a estruturação recente dos sistemas nacionais de saúde, como o caso do SUS brasileiro. De modo que nesses países, é esperado que as populações idosas emergentes presenciem a realidade da doença crônica de modo muito mais intenso e que, mais que a compressão da morbidade, talvez a "compressão da incapacidade" seja um objetivo mais realista para essas populações, conforme tem sido destacado por alguns autores (KALACHE et al., 2002).

Neste trabalho, buscou-se entender as transformações da expectativa de vida e da expectativa de vida livre de incapacidade, em relação a possíveis esforços preventivos que tenderiam, se não à eliminação das doenças crônicas, mas pelo menos ao seu controle na população idosa. Assim, para discutir o sentido dessas transformações e implicações, buscar-se-á expressar o efeito das eliminações de doenças, a partir das noções de compressão e expansão da morbidade, de acordo com 
os conceitos e hipóteses levantadas por Fries e outros autores, na década de 80 (FRIES; 1980; VERBRUGE 1984; MYERS \& MANTON, 1984).

A partir da classificação proposta por Nusselder em 2003, poder-se-ía dizer que uma diminuição na expectativa de vida com incapacidade (E.V.C.I.) implica uma compressão absoluta da morbidade, na medida em que novos anos livres de incapacidade estariam sendo adicionados à expectativa de vida total (E.V.). Já um aumento na porcentagem de expectativa de vida livre de incapacidade (E.V.L.I.) em relação à expectativa de vida total (E.V.) implicaria uma compressão relativa da morbidade, na medida em que, dos anos que seriam vividos, sem a eliminação de qualquer doença, uma parte que seria vivida com incapacidade passaria a ser convertida em anos de vida livres de incapacidade, com a eliminação de doenças. $\mathrm{O}$ raciocínio oposto poderia ser feito, então, para se compreender o significado de uma expansão absoluta ou relativa da morbidade, entendendo, por fim, que o termo "absoluto" implica um ganho de novos anos de vida, ou seja, uma mudança em quantidade, e o termo "relativo" implica uma conversão da natureza dos anos a serem vividos (de "com incapacidade" para "sem incapacidade", ou o inverso), ou seja, uma mudança em qualidade (NUSSELDER, 2003).

Assim, conforme observado na tabela 15, em relação às mulheres, tanto na idade de 60 anos como na de 75 anos, nota-se que a eliminação de doenças crônicas leva a uma diminuição da E.V.C.I., o que significa uma compressão absoluta da morbidade, ou seja, ganho de anos a serem vividos sem incapacidade. Entretanto, na idade de 60 anos esta compressão absoluta é maior.

Por outro lado, em relação à proporção de E.V.L.I. na E.V., os dados obtidos mostram um comportamento inverso. Tanto na idade de 60 anos, como na de 75 anos, com a eliminação de doenças crônicas ocorre um aumento da porcentagem de E.V.L.I. na E.V., significando, então, uma compressão relativa da morbidade, sendo que essa compressão relativa é maior nas idades mais avançadas (tabela 15).

Portanto, as estratégias preventivas que tenderiam a eliminar as doenças crônicas promoveriam maiores ganhos de vida livre de incapacidade aos 60 anos; mas aos 75 anos, apesar de os ganhos não serem da mesma magnitude, elas contribuiriam para converter anos de incapacidade em anos livre de incapacidade. 
Se for usada a doença cardíaca como exemplo, pela tabela 15 observar-se-ia que a sua eliminação aos 60 anos, implicaria em ganho de 2,72 anos na expectativa de vida das mulheres. Entretanto, esses anos ganhos correspondem simultaneamente a um ganho de 8,55 anos em termos de expectativa de vida livre de incapacidade e a uma diminuição de 5,83 anos em termos de expectativa de vida com incapacidade. Como os ganhos em expectativa de vida livre de incapacidade são maiores que os ganhos em expectativa de vida, a princípio, estar-se-ia diante de uma situação de compressão da morbidade. O que pode ser diretamente observado através da variação da porcentagem de E.V.L.I. na E.V. nessa mesma tabela, onde a doença cardíaca, quando eliminada, destaca-se como a que apresenta as maiores porcentagens e, portanto, a maior compressão de morbidade no sexo feminino, tanto na idade de 60 anos como na de 75 anos.

Já em relação aos homens, as mudanças da expectativa de vida e das expectativas de vida livre de incapacidade, aos 60 anos e aos 75 anos, variam conforme as doenças eliminadas.

Aos 60 anos, conforme a tabela 16, nota-se que todas as doenças eliminadas levaram a um aumento da expectativa de vida com incapacidade, o que significa uma expansão absoluta da morbidade, apesar da magnitude desses valores ser menor do que os correspondentes nas mulheres. Por outro lado, como a eliminação de doenças crônicas leva a um aumento da porcentagem de E.V.L.I. na E.V., espera-se uma compressão relativa da morbidade (também em porcentagens bem menores do que nas mulheres).

Portanto, pode-se dizer que, nos homens, os ganhos em expectativa de vida são maiores que nas mulheres, porém eles se dão à custa de uma expansão absoluta da morbidade e uma menor conversão dos anos com incapacidade em anos sem incapacidade (compressão relativa da morbidade).

Já aos 75 anos, também pela tabela 16, nota-se que nos homens ocorre uma diminuição de E.V.C.I. em função da eliminação da hipertensão arterial sistêmica e da doença cardíaca, o que indica uma compressão absoluta da morbidade, apesar desses valores serem pequenos. As demais doenças crônicas, como aumentam a E.V.C.I. ao serem eliminadas, levariam a uma expansão absoluta da morbidade. Entretanto, como todas as doenças, ao serem eliminadas, levaram a um aumento da 
porcentagem de E.V.L.I. na E.V., teríamos uma compressão relativa da morbidade para todas elas (tabela 16).

Da mesma forma que no sexo feminino, nos homens a compressão relativa da morbidade é maior na faixa etária mais avançada. As duas doenças (hipertensão arterial e doença cardíaca), que levam à compressão absoluta da morbidade, são as que também mais promovem uma compressão relativa, ao serem eliminadas. Entretanto, os ganhos e perdas absolutos são pequenos e a compressão relativa parece ser mais significativa nesta faixa etária.

De uma maneira geral, poder-se-ia, então, dizer que no sexo masculino seriam observados os maiores ganhos em expectativa de vida com a eliminação de doenças crônicas. No sexo feminino, apesar de os ganhos em expectativa de vida não serem tão grandes, uma parte maior desses ganhos ocorreria em função da diminuição de anos a serem vividos com incapacidade, ou seja, em função de um processo de compressão absoluta da morbidade. Em relação aos indivíduos da faixa etária mais avançada, tanto no sexo feminino como no masculino, seria observada uma maior conversão de anos a serem vividos com incapacidade para anos a serem vividos sem incapacidade, isto é, os ganhos na população mais idosa estariam ocorrendo, principalmente, em função de um processo de compressão relativa da morbidade.

Apesar do estudo das relações entre a expectativa de vida e a expectativa de vida livre de incapacidade trazer grandes contribuições para o entendimento do processo de compressão da morbidade, é preciso considerar que um aumento dos anos de vida com saúde não implica, necessariamente, em uma compressão do período com incapacidade (NUSSELDER, 2003). O contexto em que ocorrem as transformações das expectativas de saúde de uma população também se torna fundamental para o entendimento desse fenômeno.

Em primeiro lugar, é preciso considerar que as doenças são processos que envolvem tempo (duração) e o seu curso pode não estar completo no momento das avaliações de saúde, ou seja, o início pode ter se dado poucos anos antes do diagnóstico (JAGGER, 2003). Assim, do ponto de vista contextual, cabe considerar o curso da transição epidemiológica na localidade onde os dados foram obtidos. 
Em segundo lugar, é preciso considerar que a transição demográfica é um fenômeno universal que sofre a influência de uma multiplicidade de fatores e que estudos realizados em países que vivenciam diferentes etapas dessa transição ainda deixam dúvidas sobre as tendências das expectativas de saúde no futuro (KALACHE et al., 2002). Desse ponto de vista, é notório que, apesar de as pessoas viverem por mais tempo nos países desenvolvidos e terem maior oportunidade para adquirirem doenças não fatais associadas ao envelhecimento, a incapacidade tem um impacto absoluto (e relativo) maior nos países mais pobres (MATHERS et al., 2003).

Em terceiro lugar, cabe ainda considerar que as transições demográficas e epidemiológicas ocorrem simultaneamente à "transição de saúde", que expressa as mudanças nos modelos de atenção que visam a garantir o uso e o acesso a serviços de saúde adequados ao perfil epidemiológico e demográfico das populações emergentes (JOHANSSON, 1991). Assim, as transformações do sistema de saúde trazem influências marcantes para o processo de compressão da morbidade, na medida em que, como no Brasil, um aumento do acesso aos serviços de saúde por parte da população idosa tem convivido com as inadequações do modelo assistencial para esta população, conforme tem sido apontado por alguns autores brasileiros (LIMA-COSTA et al., 2007; LOUVISON et al., 2007).

Primeiramente, em relação à transição epidemiológica, é preciso considerar que as doenças cardiovasculares foram e continuam a ser, apesar de sua diminuição, a principal causa de morte no Brasil. Em um estudo sobre o padrão de mortalidade no município de São Paulo, em 1970, a ordenação dos principais grupos de doenças e agravos à saúde, em função dos ganhos propiciados à expectativa de vida ao nascer, caso não tivessem sido fatores de risco de morte, destacou as doenças cardiovasculares em primeiro lugar, tanto no sexo masculino, quanto no feminino (GOTLIEB, 1981). A importância dessas condições continua se mantendo ao longo dos anos, em especial nas idades mais avançadas, conforme a avaliação do impacto das causas básicas de morte na expectativa de vida, realizada em Salvador e São Paulo, a partir de informações obtidas para o ano de 1996 (BARBONI \& GOTLIEB, 2004).

No estudo de carga de doença no Brasil, utilizando o indicador disabilityadjusted life years (DALY), as DCNT responderam por 66,3\% da carga de doença, 
as doenças infecciosas responderam por $23,5 \%$ e as causas externas foram responsáveis por $10,2 \%$. No ranking do DALY, as doenças neuropsiquiátricas ocupam a primeira posição, sendo a segunda posição no ranking ocupada pelas doenças cardiovasculares. $\mathrm{Na}$ análise dos anos de vida perdidos por morte prematura, as doenças cardiovasculares ocupam a primeira posição (SCHRAMM et al., 2004).

Paralelamente, estudos tem destacado que a redução das doenças cardiovasculares é maior para doenças cerebrovasculares (34\%) e para a categoria de outras formas de doença cardíaca (44\%), sendo que a mortalidade por doença cardíaca isquêmica diminuiu 26\% (SCHMIDT et al., 2011). Se levar-se em conta a diminuição de prevalência e letalidade dessas condições, essas tendências epidemiológicas podem, contudo, expressar um efeito positivo na morbidade do idoso, no futuro. Colaborando com os achados deste estudo, em que a doença cardíaca ocupou a primeira posição em termos de promoção de compressão de morbidade ao ser eliminada (figura 1), grande atenção merece ser dada a essa condição pelas políticas públicas de saúde do idoso.

Por outro lado, como a prevalência de diabetes e hipertensão arterial no Brasil está aumentando, simultaneamente à prevalência de excesso de peso (SCHMIDT et al., 2011), dúvidas sobre os impactos da prevenção de doenças cardíacas e cerebrovasculares na compressão da morbidade passam a existir, na medida em que aquelas doenças são fatores de risco conhecidos para estas últimas e, conforme o presente estudo, também ocupam as primeiras posições dentre aquelas que mais promoveriam a compressão de morbidade, caso fossem eliminadas da população idosa (figura 1).

O aumento de prevalência da hipertensão arterial e do diabetes tem sido associado às mudanças desfavoráveis na dieta e à redução da prática de atividade física nas sociedades contemporâneas. Estudos tem mostrado que a prevalência autorelatada de hipertensão arterial, por exemplo, tem aumentado $0,5 \%$ ao ano, recentemente (SCHMIDT et al., 2011). Da mesma forma, a prevalência do diabetes mellitus tipo 2 tem se elevado vertiginosamente e espera-se ainda um maior incremento. Na América Latina há uma tendência do aumento da frequência dessa doença entre as faixas etárias mais jovens, cujo impacto negativo sobre a qualidade de vida da população e sobre as demandas para o sistema de saúde passa a ser cada 
vez mais relevante (SARTORELLI \& FRANCO, 2003). Dados mais recentes e nacionalmente representativos referentes a brasileiros de 20 anos de idade ou mais mostram um aumento do diabetes auto-relatado, de 3,3\% em 1998 para 5,3\% em 2008. O diabetes como causa básica de morte aumentou 11\% de 1996 a 2000 e, em seguida, diminuiu 8\% em 2007 (SCHMIDT et al., 2011).

Especificamente em relação aos idosos, de acordo com a PNAD de 1998, a prevalência de diabetes auto-referido por esta população brasileira foi de 10,3\%. Dados da PNAD 2003 apontam na população brasileira prevalência de 12\% nos homens e 16\% nas mulheres, na faixa de 70 a 79 anos (FRANCISCO et al., 2010).

As preocupações com a influência do diabetes na expectativa de vida livre de incapacidade são ainda maiores nas faixas etárias mais avançadas (acima dos 75 anos), na medida em que o aumento do impacto dessa doença na incapacidade tornase proporcionalmente mais significativo que o impacto em mortalidade (JAGGER et al., 2003).

Colaborando com o aumento da prevalência da hipertensão arterial e do diabetes mellitus, estimativas do Sistema de Vigilância de Fatores de Risco e Proteção para Doenças Crônicas por Inquérito Telefônico (Vigitel) mostram um aumento contínuo na obesidade de adultos, de 2006 a 2009, de 11,4\% para 13,9\% (SCHMIDT et al., 2011). A obesidade tem sido associada à redução da expectativa de vida livre de doença cardiovascular e a um aumento do número de anos vividos com doença cardiovascular, a partir de dados do estudo de Framingham (SILVA et al., 2006). Mas o sobrepeso, que é uma condição mais frequente, não tem sido associado a reduções da expectativa de vida ativa na população idosa (DIEHR et al., 2008).

Apesar de esses dados poderem, por fim, sugerir que a taxa de progressão das doenças esteja diminuindo (conforme a hipótese de equilíbrio dinâmico da morbidade), também é possível considerar que a propensão para referir doenças, especialmente as mais leves, tenha mudado (ROBINE et al., 1998). A diminuição das doenças cardiovasculares e cerebrovasculares, paralela ao aumento rápido e continuado da obesidade, hipertensão e diabetes deixa dúvidas sobre o processo de compressão da morbidade na população idosa; mas, seja como for, pela relevância dessas condições para esta população, conforme os resultados deste e de outros 
estudos, medidas preventivas que enfoquem essas condições tornam-se um grande desafio, sendo objeto de recomendações pela Estratégia Global para Alimentação, Atividade Física e Saúde, da OMS (BARRETO et al., 2005). Estas recomendações incluem providências fiscais que aumentem o acesso da população a alimentos saudáveis, como frutas e vegetais, e desencorajem o consumo de alimentos altamente processados, assim como intervenções que orientem o design urbano com o objetivo de promover o hábito da atividade física regular (BARRETO et al., 2005).

Já em relação ao câncer, dados do National Center of Health Statistics (EUA) mostraram que em 1997, com a queda da mortalidade por doenças do coração e o crescimento dos casos de neoplasias, o número de óbitos por doenças do aparelho circulatório foi praticamente igual ao de óbitos por neoplasmas (MALTA et al., 2008). Estatísticas brasileiras mostram que, nos homens, as taxas de mortalidade por câncer de pulmão, próstata e colorretal estão aumentando; as de câncer gástrico estão diminuindo e as de câncer de esôfago estão estáveis. Nas mulheres, as taxas de mortalidade por câncer de mama, de pulmão e colorretal aumentaram, enquanto as de câncer do colo do útero e de estômago diminuíram (SCHMIDT et al., 2011).

É preciso considerar ainda que, no período de 1980 e 2005, a taxa geral de mortalidade diminuiu 16\%, sendo que a taxa de mortalidade por doenças do aparelho circulatório diminuiu 32\% e a taxa de mortalidade por neoplasias malignas aumentou 25\% na população idosa brasileira (LIMA-COSTA et al., 2007).

Conforme os achados deste estudo, no sexo masculino, a neoplasia ocupa a oitava e a sétima posição na promoção de compressão de morbidade aos 60 e 75 anos, respectivamente; ganhando importância no sexo feminino, quando passa a figurar, na quinta posição (figuras 1 e 2). Pode-se considerar, entretanto, que as dúvidas em relação às tendências da epidemiologia das doenças cardiovasculares, cerebrovasculares e de seus fatores de risco, também se relacionam às tendências da neoplasia nessa população, mas é possível que essa condição ganhe importância nas faixas etárias mais avançadas (LIMA-COSTA et al., 2007; LIMA-COSTA \& MATOS, 2009).

A doença mental aparece com destaque nos estudos de carga de doença, pelo grande impacto em termos de incapacidade e de anos de vida perdidos (NUSSELDER et. al, 1996). No Brasil, séries temporais sobre essas condições não 
estão disponíveis, mas no estudo de carga de doença é notória a participação desse grupo de doenças, ocupando a primeira posição no ranking de DALY (SCHRAMM et al., 2004).

Em um estudo brasileiro que avaliou a prevalência de distúrbios mentais comuns (um conceito que inclui a depressão não psicótica, a ansiedade e os transtornos somatoformes) em adultos com 40 anos ou mais, a prevalência dessas doenças foi de $30,2 \%$, corrigida para a especificidade e sensibilidade do instrumento usado para a detecção (COELHO et al., 2009). No caso específico da população idosa, o aumento progressivo das síndromes demenciais, com o avançar da idade, em especial as do tipo Alzheimer, traz preocupações, na medida em que diante da inexistência de medidas de prevenção primária de efetividade comprovada, essas condições possam contribuir para a expansão da morbidade nos idosos (MACHADO, 2006).

Entretanto, em um estudo francês de 1994, os autores, utilizando também o método de Sullivan, calcularam a expectativa de vida livre de demência e, comparando essa medida com as tendências da expectativa de vida livre de incapacidade, na mesma população, concluíram que, apesar da prevalência de demência aumentar com a idade, o comportamento da expectativa de vida livre de demência é similar ao da expectativa de vida livre de incapacidade, ao longo dos anos (RITCHIE et al., 1994).

As síndromes de instabilidade e quedas também apresentam grande relevância para a população idosa e, quando associadas ao diagnóstico de osteoporose, podem levar a desfechos desfavoráveis, em especial às fraturas de quadril (CUMMINGS, MELTON, 2002). Séries temporais relacionadas a essas síndromes também não estão disponíveis no Brasil, mas recentemente, o estudo BRAZOS (Brazilian Osteoporosis Study) mostrou que aproximadamente 6\% da população brasileira acima de 40 anos relata ter recebido o diagnóstico médico de osteoporose. Fraturas de baixo impacto foram relatadas por $15,1 \%$ das mulheres e $12,8 \%$ dos homens, confirmando que o relato de osteoporose pode ter sido subestimado. Com base nos dados do Sistema de Vigilância de Fatores de Risco e Proteção para Doenças Crônicas por Inquérito Telefônico (Vigitel) do Ministério da Saúde, a prevalência de osteoporose auto-relatada foi de 4,4\%, com predominância 
em mulheres $(7,0 \%)$, com idade maior ou igual a 45 anos, com estado marital diferente de solteira e que relataram antecedente de tabagismo (MARTINI et al., 2009). Apesar de ainda não ser possível acompanhar plenamente as tendências de mortalidade e morbidade dessa síndrome no contexto brasileiro, o acompanhamento das grandes estratégias preventivas de controle da instabilidade e da queda, como o acesso a programas de manejo de risco destinados à população idosa e o aumento da prática da atividade física regular, podem ser sugestivos da evolução dessa condição no futuro (GREGG et al., 2000; CHANG et al., 2001).

As outras doenças crônicas, avaliadas conforme a análise de eliminação, tiveram impactos menores que as anteriores descritas, mas todas contribuíram significativamente para o processo de compressão da morbidade, seja em termos absolutos ou relativos (figuras 1 e 2).

Merece destaque o grupo das doenças respiratórias crônicas que ganham importância nos homens na faixa etária mais avançada, aparecendo como a terceira a promover maior compressão de morbidade, quando eliminada. Nesse sentido, a queda na taxa de mortalidade ajustada por idade para doenças respiratórias crônicas, que tem sido verificada tanto para doença pulmonar obstrutiva crônica (DPOC) com diminuição de 28,2\%, como para asma (redução de 34,1\%), pode contribuir para a compressão da morbidade no futuro (SCHMIDT et al., 2011).

Os estudos disponíveis tem mostrado que tanto a prevalência quanto a mortalidade atribuível a doenças pulmonares crônicas parecem estar diminuindo em países de baixa e média renda, mas poucos dados estão disponíveis. Entretanto, os resultados sugerem que a DPOC é um problema muito maior do que o imaginado previamente, na América Latina (MENEZES et al., 2005b).

A prevalência e a mortalidade por DPOC, especificamente em mulheres, vem crescendo nos últimos 20 anos e desde 1990 morrem mais mulheres do que homens com DPOC no Reino Unido, EUA e Canadá. O estudo transversal randomizado de base populacional denominado PLATINO, realizado na Grande São Paulo com 918 indivíduos maiores de 40 anos, revelou que 15,8\% deles preencheram os critérios diagnósticos de DPOC, sendo que desses, apenas $10 \%$ haviam sido diagnosticados. Em outras palavras, o sub-diagnóstico dessa 
enfermidade atinge a assustadora taxa de 90\% (MENEZES et al., 2005b; CAMARGOS et al., 2008).

A DPOC está projetada para ser a $5^{\mathrm{a}}$ doença no ranking mundial de carga de doença da OMS, em 2020, e sua participação em termos de carga de doença global encontra-se intimamente associada ao seu principal fator de risco, o tabagismo (MENEZES et al., 2005a). Nesse sentido, duas pesquisas nacionais mostram que a prevalência do tabagismo em pessoas com 18 anos ou mais diminuiu substancialmente no Brasil, de 34,8\% em 1989 para 22,4\% em 2003, o que é de relevância não só para as doenças pulmonares crônicas, mas, também, para as cardiovasculares e as neoplasias (MALTA et al., 2008). Embora esses dados não sejam completamente comparáveis, pode-se inferir uma queda importante na prevalência do tabagismo no período, o que de acordo com um estudo realizado na Holanda, pode significar não só um aumento na extensão da vida e dos anos vividos sem incapacidade, como resultar em compressão da morbidade (NUSSELDER et al., 1999).

As doenças articulares também tem sido destacadas em estudos internacionais realizados em países desenvolvidos, como importante participante nos processos de compressão de morbidade (NUSSELDER, 1996). Assim como no estudo SABE, a alta prevalência de doença articular auto-referida chama a atenção em outros estudos brasileiros que avaliaram a população idosa. No estudo Bambuí, a prevalência de relato de sintomas crônicos nas mãos e joelhos foi de 44,2\% e de reumatismo diagnosticado por médico foi de 25,3\% (15,3\% nos homens e 31,9\% nas mulheres) (MACHADO et al., 2004). Com o controle das doenças cardiovasculares e das neoplasias, a tendência futura é que tanto essas doenças, como as doenças mentais, ganhem importância progressiva na população idosa.

Se considerarem-se os estudos de eliminação de doenças realizados em outros países, perceber-se-á que, em várias situações, a eliminação de doenças crônicas tem levado à compressão da morbidade (PERENBOOM et al., 2003). Nesses estudos cabe destacar que a doença cardíaca tem trazido ganhos variáveis, quando eliminada.

$\mathrm{Na}$ Austrália, por exemplo, a eliminação das doenças circulatórias na população idosa levou aos maiores ganhos de anos de vida saudável, tanto em 
homens como em mulheres, seguida pela eliminação das neoplasias no sexo masculino e pela eliminação das doenças musculoesqueléticas, no sexo feminino (MATHERS, 1999; DAVIS et al., 2003). No Reino Unido, os resultados obtidos para a análise de eliminação de doenças foram parecidos com os da Austrália, com exceção dos ganhos obtidos com acidentes e envenenamento (MATHERS, 2003).

$\mathrm{Na}$ Holanda, a eliminação da doença cardíaca, das artrites e das lombalgias levou aos maiores ganhos em expectativa de vida livre de incapacidade na população geral. Ordenando as doenças conforme o impacto, diferenças puderam ser notadas entre os sexos: entre os homens, a doença cardíaca teve o maior impacto, enquanto entre as mulheres, a artrite e a lombalgia apresentaram os maiores impactos. Resultados semelhantes foram obtidos nessa população para os indivíduos com 65 anos ou mais, com exceção para a doença cardíaca, cuja eliminação não implicou nem em expansão relativa nem em compressão da morbidade (NUSSELDER, 1996).

$\mathrm{Na}$ Dinamarca, em um estudo de eliminação de doenças crônicas na população idosa, os autores concluíram que, de uma maneira geral, o efeito da eliminação de doenças letais (como as cardiovasculares) levaria a uma compressão relativa da morbidade, enquanto uma compressão absoluta seria alcançada com a eliminação de doenças não letais, como as osteo-articulares (BRØNNUM-HANSEN et al., 2006).

Nos EUA, a eliminação da mortalidade por doença cardíaca resultou nos maiores ganhos na expectativa de vida (três anos para homens e quatro anos para mulheres aos 70 anos). A maior parte dos ganhos em expectativa de vida livre de incapacidade ocorreu aos 70 anos, apesar de uma mudança dessa tendência com o avançar da idade, sendo que a eliminação da doença cardíaca nos muito idosos levou à adição de mais anos com incapacidade do que sem incapacidade, diferente do observado em nosso estudo (HAYWARD et al., 1998; MATHERS, 2003).

Apesar da variação do impacto das doenças crônicas em diferentes estudos internacionais, é considerável a afirmação de alguns autores de que, aparentemente, nenhum estudo realizado nos EUA, desde a década de 60, tenha mostrado uma deterioração da saúde funcional das novas gerações de idosos (ROBINE et al., 2003). Pelo contrário, de uma maneira geral, os resultados dos estudos sugerem que o estado funcional dos idosos tem melhorado ao longo dos anos (FREEDMAN et al., 2002). 
Considerar, então, as variações no processo de transição demográfica e outros fatores que interferem nas expectativas de saúde, bem como suas tendências temporais, torna-se fundamental.

Primeiramente, os estudos internacionais, de uma maneira geral, tem mostrado que as tendências temporais da expectativa de vida livre de incapacidade parecem variar conforme o grau de gravidade da incapacidade avaliada, com uma diminuição para os níveis mais graves de incapacidade e um aumento para os níveis mais leves (BURATA \& EGIDI, 2003; ROBINE et al., 2003).

Da mesma forma, os estudos que tem sugerido uma possível compressão da morbidade, mostram que esse processo tem ocorrido da década de 70 para a de 90 , nos EUA, iniciando pelos grupos de alta escolaridade enquanto os grupos de baixa escolaridade tem experimentado uma expansão da morbidade (ROBINE et al., 2003).

É possível, então, que uma sinergia positiva entre o aumento do nível educacional e nutricional, a melhoria das condições de trabalho e dos hábitos e comportamentos de saúde possam levar a uma melhoria da capacidade funcional e do desempenho das ABVDs nas futuras coortes. Entretanto, torna-se cada vez mais claro que os indivíduos de nível social mais baixo tem as menores expectativas de vida e de saúde e, geralmente, os maiores períodos de vida em mau estado de saúde (LIMA-COSTA et al., 2003b; MATTHEWS et al., 2006; NAGEL et al., 2008).

Considerando os fatores sócio-demográficos que interferem na evolução das expectativas de vida e de saúde, é possível notar primeiramente que as diferenças de nível educacional são indicativas das desigualdades socioeconômicas entre os idosos, nas cidades onde o estudo SABE foi realizado (HAM-CHANDE, 2003). É importante destacar, ainda, que, na Espanha, os fatores que melhor explicaram as diferenças regionais na expectativa de vida livre de incapacidade foram o nível educacional, as taxas de desemprego e o tabagismo (GUTIÉRREZ-FISAC et al., 2000).

No Brasil, alguns estudos tem avaliado a expectativa de vida saudável da população geral e da população de idosos. Santos (2003) mostrou as influências do sexo, da escolaridade, da renda, do estado marital e da condição de viver só na expectativa de vida livre de incapacidade da população da comunidade de São Paulo, através do estudo SABE (LEBRÃO \& DUARTE, 2003). 
Camargos e colaboradores (2005) também utilizaram a base de dados do estudo SABE e, avaliando a expectativa de vida com incapacidade funcional em idosos em São Paulo reforçaram os achados anteriormente descritos, mostrando que, apesar de as mulheres idosas paulistanas terem apresentado maior expectativa de vida do que os homens, foi menor a proporção de anos vividos livres de incapacidade funcional (CAMARGOS et al., 2005).

Ainda em 2005, Romero e colaboradores avaliaram a expectativa de vida saudável na população brasileira a partir da base de dados do Instituto Brasileiro de Geografia e Estatística (IBGE), utilizando duas abordagens: uma a partir da autoavaliação do estado de saúde e outra, a partir da auto-avaliação de limitações em atividades de vida diária. Os autores mostraram que as duas abordagens apresentaram estimativas muito próximas, principalmente nas populações de idades mais avançadas e que a proporção de anos de vida saudável perdidos é mais importante nas mulheres (ROMERO et al., 2005).

Em outro estudo, conduzido a partir da base de dados do SABE, no Brasil, também as mulheres apresentaram mais dificuldades que os homens para levantar da cama e deambular dentro do quarto. Em outras atividades de vida diária não foram observadas diferenças na capacidade de realização entre homens e mulheres. Os resultados mostraram, ainda, que as mulheres na idade de 60 anos viviam, aproximadamente, três vezes mais do que os homens em estado de incapacidade grave (ANDRADE et al., 2011). A diferença na expectativa de vida com incapacidade entre homens e mulheres foi relacionada à maior expectativa de vida $\mathrm{e}$ à maior incidência de incapacidade nas mulheres (SAUVAGET et al., 1999).

Já as estimativas de disability-adjusted life expectancy (DALE), pelo estudo de carga da doença conduzido pela OMS, mostraram que tanto as pessoas do sexo feminino quanto do masculino gastam a mesma proporção do tempo de vida em estado de incapacidade quando se utiliza um indicador de expectativa de saúde com ajuste para os níveis de incapacidade. Esse fato sugere que os homens, apesar de passarem menos tempo em incapacidade, apresentam graus de incapacidade mais graves (BARENDREGT, 2003).

Quando se considera a "transição de saúde", em especial em relação à atenção que tem sido dispensada à população idosa no Brasil, as informações 
provenientes da PNAD 1998 mostraram que as condições de saúde dos idosos brasileiros eram muito semelhantes às de outras populações idosas (LIMA-COSTA et al., 2007). Além disso, a base de dados da PNAD 1998 e 2003 permitiu identificar melhora nas condições de saúde auto-referidas da população idosa brasileira, assim como um aumento no número de consultas médicas. Esse aumento parece estar relacionado à melhora de acesso, possivelmente no âmbito do SUS (LIMA-COSTA \& MATOS, 2009). Atribuir os resultados identificados nessas análises total ou parcialmente, direta ou indiretamente, ao processo de implantação do SUS é tarefa difícil e não pretendida pelos autores dos estudos referidos. Entretanto, acumulam-se evidências sobre o possível impacto do SUS na saúde da população brasileira (BARRETO et al., 2009).

O documento Saúde Brasil 2008: 20 anos de Sistema Único de Saúde (SUS) no Brasil (BRASIL. MINISTÉRIO DA SAÚDE, 2009) destaca que quando comparado com o final dos anos 80, o padrão socioeconômico emergente da população brasileira indica que ela é mais urbana, mais escolarizada, com maiores níveis de emprego e com maior renda (PAES-SOUSA et al., 2009). Nesse mesmo documento também são relatados vários avanços do sistema de saúde brasileiro, dos quais alguns são mais relevantes para as condições de saúde do idoso no futuro, conforme se descreverá sucintamente a seguir.

A oferta de serviços e ações programáticas tem sido crescente, sendo que estudos avaliativos apontam, entre outros efeitos positivos, o impacto da estratégia de Saúde da Família na redução da mortalidade infantil e na promoção da equidade (FACCHINI \& GARCIA, 2009). O investimento na auto-suficiência, a disponibilidade de imunobiológicos na rede de serviços, a busca das metas de cobertura vacinal na rotina em campanhas de vacinação, o aperfeiçoamento da força de trabalho, a promoção de estudos e pesquisas, são as principais frentes desenvolvidas na perspectiva da obtenção de impacto epidemiológico sobre a ocorrência de doenças imunopreveníveis (CARVALHO et al., 2009). Ao longo da trajetória de implementação do SUS, a mulher passa a ter acesso a uma gama de serviços que expressam a busca da integralidade da atenção à saúde (VIOLA, 2009). Em relação à epidemiologia do HIV/AIDS, estudos mostraram o impacto positivo das políticas de prevenção, assistência e tratamento implementadas, nas últimas 
décadas, na redução da infecção por HIV e na redução da morbidade e mortalidade por AIDS no país (PIMENTA \& BRITO, 2009). As discussões em torno da Saúde do Trabalhador, que contaram com a participação crescente da sociedade, conforme demonstrado nas Conferências Nacionais, revelaram um avanço na perspectiva democrática e um amadurecimento dos mecanismos de controle social no SUS (SANTANA \& SILVA, 2009). A articulação de redes de atenção e os processos de pactuação regionais induzidos pela constituição dos serviços móveis de atenção às urgências (Samu 192), envolvendo a participação de outros atores não oriundos da saúde, como, por exemplo, o Corpo de Bombeiros, a Polícia Rodoviária Federal e as Forças Armadas, revelaram também um avanço estrutural e gerencial do sistema de saúde brasileiro como um todo (ALVES \& CRUZ, 2009).

Assim, independente da magnitude e da excelência dos possíveis avanços conquistados na implantação do SUS, o que muitos desses estudos explicitaram é que a Saúde Pública no Brasil tem avançado, de uma maneira geral, em um processo histórico para além dos mais de 20 anos de SUS e que essas transformações poderão estar relacionadas com a saúde das atuais e futuras coortes de idosos no país.

Apesar da evolução variável da epidemiologia das doenças crônicas, em sua relação contextual com os fatores sócio-demográficos e com a contribuição diferenciada dos diferentes modelos assistenciais em saúde vigentes no Brasil, é considerável que, entre 1996 e 2007, a mortalidade padronizada por idade diminuiu $20 \%$, sobretudo devido a reduções em doenças cardiovasculares $(31 \%)$ e respiratórias crônicas (38\%), na população geral (SCHMIDT et al., 2011). Essas diminuições têm sido associadas, em seu conjunto, com a implementação bem-sucedida de políticas de saúde que levaram principalmente à redução do tabagismo e à expansão do acesso à atenção básica em saúde.

Os resultados de estudos específicos sobre os idosos brasileiros tem indicado, também, que houve redução da mortalidade geral, da mortalidade por doenças do aparelho circulatório e melhora do uso de serviços de saúde, por parte dessa população, nos períodos investigados. As doenças do aparelho circulatório tem se apresentado como a principal causa de mortalidade entre os idosos brasileiros. Entre elas, predominam as doenças cerebrovasculares, seguidas pela doença isquêmica do coração. Entretanto, as tendências de mortalidade da população idosa 
brasileira nas últimas décadas mostram redução da taxa de mortalidade por doenças cardiovasculares e redução da taxa de mortalidade por doença isquêmica do coração. Os resultados mencionados chamam a atenção para a importância da hipertensão arterial como principal fator de risco para a mortalidade em idosos. Outros indicadores das condições gerais de saúde (auto-avaliação da saúde e capacidade funcional) também apresentaram evolução positiva. Por outro lado, houve aumento na taxa de mortalidade por neoplasias, que passou a representar o segundo maior grupo de causa de óbitos nessa população. Apesar das limitações desses estudos referidos, tendências de melhora foram observadas e nenhum dos indicadores de condições de saúde e de uso de serviços de saúde apresentou piora na sua evolução, exceto a mortalidade por neoplasias malignas (LIMA-COSTA et al., 2003a; LIMACOSTA et al., 2007; LIMA-COSTA \& MATOS, 2009).

Quando se relacionam as tendências atuais da atenção à saúde do idoso no Brasil, com os achados deste estudo, percebe-se que a prevenção de doenças crônicas na população idosa pode ter um grande potencial de contribuir para a compressão da morbidade nessa população.

A estruturação de modelos assistenciais em saúde com enfoque preventivo, articulado com políticas sociais amplas que busquem interferir na iniquidade, parece ser uma perspectiva e um grande desafio para a promoção do envelhecimento ativo, em nosso contexto. Não se pode perder de vista que nesses mais de 20 anos de organização do SUS atingiu-se significativo avanço na descentralização da gestão e execução das ações de saúde; a municipalização atingiu cerca de $97 \%$ dos municípios brasileiros; as estratégias de Saúde da Família ampliaram significativamente o acesso à Atenção Básica, com foco na prevenção e promoção da saúde (BRASIL. MINISTÉRIO DA SAÚDE, 2008). Em 2003, a estruturação da Coordenação Nacional para Vigilância de Doenças e Agravos Não Transmissíveis e Promoção da Saúde, junto à Secretaria de Vigilância à Saúde do Ministério da Saúde, também pode ser considerada um esforço importante no sentido de coordenar a implantação de ações de saúde voltadas para o controle das DCNT (BRASIL. MINISTÉRIO DA SAÚDE, 2005).

Contudo, a transição epidemiológica no Brasil apresenta-se ainda influenciada por importantes diversidades regionais decorrentes das diferenças sócio- 
econômicas e de acesso aos serviços de saúde, resultando em um "modelo polarizado de transição", no qual a ocorrência ainda alta de doenças infecciosas convive com o crescimento da morbidade e da mortalidade por DCNT, nas distintas regiões do país (FRENK et al., 1991; ARAÚJO, 1992).

Neste sentido, pode-se dizer, conforme a constatação do próprio autor da hipótese de compressão da morbidade, que se esse processo encontra-se em curso no presente, ele ocorre apenas em parte e para alguns grupos populacionais (FRIES, 1989). A maioria dos estudos de tendências temporais das expectativas de vida livre de incapacidade dá suporte à hipótese de equilíbrio dinâmico da morbidade, enquanto estudos realizados nos EUA apontam para a compressão da morbidade e estudos realizados na Austrália, para a expansão da morbidade (ROBINE \& RITCHIE, 1991; MURRAY \& LOPEZ, 1997; GRAHAM et al., 2004; PERENBOOM et al., 2004).

Porém, a "retangularização" das curvas de sobrevivência de várias populações parece dar suporte à teoria da compressão da morbidade, na medida em que sinaliza para o alcance progressivo dos limites do span vital na espécie humana (FRIES, 1983).

De qualquer forma, diante dessa variação das tendências internacionais, alguns autores tem considerado que, em se tratando de análises focadas em populações idosas, as teorias de "transição de incapacidade" devem sofrer mudanças para contemplar a heterogeneidade dos aspectos sociais e melhor embasar as estratégias de saúde destinadas a essa população, passando a considerar a “polarização social” presenciada por esse grupo (DAVIS et al., 1999).

Do mesmo modo, reconhecer a importância desses fatores nas práticas clínicas, torna-se, cada vez mais urgente, quando se considera que implementar serviços de alta qualidade envolve também a competência cultural dos agentes de saúde para reconhecer diferenças individuais e populacionais (LAVIZZO-MOUREY \& MACKENZIE, 1995).

Pode-se, então, dizer que, no presente, o grande desafio para a compressão da morbidade parece ser o de estender os benefícios desse processo para os grupos menos favorecidos (FRIES, 1992). Na população de idosos, esse desafio encontra-se 
fortemente relacionado com mudanças de comportamento em saúde, articuladas em estratégias preventivas (FRIES, 1992).

A teoria da compressão da morbidade sugere, portanto, uma estratégia para a redução da morbidade na população geral (FRIES, 1992; FRIES et al., 2011). Quando se pensa, entretanto, nos indivíduos idosos, é importante lembrar que essa compressão depende de a idade de início das primeiras incapacidades aumentar mais rapidamente do que a expectativa de vida, quando, então, poder-se-á falar, mais precisamente, em uma “compressão da incapacidade" (KALACHE et al., 2002).

Colaborando com as políticas de envelhecimento ativo, os achados deste estudo mostraram que a eliminação de doenças crônicas nos modelos de análise de expectativa de vida livre de incapacidade, busca corresponder ao controle dessas doenças, em termos práticos, na população idosa. Se os resultados desta pesquisa, e os de outros autores, expressam o grande potencial que o controle dessas doenças pode ter em temos de longevidade e qualidade de vida na velhice (MATHERS, 1999), pode se concordar, então, com Fries em duas de suas mais importantes proposições.

Em primeiro lugar, caberia considerar que, para a população idosa, a compressão da morbidade só se tornaria uma realidade se o início da incapacidade funcional fosse adiado; o que, entretanto, só poderia ser alcançado a partir de esforços preventivos que antecedessem o início desse processo de incapacitação (FRIES, 1992).

Em segundo lugar, poder-se-ia questionar se os programas de manutenção de saúde, não seriam ainda mais benéficos na população de faixa etária mais avançada, na medida em que esta apresenta os maiores gastos em saúde e a maior proximidade entre as intervenções e os desfechos a serem alcançados. (FRIES, 1992).

Retoma-se, assim, o "paradoxo da longevidade" expresso na introdução deste estudo, que agora se apresenta, de modo diferenciado, no que foi chamado por Barsky, em 1988, de "paradoxo da saúde". Barsky se referia, assim, ao fato de as "vozes do pessimismo" serem as mais frequentemente ouvidas, apesar de as estatísticas disponíveis não trazerem conclusões convincentes e definitivas sobre o processo de "transição de saúde" (NUSSELDER \& PEETERS, 2006). Com esse 
termo, o autor procurou expressar a tendência para o declínio da satisfação com o bem-estar pessoal, apesar das enormes melhorias nas condições de saúde (BARSKY, 1988).

Realidade ou utopia, próxima ou distante, pode-se, por fim, dizer que a compressão da morbidade talvez seja a afirmação de todos os paradoxos que a revolução demográfica reservou à humanidade. 


\section{LIMITAÇÕES E IMPLICAÇÕES DA PESQUISA}

A primeira e mais importante limitação do presente estudo é o pressuposto de independência das causas de morte. Entretanto, informações sobre causas múltiplas de óbito não estão amplamente disponíveis, sendo que essa limitação dificilmente poderia ser contornada até que se conheça melhor a relação de dependência entre as diferentes causas de óbito, no contexto brasileiro.

De qualquer forma, é preciso considerar que o pressuposto de independência pode fazer com que a redução da mortalidade nas idades mais avançadas, momento em que a co-existência de várias doenças torna-se mais frequente, tenham sido superestimadas.

O fato de algumas doenças serem fatores de risco para outras, pode fazer com que a causa final de óbito seja subestimada. Por exemplo, como foi trabalhado com diabetes como causa de óbito e essa doença é um fator de risco para a doença cerebrovascular, as estimativas deste estudo podem ter subestimado os efeitos da eliminação da doença cerebrovascular.

Também é preciso considerar que, como se trabalhou com grupo de doenças (por exemplo: doenças articulares), não foi levado em conta que doenças diferentes dentro de um mesmo grupo (por exemplo: artrite reumatóide e osteoartrose) possam ter impactos variáveis em termos de incapacidade. Do mesmo modo, também não se considerou que uma mesma doença possa levar a diferentes graus de comprometimento de funcionalidade, conforme a faixa etária. $\mathrm{O}$ infarto agudo do miocárdio, por exemplo, em idades mais jovens pode contribuir para uma menor incapacidade, quando comparado com as idades mais avançadas.

Outra limitação diz respeito ao fato de que a probabilidade de morrer não foi relacionada com a incapacidade na análise de regressão. Além do que, não foi considerado que a incapacidade pode predispor a doenças letais (por exemplo, a incapacidade decorrente de uma doença cerebrovascular pode predispor a pneumonia, aumentando a mortalidade). As relações entre incapacidade e mortalidade são difíceis de serem previstas, mas de qualquer forma os vieses gerados podem operar em ambas as direções, não sendo tão grande de uma maneira geral. 
As informações auto-referidas, tanto em relação às doenças crônicas, quanto à presença de incapacidade, também podem trazer vieses aos resultados. Estudos realizados no Brasil tem mostrado, entretanto, a validade de informações autoreferidas, com boa sensibilidade e especificidade para detectar condições de saúde. As doenças cardiovasculares e o diabetes parecem ser adequadamente reportados pelos indivíduos, em virtude da cobertura universal pelo sistema de saúde brasileiro (BARRETO \& FIGUEIREDO, 2009).

Resultados de outro estudo foram sugestivos de que uma pior autopercepção de saúde pode estar correlacionada com a baixa prevalência de comportamentos de risco entre indivíduos com DCNT, em especial em homens com duas o mais DCNT, o que merece especial atenção na interpretação dos resultados do presente estudo. Na PNAD 2003, a prevalência de DCNT foi 62\% maior entre adultos com baixa escolaridade. Apesar de os homens reportarem menos condições de saúde, eles parecem ter uma pior percepção de saúde quando diagnosticados com uma DCNT (MARCOPITO et al., 2005). Outro estudo revelou dissimilaridades na morbidade auto-referida entre homens e mulheres, mas as diferenças dependeram do tipo de morbidade considerada. Essas diferenças foram explicadas pelo comportamento de busca de assistência à saúde, percepção ou relato de problemas de saúde (MENDOZA-SASSI \& BÉRIA, 2007).

Ainda em relação à auto-avaliação em saúde, um estudo recente, utilizando as PNADs de 1998 e 2003, mostrou que o uso de outro respondente não modifica a distribuição da auto-avaliação da saúde entre idosos, nem os fatores associados a ela (LIMA-COSTA et al., 2007).

Outro aspecto a ser considerado diz respeito à não inclusão de idosos institucionalizados, o que também poderia gerar uma superestimação do efeito da eliminação de doenças crônicas para essa população em especial, na medida em que esses idosos poderiam estar vivendo em instituições por motivos outros que não doenças crônicas e suas consequências.

O fato de não se haver trabalhado com dados longitudinais, usando taxas de prevalência conforme o método de Sullivan, traz desvantagens quando se tenta pensar em termos das mudanças que vem ocorrendo na mortalidade e na incapacidade da população idosa ao longo do tempo (BARENDREGT, 2002). 
Entretanto, quando eliminadas, simultaneamente, a mortalidade e a incapacidade relacionadas às doenças, os efeitos dinâmicos dessas transformações, em uma mesma população, passam a não existir. Além disso, devido a sua simplicidade, as tábuas de vida em vários estudos tem sido calculadas a partir do método de Sullivan, que tem sido a técnica mais amplamente utilizada em diversos países, facilitando, assim, futuras comparações (MATHERS, ROBINE, 1997; IMAI, SONEJI, 2007).

Como implicações de pesquisa, considera-se que os estudos futuros poderiam utilizar delineamentos longitudinais que permitam compreender melhor as relações entre as diferentes doenças crônicas e as transições entre os estados de saúde, principalmente a capacidade funcional (CRUZ et al., 2007; JAGGER et al., 2007a). Estudos que incluam a população idosa institucionalizada poderiam trazer maiores informações sobre o comportamento de doenças de alta prevalência nestas condições, como as neuropsiquiátricas, por exemplo. O uso do indicador DALE para a comparação das diferenças entre os sexos, talvez possa trazer novas informações sobre as diferenças nas E.V.L.I., na população idosa. Estudos que abordem a multicausalidade dos óbitos e as relações entre multimorbidade e capacidade funcional talvez contribuam no entendimento do processo de compressão da morbidade na população idosa.

Por fim, considerando as características das transições demográfica, epidemiológica e de saúde no Brasil, futuros estudos poderiam trazer grandes contribuições científicas ao acompanhar as tendências temporais da E.V.L.I. na população idosa e as diferenças geográficas da E.V.L.I., nas várias regiões do país. 


\section{CONCLUSÕES}

Conforme os resultados deste estudo, a eliminação de doenças crônicas na população idosa poderia levar a uma compressão da morbidade em homens e mulheres, tanto na idade de 60 anos, quanto na de 75 anos.

A doença cardíaca apresentou-se como aquela que mais promoveria a compressão da morbidade, caso fosse eliminada, em ambos os sexos.

Os maiores ganhos em expectativa de vida livre de incapacidade, com a eliminação de doenças crônicas, ocorreriam no sexo feminino, levando a um processo de compressão absoluta da morbidade.

Nos indivíduos de idade mais avançada, com 75 anos, os ganhos em expectativa de vida livre de incapacidade poderiam ocorrer em função de um processo de compressão relativa da morbidade.

Nos homens com idade de 75 anos, todas as doenças estudadas, com exceção da doença cardíaca e da hipertensão arterial sistêmica, levariam a um processo de expansão absoluta da morbidade, mas simultaneamente a um processo de compressão relativa da morbidade, ao serem eliminadas.

Os resultados obtidos podem contribuir para o planejamento de programas de saúde destinados à população idosa, com ênfase na abordagem preventiva e na perspectiva do envelhecimento ativo. 


\section{REFERÊNCIAS}

Abdalla SD, Peter AS, Deepa LP, Stig KP, David RM, Robert B, et al. Nature 2007; 450 (22 November): 494-6.

Abegunde DO, Mathers CD, Adam T, Ortegon M, Strong K. The burden and costs of chronic diseases in low-income and middle-income countries. Lancet 2007; 370: 1929-38.

Albala C, Lebrão ML, León Díaz EM, Ham-Chande R, Hennis AJ, Palloni A, et al. Encuesta Salud, Bienestar y Envejecimiento (SABE): metodologia de la encuesta y perfil de la población estudiada. Rev Panam Salud Pública 2005; 17(5/6): 307-22.

Albuquerque SMRL. Envelhecimento ativo: desafios dos serviços de saúde para a melhoria da qualidade de vida dos idosos [tese]. São Paulo (SP); Faculdade de Medicina da USP; 2005.

Alves CV, Cruz KDF. O SAMU 192 no cenário das urgências: desafios da Política Nacional de Atenção às Urgências no Sistema Único de Saúde no Brasil. In: Ministério da Saúde. Saúde Brasil 2008: 20 anos de Sistema Único de Saúde (SUS). Brasília (BR), 2009: 205 - 19.

Alves LC, Leimann BCQ, Vasconcelos MEL, Carvalho MS, Vasconcelos AGG, Fonseca TCO, et al. A influência das doenças crônicas na capacidade funcional dos idosos do Município de São Paulo, Brasil. Cad Saúde Pública 2007; 23(8): 1924-30.

Alves LC, Rodrigues RN. Determinantes da auto-percepção de saúde entre idosos do Município de São Paulo, Brasil. Rev Panam Salud Pública 2005; 17(5/6): 333-41.

Andrade FCD, Guevara PE, Lebrão ML, Duarte YAO, Santos JLF. Gender differences in life expectancy and disability-free life expectancy among older adults in São Paulo, Brazil. Women's Health Issues 2011; 21(1): 64-70.

Araújo JD. Polarização epidemiológica no Brasil. Informe Epidemiológico SUS 1992; 1: 5-16.

Assis M, Hartz ZMA, Valla VV. Programas de promoção da saúde do idoso: uma revisão da literatura científica no período de 1990 a 2002. Ciênc Saúde Coletiva 2004; 9(3): 557-81.

Barbosa AR, Souza JMP, Lebrão ML, Marucci MFN. Functional limitations of Brazilian elderly by age and gender differences: data from SABE Survey. Cad Saúde Pública 2005; 21(4): 1177-85.

Bardoni AR, Gotlieb SLD. Impacto de causas básicas de morte na esperança de vida em Salvador e São Paulo, 1996. Rev Saúde Pública 2004; 38(1): 16-23. 
Barsky AJ. The Paradox of Health. NEJM 1988; 144: 205-11.

Barendregt JJ. Disability-adjusted life years (DALYs) and Disability-adjusted Life Expectancy (DALE). In: Robine JM, Jagger C, Mathers CD, Crimmins EM, Suzman RM (editores). Determining Health Expectancies. England: John Wiley \& Sons; 2003. p. 247-61.

Barendregt JJ. Incidence and prevalence-based SMPH: Making the Twain Meet. In: Murray CJL, Salomon JA, Mathers CD, Lopez AD, editores. Summary Measures of Population Health: Concepts, Ethics, Measurement and Applications. Geneva: World Health Organization, 2002. pp 221-31.

Barreto ML, Teixeira MG, Morais Neto OL, Duarte EC. O nascimento, a vida, o adoecimento, a morte e a atenção à saúde da população brasileira durante 20 anos de Sistema Único de Saúde: uma síntese. In: Ministério da Saúde. Saúde Brasil 2008: 20 anos de Sistema Único de Saúde (SUS). Brasília (BR), 2009: 407-16.

Barreto SM, Figueiredo RC. Chronic diseases, self-perceived health status and health risk behaviors: gender differences. Rev Saúde Pública 2009; 43(supl. 2): 1-9.

Barreto SM, Pinheiro ARO, Sichieri R, Monteiro CA, Schimidt MI, Lotufo P, Assis AM, Guimarães V, Recine EGIG, Victora CG, Coitinho D, Passos VMA. Análise da Estratégia Global para Alimentação, Atividade Física e Saúde, da Organização Mundial da Saúde. Epidemiol Serv Saúde 2005; 14(1): 41-68.

Bayliss EA, Edwards AE, Steiner JF, Main DS. Processes of care desired by elderly patients with multimorbidities. Fam Pract 2008; 25: 287-93.

Beaglehole R, Ebrahim S, Reddy S, Voûte J, Leeder S, on behalf of the Chronic Disease Action Group. Prevention of chronic disease: a call to action. Lancet 2007; 370: 2152-57.

Bergson H. A Evolução Criadora. trad. Bento Prado Neto. São Paulo: Martins Fontes, 2005.

Bondenheimer T, Wagner EH, Grumbach K. Improving primary care for patients with chronic illness. JAMA 2002a; 288 (14): 1775-1779.

Bondenheimer T, Wagner EH, Grumbach K. Improving primary care for patients with chronic illness: The Chronic Care Model, Part 2. JAMA 2002b; 288 (15): 19091914.

Boyd CM, Boult C, Shadmi E, Leff B, Brager R, Dunbar L, et al. Guided Care for Multimorbid Older Adults. Gerontologist 2007; 47(5): 697-703. 
Brasil. Ministério da Saúde. A vigilância, o controle e a prevenção das doenças crônicas não-transmissíveis: DCNT no contexto do Sistema Único de Saúde. Brasília (2005): Organização Pan Americana da Saúde. 80 pp.

Brasil. Ministério da Saúde. DATASUS. Mortalidade - Brasil [online]. http://tabnet.datasus.gov.br/cgi/tabcgi.exe?sim/cnv/obtuf.def [acesso em 22 mar. 2010].

Brasil. Ministério da Saúde. Política Nacional de Pessoa Idosa. Portaria n. 2528; 2006.

Brasil. Ministério da Saúde. Saúde Brasil 2008: 20 anos de Sistema Único de Saúde (SUS). Brasília (BR), 2009: 416 pp.

Brønnum-Hansen H, Juel K, Davidsen M. The burden of selected disease among older people in Denmark. J Aging Health 2006; 18(4): 491-506.

Buratta V, Egidi V. Data collection methods and comparability issues. In: Robine JM, Jagger C, Mathers CD, Crimmins EM, Suzman RM, editores. Determining Health Expectancies. England: John Wiley \& Sons; 2003. p. 187-201.

Camarano AA, Kanso S, Leitão e Mello J. Quão além dos 60 poderão viver os idosos brasileiros? In: Camarano AA, organizador. Os novos idosos brasileiros: muito além dos 60? Rio de Janeiro: IPEA; 2004. p. 77-105.

Camargos MCS, Perpetuo IHO, Machado CJ. Expectativa de vida com incapacidade funcional em idosos em São Paulo, Brasil. Rev Panam Salud Pública 2005;17(5/6): 379-86.

Camargos PAM, Jardim JR, Rosário Filho NA, Machado MCL, Barreto ML, Cerqueira CMP, et al. Aliança global contra doenças respiratórias crônicas - GARD no Brasil. Gazeta Médica da Bahia 2008; 78 (supl 2): 69-74.

Carvalho JAM, Garcia RA. O envelhecimento da população brasileira: um enfoque demográfico. Cad Saúde Pública 2003; 19 (3): 725-33.

Carvalho MTB, Rocha CMV, Pinto LLS, Bulhões MM, Sato HK. O Programa Nacional de Imunizações nos 20 anos do Sistema Único de Saúde no Brasil. In: Ministério da Saúde. Saúde Brasil 2008: 20 anos de Sistema Único de Saúde (SUS). Brasília (BR), 2009: 63 - 83.

Chaimowicz F. A saúde dos idosos brasileiros às vésperas do século XXI: problemas, projeções e alternativas. Rev Saúde Pública 1997; 31(2): 184-200.

Chang JT, Morton SC, Rubenstein LZ, Mojica WA, Maglione M, Suttorp MJ, Roth EA, Shekelle PG. Interventions for the prevention of falls in older adults: systematic review and meta-analysis of randomized clinical trials. BMJ 2001; 328: 680-6. 
Coelho FMC, Pinheiro RT, Magalhães PVS, Garcias CMM, Silva CV. Common mental disorders and chronic non-communicable diseases in adults: a populationbased study. Cad Saúde Pública 2009; 25(1): 59-67.

Crimmins EM. Health expectanies: What can we expect from summary indicator of population health? In: Murray CJL, Salomon JA, Mathers CD, Lopez AD, editores. Summary Measures of Population Health: Concepts, Ethics, Measurement and Applications. Geneva: World Health Organization; 2002. pp 214-9.

Cruz GT, Saito Y, Natividad JN. Active life expectancy and functional health transition among Filipino older people. Canadian Studies in Population 2007; 34(1): $29-47$.

Cummings SR, Melton LJ. Epidemiology and outcomes of osteoporotic fractures. Lancet 2002; 359 (18): 1761- 7.

Daar AS, Singer PA, Persad DL, Pramming SK, Matthews DR, Beaglehole R, et al. Grand challenges in chronic non-communicable diseases. Nature 2007; 450(22): 494-6.

Davis P, Graham P, Pearce N. Health expectancy in New Zealand, 1981-1991: social variation and trends in a period of rapid social and economic change. J Epidemiol Community Heatlh 1999; 53: 519-27.

Davis P, Mathers CD, Graham P. Health expectancy in Australia and New Zeland. In: Robine JM, Jagger C, Mathers CD, Crimmins EM, Suzman RM, editores. Determining Health Expectancies. England: John Wiley \& Sons; 2003. p. 392-408.

Deeg DJH, Verbrugge LM, Jagger C. Disability Measurement. In: Robine JM, Jagger C, Mathers CD, Crimins EM, Suzman RM, editores. Determining Health Expectancies. England: John Wiley \& Sons; 2003. p.203-19.

Diehr P, O’Meara ES, Fitzpatrick A, Newman AB, Kuller L, Burke G. Weight, mortality, years of healthy life, and active life expectancy in older adults. JAGS 2008; 56: 76-83.

Duarte YAO, Andrade CL, Lebrão ML. O índice de Katz na avaliação da funcionalidade dos idosos. Rev Esc Enferm USP 2007; 41(2): 317-25.

Duarte YAO, Lebrão ML, Lima FD. Contribuição dos arranjos domiciliares para o suprimento de demandas assistenciais dos idosos com comprometimento funcional em São Paulo, Brasil. Pan Am J Public Health 2005; 17 (5/6): 370-7.

Facchini LA, Garcia LP. Evolução e avanços da Saúde da Família e os 20 anos do Sistema Único de Saúde no Brasil. In: Ministério da Saúde. Saúde Brasil 2008: 20 anos de Sistema Único de Saúde (SUS). Brasília (BR), 2009: 39 - 62. 
Fiedler MM, Peres KG. Capacidade funcional e fatores associados em idosos do Sul do Brasil: um estudo de base populacional. Cad Saúde Pública 2008; 24 (2): 409-15.

Fortin M, Bravo G, Hudon C, Vanasse A, Lapointe L. Prevalence of multimorbidity among adults seen in family practice. Ann Fam Med 2005; 3: 223-8.

Fortin M, Lapointe L, Hudon C, Vanasse A, Ntetu AL, Maltais D. Multimorbidity and quality of life in primary care: a systematic review. Health Qual Life Outcomes 2004; 2 (51): 1-12

Francisco PMSB, Belon AP, Barros MBA, Carandina L, Alves MCGP, Goldbaum $\mathrm{M}$, et al. Diabetes auto-referido em idosos: prevalência, fatores associados e práticas de controle. Cad Saúde Pública 2010; 26 (1): 175-84.

Freedman VA, Martin LG, Schoeni RF. Recent trends in disability and functioning among older adults in the United States: a systematic review. JAMA 2002; 288 (24): 3137-46.

Frenk J, Frejka T, Bobadilla JL, Stern C, Lozano R, Sepúlveda J, et al. La transición epidemiológica en América Latina. Bol of Sanit Panam 1991; 111 (6): 485-96.

Fries JF. Aging, natural death and the compression of morbidity. NEJM 1980; July 17: $130-5$.

Fries JF, Bruce B, Chakravarty E. Compression of morbidity 1980-2011: a focused review of paradigms and progress. Journal of Aging Research 2011; publicado online em 11 de Abril de 2011. DOI: 10.4061/2011/261702.

Fries JF. Strategies for reduction of morbidity. Am J Clin Nutr 1992; 55: 1257S-62S.

Fries JF. The compression of morbidity. Milbank Meml Q Health Soc 1983; 61 (3): 397- 419.

Fries JF. The compression of morbidity: near or far? Milbank Q 1989; 67(2): 208-33.

Fundação Sistema Estadual de Análise de Dados (SEADE). Óbitos ocorridos no município de São Paulo, 2000. São Paulo: Fundação SEADE, 2002.

Glynn GL, Buckley B, Reddan D, Newell J, Hinde J, Dinneen SF, Murphy AW. Multimorbidity and risk among patients with established cardiovascular disease: a cohort study. Br J Gen Pract 2008; 58: 488-94.

Gotlieb SLD. Mortalidade diferencial por causa, São Paulo, Brasil, 1970: tábuas de vida de múltiplo decremento. Rev Saúde Pública 1981; 15: 401-17. 
Graham P, Blakely T, Davis P, Sporle A, Pearce A. Compression, expansion, or dynamic equilibrium? The evolution of health expectancy in New Zealand. J Epidemiol Community Health 2004; 28: 659-66.

Gregg EW, Pereira MA, Caspersen CJ. Physical activity, falls, and fractures among older adults: a review of the epidemiologic evidence. JAGS 2000; 48: 883-93.

Gruemberg EM. The failure of success. Milbank Meml Q 1977; 55 (1): 3-24.

Grundy EMD. The epidemiology of aging. In: Tallis RC, Fillit HW, editores. Brocklehurst's Textbook of Geriatric Medicine and Gerontology. Spain: Elsevier Science Limited; 2003. p. 03-20.

Gutiérrez-Fisac JL, Gispert R, Sola J. Factors explaining the geographical differences in Disability Free Life Expectancy in Spain. J Epidemiol Community Health 2000 Jun; 54(6): 451-5.

Ham-Chande R. Ageing and health expectancies in urban Latin America. In: Robine JM, Jagger C, Mathers CD, Crimmins EM, Suzman RM, editores. Determining Health Expectancies. England: John Wiley \& Sons; 2003. p. 319-33.

Hayward M, Crimmins E, Saito Y. Cause of death and active life expectancy in the older population of the United States. J Aging Health 1998; 10 (2): 192-213.

Imai K, Soneji S. On the estimation of disability-free life expectancy: Sullivan's method and its extension. Journal of the American Statistical Association 2007; 102(480): 1199-211.

Instituto Brasileiro de Geografia e Estatística (IBGE). Censo demográfico: 2000. Rio de Janeiro: IBGE; 2001.

Jagger C, Cox B, Le Roy S, EHEMU. Health Expectancy Calculation by the Sullivan Method. $3^{\circ}$ ed. Montpellier (France): EHEMU; June 2007, EHEMU Technical Report 2006 - 3.

Jagger C, Goyder E, Clarke M, Brouard N, Arthur A. Active life expectancy in people with and without diabetes. J Public Health Med 2003; 25 (1): 42-46.

Jagger C, Matthews RJ, Matthews F, Robinson T, Robine J-M, Brayne C. The burden of diseases on disability-free life expectancy in later life. J Gerontol Biological Sciences and Medical Sciences 2007a; 62A (4): 408-414.

Jagger C, Matthews R, Melzer D, Matthews F, Brayne C. Educational differences in the dynamics of disability incidence, recovery and mortality: Findings from the MRC Cognitive Function and Ageing Study (MRC CFAS). Int J Epidemiol 2007b Apr; 36 (2): 365-7. 
Johansson SR. The health transition: the cultural inflation of morbidity during the decline of mortality. Health Transition Review 1991; 1 (1): 39-65.

Kalache A, Aboderin I, Hoskins I. Compression of morbidity and active ageing: key priorities for public health policy in the $21^{\text {st }}$ century. Bull World Health Organ 2002; 80 (3): $243-4$.

Kalache A, Veras RP, Ramos LR. O envelhecimento da população mundial. Um desafio novo. Rev Saúde Pública 1987; 21 (3): 200-10.

Kirkwood TBL. Evolution theory and the mechanisms of aging. In: Tallis RC, Fillit HM, editores. Brocklehurst's Textbook of Geriatric Medicine and Gerontology. 6th ed. Spain: Elsevier Science; 2003. p. 31-5.

Kondo N, Mizutani T, Minai J, Kazuma M, Imai H, Takeda Y, et al. Factors explaining disability-free life expectancy in Japan: the proportion of older workers, self-reported health status, and the number of public health nurses. J Epidemiol 2005 Nov; 15(6): 219-27.

Kramer M. The rising pandemic of mental disorders and associated chronic diseases and disabilities. Acta Psychiatr Scand 1980; 62 (S285): 382-97.

Laurenti R, Mello Jorge MHP, Lebrão ML, Gotlieb SLD. Estatísticas de Saúde. $2^{\circ}$ ed. rev. e atual. São Paulo: EPU; 2005a.

Laurenti R, Mello Jorge MHP, Lebrão ML, Gotlieb SLD. População: recenseamento e estimativas. In: Laurenti R, Mello Jorge MHP, Lebrão ML, Gotlieb SLD, editores. Estatísticas de Saúde. $2^{\circ}$ ed. rev. e atual. São Paulo: EPU; 2005b. p. 25-51.

Lavizzo-Mourey RJ, Mackenzie E. Cultural competence - an essencial hybrid for delivering high quality care in the 1990's and beyond. Transaction of The American Clinical and Climatological Association 1995; 107: 226 - 37.

Lebrão ML, Duarte YAO. SABE - Saúde, Bem-estar e Envelhecimento - O Projeto Sabe no município de São Paulo. São Paulo (Brasil): FSP- USP; 2008 [Cd-Rom].

Lebrão ML, Duarte YAO. SABE - Saúde, Bem-estar e Envelhecimento - O Projeto Sabe no município de São Paulo: uma abordagem inicial. Brasília (Brasil): Organização Pan-Americana da Saúde; 2003.

Lebrão ML, Laurenti R. Saúde, Bem-estar e Envelhecimento: o estudo SABE no município de São Paulo. Rev Bras Epidemio 2005; 8(2): 127-41.

Lebrão ML, Louvison M, Duarte YAO. A regulação da saúde suplementar e o direito da pessoa idosa à assistência à saúde. Rev Direito Sanit 2008; 9(2): 190-206. 
Lima-Costa MF, Barreto SM, Giatti L. Condições de saúde, capacidade funcional, uso de serviços de saúde e gastos com medicamentos da população idosa brasileira: um estudo descritivo baseado na Pesquisa Nacional por Amostra de Domicílios. Cad Saúde Pública 2003a, 19(3): 735-43.

Lima-Costa MF, Barreto SM, Giatti L, Uchôa E. Desigualdade social e saúde entre idosos brasileiros: um estudo baseado na Pesquisa Nacional por Amostra de Domicílios. Cad Saúde Pública 2003b; 19(3): 745-57.

Lima-Costa MF, Loyola Filho AI, Matos DL. Tendências nas condições de saúde e uso de serviços de saúde entre idosos brasileiros: um estudo baseado na Pesquisa Nacional por Amostra de Domicílios (1998, 2003). Cad Saúde Pública 2007; 23 (10): 2467-78.

Lima-Costa MF, Matos DL. Tendências das condições de saúde e uso de serviços de saúde da população idosa brasileira: 20 anos de Sistema Único de Saúde. In: Ministério da Saúde. Saúde Brasil 2008: 20 anos de Sistema Único de Saúde (SUS). Brasília (BR), 2009: 385-405.

Litvoc J, Brito FC. Conceitos básicos. In: Litvoc J, Brito FC, organizadores. Envelhecimento: prevenção e promoção da saúde. São Paulo: Atheneu; 2004. p. 116.

Louvison MCP, Lebrão ML, Lima FD, Duarte YAO. Uso e acesso de serviços de saúde entre a população idosa do município de São Paulo. Divulg Saúde Debate 2007; 38: 7-13.

Lupien SJ, Wan N. Successful Ageing: from cell to self. Phil Trans R Soc Lond B 2004; 359: 1413-26.

Machado GPM, Barreto SM, Passos VMA, Lima-Costa MF. Projeto Bambuí: Prevalência de sintomas articulares crônicos em idosos. Rev Assoc Med Bras 2004; 50 (4): 367-72.

Machado JCB. Doença de Alzheimer. In: Freitas EV, Py L, Cançado FAX, Doll J, Gorzoni ML, editores. Tratado de Geriatria e Gerontologia. $2^{\circ}$ ed. Rio de Janeiro: Guanabara Koogan; 2006. p. 260-80.

Maciel ACC, Guerra RO. Influência dos fatores biopsicossociais sobre a capacidade funcional de idosos residentes no nordeste do Brasil. Rev Bras Epidemiol 2007; 10(2): 178-88.

Maia FOM, Duarte YAO, Lebrão ML. Análise dos óbitos em idosos no Estudo SABE. Rev Esc Enferm USP 2006a; 40 (4): 540-7.

Maia FOM, Duarte YAO, Lebrão ML, Santos JLF. Fatores de risco para mortalidade em idosos. Rev Saúde Pública 2006b; 40: 1049-56. 
Malta DC, Moura L, Souza FM, Rocha FM, Fernandes RM. Doenças crônicas não transmissíveis; mortalidade e fatores de risco no Brasil, 1990 a 2006. In: Ministério da Saúde. Saúde Brasil 2008: 20 anos de Sistema Único de Saúde (SUS). Brasília (BR), 2009: 337-63.

Manton KG. Changing concepts of morbidity and mortality in the elderly population. Milbank Meml Q Health Soc 1982; 60(2): 183-244.

Manuel DG, Leung M, Nguyen K, Tanuseputro P, Johansen H. Burden of cardiovascular disease in Canada. Can J Cardiol 2003a; 19 (9): 997-1004.

Manuel DG, Luo W, Ugnat AM, Mao Y. Cause-deleted health-adjusted life expectancy of Canadians with selected chronic conditions. Chronic Dis Can 2003b; 24 (4): 108-15.

Manuel DG, Schultz SE, Kopec JA. Measuring the health burden of chronic disease and injury using health adjusted life expectancy and the Health Utilities Index. J Epidemiol Community Health 2002; 56: 843-50.

Marcopito LF, Rodrigues SSF, Pacheco MA, Shirassu MM, Goldfeder AJ, Moraes MA. Prevalence of a set of risk factors for chronic diseases in the city of São Paulo, Brazil. Rev Saúde Pública 2005; 39 (5): 1-7.

Martini LA, Moura EC, Santos LC, Malta DC, Pinheiro MM. Prevalence of selfreported diagnosis of osteoporosis in Brazil, 2006. Rev Saúde Pública 2009; 43(supl 2): $1-9$.

Mathers CD. Cause-deleted health expectancies. In: Robine JM, Jagger C, Mathers CD, Crimmins EM, Suzman RM, editores. Determining Health Expectancies. England: John Wiley \& Sons; 2003. p. 149-74.

Mathers CD, Ezzati M, Lopez AD, Murray CJL, Rodgers A. Causal decomposition of summary measures of population health. In: Murray CJL, Salomon JA, Mathers CD, Lopez AD, editores. Summary Measures of Population Health: Concepts, Ethics, Measurement and Applications. Geneva: World Health Organization; 2002. p. 274-90.

Mathers CD. Gains in health expectancy from the elimination of diseases among older people. Disabil Rehabil 1999; 21(5-6): 211-21.

Mathers CD. Health expectancies: an overview and critical appraisal. In: Murray CJL, Salomon JA, Mathers CD, Lopez AD, editores. Summary measures of population health: concepts, ethics, measurement and applications. Geneva: World Health Organization; 2002. p. 177-204. 
Mathers CD, Murray CJL, Lopez AD, Salomon JA, Sadana R. Global Paterns of Health Expectancy in the year 2000. In: Robine JM, Jagger C, Mathers CD, Crimmins EM, Suzman RM, editores. Determining Health Expectancies. England: John Wiley \& Sons; 2003. p. 335-58.

Mathers CD, Robine JM. How good is Sullivan's method for monitoring changes in population health expectancies. J Epidemiol Community Health 1997; 51: 80-6.

Mathers CD, Sadana R, Salomon JA, Murray CJL, Lopez AD. Healthy life expectancy in 191 countries, 1999. Lancet 2001a; 357: 1685-91.

Mathers CD, Vos T, Lopez AD, Salomon J, Ezzati M. National Burden of Disease Studies: A Practical Guide. $2^{\circ}$ ed. Geneva: World Health Organization; 2001b.

Mathews RJ, Jagger C, Hancock RM. Does socio-economic advantage lead to a longer, healthier old age? Soc Sci Med 2006 May; 62 (10): 2489-99.

McDowell I, Spasoff RA, Kristjansson B. On the classification of population health measurements. Am J Public Health 2004; 94 (3): 388-93.

Mendoza-Sassi RA, Béria JU. Gender differences in self-reported morbidity: evidence from a population-based study in southern Brazil. Cad Saúde Pública 2007; 23 (2): 341-6.

Menezes AMB, Jardim JR, Pérez-Padilha R, Camelier A, Rosa F, Nascimento O, et al. Prevalence of chronic obstructive pulmonary disease and associated factors: the PLATINO Study in São Paulo, Brazil. Cad Saúde Pública 2005a; 21 (5): 1565-73.

Menezes AMB, Pérez-Padilha R, Jardim JRB, Muiño A, Lopez MV, Valdivia G, et al. Chronic obstructive pulmonary disease in five Latin American cities (the PLATINO study): a prevalence study. Lancet 2005. Publicado online em 4 de novembro de 2005b. DOI: 10.1016/S0140-6736(05)67632-5.

Murray CJL, Lopez AD. Regional patterns of disability-free life expectancy and disability-adjusted life expectancy: Global Burden of Disease Study. Lancet 1997; 349:1347-52.

Murray CJL, Salomon JA, Mathers CD. A critical examination of summary measures of population health. Bull World Health Organ 2000; 78(8): 981-94.

Myers GC, Lamb VL, Agree EM. Patterns of disability change associated with the epidemiologic transition. In: Robine JM, Jagger C, Mathers CD, Crimmins EM, Suzman RM, editores. Determining Health Expectancies. England: John Wiley \& Sons; 2003. p.59-74.

Myers GC, Manton KG. Compression of mortality: myth or reality? Gerontologist 1984; 24 (4): 346- 59. 
Nagel G, Peter R, Braig S, Hermann S, Rohrmann S, Linseisen J. The impact of education on risk factors and the occurrence of multimorbidity in the EPICHeidelberg cohort. BMC Public Health 2008; publicado online em 4 de junho de 2008. DOI: $10.1186 / 1471-2458-8-384$.

Nardi R, Scanelli G, Corrao S, Iori I, Mathieu G, Amatrian RC. Co-morbity does not reflect complexity in internal medicine patients. Eur J Intern Med 2007; 18: 359-68.

Nazário CL. Aspectos metodológicos: trabalho de campo para coleta de dados. In: Lebrão ML, Duarte YAO, editores. SABE: Saúde, Bem-estar e Envelhecimento - O projeto SABE no município de São Paulo: uma abordagem inicial. Brasília: OPAS; 2003. p. 59-67.

Neri AL, Cachioni M. Velhice bem sucedida e educação. In: Neri AL, Debert GG, editores. Velhice e sociedade. Campinas: Papirus; 1999. p. 113-36.

Neri AL. O legado de Paul B. Baltes à psicologia do desenvolvimento e do envelhecimento. Temas em Psicol 2006; 14 (1): 17-34.

Nóbrega TCM, Jaluul O, Machado AN, Paschoal SMP, Jacob Filho W. Quality of life and multimorbidity of elderly outpatients. Clinics 2009; 64 (1): 45-90.

Nusselder WJ. Compression of Morbidity. In: Robine JM, Jagger C, Mathers CD, Crimmins EM, Suzman RM, editores. Determining Health Expectancies. England: John Wiley \& Sons; 2003. p. 35-58.

Nusselder WJ, Looman CW, Marang-van de Mheen PJ, van de Mheen H, Machenbach JP. Smoking and the compression of morbidity. J Epidemiol Community Health 2000 Aug; 54 (8): 566-74.

Nusselder WJ, Peeters A. Succesful aging: measuring the years lived with functional loss. J Epidemiol Community Health 2006; 60: 448-55.

Nusselder WJ, Van der Velden K, Van Sonsbeek JLA, Lenior M, Van den Bos GAM. The elimination of selected chronic diseases in a population: the compression and expansion of morbidity. Am J Public Health 1996; 86 (2): 187-94.

Omran AR. The epidemiologic transition: a theory of the epidemiology of population change. Milbank Meml Q 1971; 49 (4): 509-38.

Omran AR. The epidemiologic transition theory. A preliminary update. J Trop Pediatr 1983; 29: 305-16.

Organização Mundial da Saúde (OMS), Centro Colaborador da Organização Mundial da Saúde para a Família de Classificações Internacionais. CIF: Classificação Internacional de Funcionalidade, Incapacidade e Saúde. São Paulo: Edusp; 2003a. 
Organização Mundial da Saúde (OMS). Classificação Estatística Internacional de Doenças e Problemas Relacionados à Saúde - 10 $10^{a}$ Revisão. São Paulo: Centro Colaborador da OMS para a Classificação de Doenças em Português; 1995.

Organização Mundial da Saúde (OMS). Cuidados inovadores para condições crônicas: componentes estruturais de ação: relatório mundial. Brasília: Organização Mundial da Saúde; 2003b.

Organização Mundial da Saúde (OMS). Envelhecimento ativo: uma política de saúde. (trad. Suzana Gontijo). Brasília: Organização Pan-Americana de Saúde; 2005. $60 \mathrm{p}$.

Organização Pan-Americana da Saúde (OPAS). Saúde nas Américas: 2007. Washington, D.C.: OPAS; 2007-2v (OPAS), Publicação Científica e Técnica $\mathrm{N}^{0}$. 622.

Paes-Sousa R, Carepa J, Vaitsman J. A dinâmica dos macrodeterminantes da saúde nos 20 anos de Sistema Único de Saúde no Brasil. In: Ministério da Saúde. Saúde Brasil 2008: 20 anos de Sistema Único de Saúde (SUS). Brasília (BR), 2009: 17-35.

Palloni A, Peláez M. Histórico e natureza do estudo. In: Lebrão ML, Duarte YAO, editores. SABE: Saúde, Bem-estar e Envelhecimento - O projeto SABE no município de São Paulo: uma abordagem inicial. Brasília: OPAS; 2003. p. 15-32.

Paschoal SMP. Epidemiologia do envelhecimento. In: Papaléo Netto M. Gerontologia: a velhice e o envelhecimento em visão globalizada. São Paulo: Editora Atheneu; 1996. p. 26-43.

Perenboom RJM, Van Herten LM, Boshuizen HC, Van den Bos GAM. Trends in disability-free life expectancy. Disabil Rehabil 2004; 26 (7): 377-86.

Perenboom RJM, Van Oyen H, Mutafova M. Health Expectancies in European Countries. In: Robine JM, Jagger C, Mathers CD, Crimmins EM, Suzman RM, editores. Determining Health Expectancies. England: John Wiley \& Sons; 2003. p.359-76.

Phelan EA, Paniagua MA, Hazzard WR. Preventive gerontology: strategies for optimizing health across the life span. In: Hazzard WR , editor. Principles of Geriatric Medicine and Gerontology. $5^{\text {th }}$ Edition. New York: McGraw-Hill Professional; 2003. p. 85-92.

Pimenta MC, Brito I. HIV / AIDS no Sistema Único de Saúde: Respostas e desafios à epidemia no Brasil. In: Ministério da Saúde. Saúde Brasil 2008: 20 anos de Sistema Único de Saúde (SUS). Brasília (BR), 2009: 131 - 54. 
Ramos LR. Epidemiologia do Envelhecimento. In: Freitas EV, Py L, Néri AL, Cançado HAX, Gorzoni ML, Rocha SM, editores. Tratado de Geriatria e Gerontologia. Rio de Janeiro: Guanabara Koogan; 2002. p. 72-8.

Ramos LR. Fatores determinantes do envelhecimento saudável em idosos residentes em centro urbano: Projeto Epidoso, São Paulo. Cad Saúde Pública 2003 (Mai-Jun); 19 (3): 793-98.

Ramos LR, Veras RP, Kalache A. Envelhecimento populacional: uma realidade brasileira. Rev Saúde Publ 1987; 21 (3): 211-24.

Rao JNK, Scott AJ. On Chi - squared tests for multiway contingency tables with cell proportions estimated from survey data. Annals of Statistics 1984; 12: 46-60.

Ritchie K, Robine JM, Letenneur L, Dartigues JF. Dementia-Free Life Expectancy in France. Am J Public Health 1994; 84 (2): 232-6.

Robine JM, Mormiche P, Sermet C. Examination of the causes and mechanisms of the increase in disability-free life expectancy. J Aging Health 1998; 10 (2): 171-91.

Robine JM, Ritchie K. Healthy life expectancy: evaluation of global indicator of change in population health. BMJ 1991; 302: 457-60.

Robine JM, Romieu I, Cambois E. Health expectancy indicators. Bull World Health Organ 1999; 77(2): 181-5.

Robine JM, Romieu I, Michel JP. Trends in health expectancies. In: Robine JM, Jagger C, Mathers CD, Crimmins EM, Suzman RM, editores. Determining Health Expectancies. England: John Wiley \& Sons; 2003. p. 75-101.

Romero DE, Costa Leite I, Szwarcwald CL. Healthy life expectancy in Brazil: applying the Sullivan method. Cad Saúde Pública 2005; 21(suppl 1):S7-S18.

Safford M, Allison JJ, Kiefe CI. Patient complexity: more than comorbidity. The vector model of complexity. J Gen Intern Med 2007; 22 (suppl 3): 382-90.

Santana VS, Silva JM. Os 20 anos da saúde do trabalhador no Sistema Único de Saúde do Brasil: limites, avanços e desafios. In: Ministério da Saúde. Saúde Brasil 2008: 20 anos de Sistema Único de Saúde (SUS). Brasília (BR), 2009: 175 - 204.

Sartorelli DS, Franco LJ. Tendências do diabetes mellitus no Brasil: o papel da transição nutricional. Cad Saúde Pública 2003; 19 (suppl 1): S29-S36.

Sauvaget C, Tsuji I, Aonuma T, Hisamichi S. Health-life expectancy according to various functional levels. JAGS 1999; 47: 1326-31. 
Schmidt MI, Duncan BB, Azevedo e Silva G, Menezes AM, Monteiro CA, Barreto SM, Chor D, Menezes PR. Doenças crônicas não transmissíveis no Brasil: carga e desafios atuais. Lancet 2011; publicado online em 9 de maio de 2011. DOI: 10,1016/S0140-6736(11)60135-9.

Schramm JMA, Oliveira AF, Leite IC, Valente JG, Gadelha AMJ, Portela MC, et al. Transição epidemiológica e o estudo de carga de doença no Brasil. Ciênc Saúde Coletiva 2004; 9(4): 897-908.

Secretaria de Estado de Saúde de São Paulo (SES-SP). Linha de Cuidado Hipertensão Arterial Sistêmica. São Paulo: 2010, 74 p.

Silva MCP, De Laet C, Nusselder WJ, Mamun AA, Peters A. Adult obesity and number of years lived with and without cardiovascular disease. Obesity 2006; 14 (7): 1264-73.

Silva NN. Aspectos metodológicos: processo de amostragem. In: Lebrão ML, Duarte YAO, organizadores. SABE: Saúde, Bem-estar e Envelhecimento - O projeto SABE no município de São Paulo: uma abordagem inicial. Brasília: OPAS; 2003. p. 47-57.

Soubhi $\mathrm{H}$, et al. Learning and caring in communities of practice: using relationships and collective learning to improve primary care for patients with multimorbidity. Ann Fam Med 2010; 8(2): 170-7.

Strong K, Mathers C, Leeder S, Beaglehole R. Preventing chronic diseases: how many lives can we save? Lancet 2005; 366: 1578-82.

Sullivan DF. A single index of mortality and morbidity. HSMHA Health Reports 1971; 86: 347-54.

Szwarcwald CI, Viacava F. World Health Survey in Brazil, 2003. Cad. Saúde Pública 2005; 21 (suppl 1): S4-S5.

Takahashi PY, Okhravi HR, Lim LS, Kasten MJ. Preventive health care in the elderly population: a guide for practicing physicians. Mayo Clin Proc 2004; 79: 41627.

Tsai SP, Lee ES, Hardy RJ. The effect of a reduction in leading causes of death: potencial gains in life expectancy. Am J Public Health 1978; 68: 966-71.

Verbrugge LM. Longer life but worsening health? Trends in health and mortality of middle-aged and older persons. Milbank Meml Q Health Soc 1984; 62 (3): 475 519.

Viola RC. Políticas de atenção à saúde da mulher e os 20 anos de Sistema Único de Saúde no Brasil. In: Ministério da Saúde. Saúde Brasil 2008: 20 anos de Sistema Único de Saúde (SUS). Brasília (BR), 2009: 111-30. 
Waldman EA. A transição epidemiológica: tendências e diferenciais dos padrões de morbimortalidade em diferentes regiões do mundo. Mundo Saúde 2000; 24 (1): 1018 . 


\section{ANEXO 1 - QUESTIONÁRIO SABE 2000 (CD-ROM)}

Seção A - Dados Pessoais

Seção B - Avaliação Cognitiva

Seção C - Estado de saúde

Seção D - Estado Funcional

Seção E - Medicamentos

Seção F - Uso e acesso a serviços

Seção G - Rede de apoio familiar e social

Seção H - História laboral e fontes de renda

Seção J - Características da moradia

Seção K - Antropometria

Seção L - Flexibilidade e Mobilidade 


\section{ANEXO 2 - TÁBUAS DE VIDA (CD-ROM)}

1- Tábua de Eliminação de Causa Articular Feminino

2- Tábua de Eliminação de Causa Articular Masculino

3- Tábua de Eliminação de Causa Cardíaca Feminino

4- Tábua de Eliminação de Causa Cardíaca Masculino

5- Tábua de Eliminação de Causa Cerebrovascular Feminino

6- Tábua de Eliminação de Causa Cerebrovascular Masculino

7- Tábua de Eliminação de Causa Diabetes Feminino

8- Tábua de Eliminação de Causa Diabetes Masculino

9- Tábua de Eliminação de Causa Hipertensão Feminino

10- Tábua de Eliminação de Causa Hipertensão Masculino

11- Tábua de Eliminação de Causa Mental Feminino

12- Tábua de Eliminação de Causa Mental Masculino

13- Tábua de Eliminação de Causa Neoplasia Feminino

14- Tábua de Eliminação de Causa Neoplasia Masculino

15- Tábua de Eliminação de Causa Pulmonar Feminino

16- Tábua de Eliminação de Causa Pulmonar Masculino

17- Tábua de Eliminação de Causa Queda Feminino

18- Tábua de Eliminação de Causa Queda Masculino

19- Tábua de Vida pelo Método de Sullivan - Sexo Feminino

20- Tábua de Vida pelo Método de Sullivan - Sexo Masculino 


\section{ANEXO 3 - PARECERES DO COMITÊ DE ÉTICA EM PESQUISA}

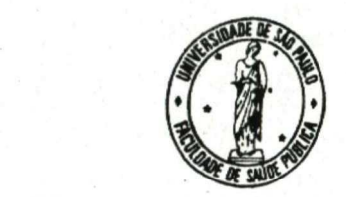

Universidade de São Paulo

Faculdade de Saúde Pública

COMITÊ DE ÉTICA - COEP

Av. Dr. Arnaldo, 715 - Assessoria Acadêmica - CEP 01246-904 - Sĩos Paulo - Brasil Telefones: (55-11) 3066-7779 - e-mail: coep(u)fsp.usp.hr

\section{Of.COEP/83/06}

Pelo presente, informo que o Comitê de Ética em Pesquisa da Faculdade de Saúde Pública da Universidade de São Paulo-COEP, aprovou o Protocolo de Pesquisa n. ${ }^{\circ}$ 1345, intitulado: "PROJETO SABE-2005 - SAÚDE, BEM-ESTAR E ENVELHECIMENTO. AS CONDIÇÕES DE SAÚDE E DE VIDA DOS IDOSOS NO MUNICÍPIO DE SÃO PAULO”, apresentado pela pesquisádora Maria Lúcia Lebrão.

Atenciosamente,

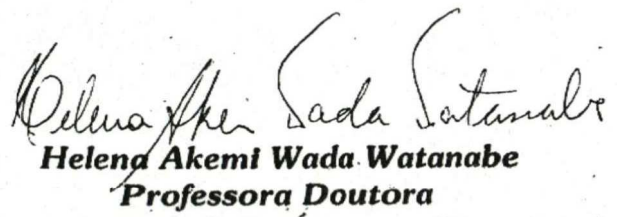

Vice-Coordenadora do Comitê de Ética em Pesquisa da FSP-COEP 


\section{Of.COEP/67/99}

24 de maio de 1999

Pelo presente, informo que o Comitê de Ética em Pesquisa, aprovou, em sua 3. ${ }^{2} / 99$, Sessão Ordinária, de 19.05.99, de acordo com os requisitos da Resolução CNS/196/96, o Projeto de Pesquisa "AS CONDIÇÕES DE SAÚDE DOS IDOSOS NA AMÉRICA DO SUL E CARIBE", apresentado pelo pesquisador Ruy Laurenti, devendo ser remetido à CONEP conforme as normas da Resolução 196/96.

Atenciosamente,

Prof.Dr. Paulo Anfonce de Carvalho Fortes

Vice-Coordenador do Comitê łe h́tita em Pesquisa da FSP-COEP

Vice-Coordenador do Comite ay 


\section{ALESSANDRO GONCALVES CAMPOLINA}

possui graduação em medicina pela Universidade Federal de São Paulo (2000), Residência Médica em Geriatria e Gerontologia (2004), Título de Especialista em Geriatria (2009) e Mestrado em Ciências pela Universidade Federal de São Paulo (2007). Tem experiência em avaliação de qualidade de vida, análise de decisão e saúde do idoso. Atualmente atua como médico geriatra e intensivista na rede pública e privada de saúde.(Texto informado pelo autor)

Última atualização do currículo em 13/11/2011

Endereço para acessar este CV:

http://lattes.cnpq.br/0176903783847881

Dados pessoais

Nome Alessandro Gonçalves Campolina

Nome em CAMPOLINA, A. G.

citações

bibliográficas

Sexo Masculino

Endereço Centro Integrado em Geriatria e Gerontologia.

profissional Rua Pedro de Toledo, 129 - 83

Vila Clementino

04039-030 - São Paulo, SP - Brasil

Telefone: (11) 38072550 Fax: (11) 39262553

URL da Homepage: www.gerocenter.com.br

Formação acadêmica/Titulação

2005 - $2007 \quad$ Mestrado em Reumatologia (Conceito CAPES 5) .

Universidade Federal de São Paulo, UNIFESP, Brasil.

Título: Avaliação de preferências em artrite reumatóide: uma comparação de métodos derivados do SF-36 com medidas diretas de preferência, Ano de Obtenção: 2007.

Orientador: (9)Rozana Mesquita Ciconelli.

Bolsista do(a): Coordenação de Aperfeiçoamento de Pessoal de Nível Superior .

Grande área: Ciências da Saúde / Área: Medicina.

Grande área: Ciências da Saúde / Área: Medicina / Subárea:

Economia da Saúde.

Grande área: Ciências da Saúde / Área: Medicina / Subárea: Economia da Saúde / Especialidade: Avaliação de Qualidade de Vida.

Setores de atividade: Cuidado À Saúde das Pessoas. 


\section{MARIA LUCIA LEBRAO}

MARIA LUCIA LEBRAO CONCLUIU O DOUTORADO EM SAÚDE PÚBLICA PELA UNIVERSIDADE DE SÃO PAULO EM 1982. ATUALMENTE E PROFESSOR TITULAR DA UNIVERSIDADE DE SÃO PAULO. PUBLICOU 23 ARTIGOS EM PERIÓDICOS ESPECIALIZADOS E 26 TRABALHOS EM ANAIS DE EVENTOS. POSSUI 5 CAPÍTULOS DE LIVROS E 5 LIVROS PUBLICADOS. POSSUI 104 ITENS DE PRODUÇÃO TÉCNICA. PARTICIPOU DE 13 EVENTOS NO BRASIL. ORIENTOU 9 DISSERTAÇÕES DE MESTRADO E 3 TESES DE DOUTORADO NA ÁREA DE MEDICINA. RECEBEU 9 PREMIOS E/OU HOMENAGENS. ATUA NA ÁREA DE SAUDE COLETIVA, COM ÊNFASE EM EPIDEMIOLOGIA. EM SUAS ATIVIDADES PROFISSIONAIS INTERAGIU COM 49 COLABORADORES EM CO-AUTORIAS DE TRABALHOS CIENTÍFICOS. EM SEU CURRÍCULO LATTES OS TERMOS MAIS FREQUENTES NA CONTEXTUALIZAÇÃO DA PRODUÇÃO CIENTÍFICA, TECNOLOGICA E ARTÍSTICO-CULTURAL SAO: MORBIDADE, DADOS HOSPITALARES, MORBIDADE HOSPITALAR, CID, CID PARA A PRÁTICA, CLASSIFICAÇÃO INTERNACIONAL DE DOENÇAS, CLASSIFICAÇÃO INTERNACIONAL DE DONÇAS, DEMANDA HOSPITALAR, ENSINO MÉDICO E ESTATÍSTICA EM SAÚDE, ESTUDOS DE ENVELHECIMENTO.

(Texto informado pelo autor)

Última atualização do currículo em 28/09/2011

Endereço para acessar este CV:

http://lattes.cnpq.br/5317708343061802

Dados pessoais

$\begin{array}{ll}\begin{array}{ll}\text { Nome } \\ \text { Nome em } \\ \text { citações } \\ \text { bibliográficas }\end{array} & \text { LEBria Lúcia Lebrão } \\ \text { Sexo } & \text { Feminino } \\ \text { Endereço } & \text { Universidade de São Paulo, Faculdade de Saúde Pública, Departamento de } \\ \text { profissional } & \begin{array}{l}\text { Epidemiologia. } \\ \text { Av Dr. Arnaldo, 715 - Pinheiros } \\ \end{array} \\ & \begin{array}{l}\text { 01246-904 - São Paulo, SP - Brasil } \\ \text { Telefone: (11) 30667724 Fax: (11) 30823886 }\end{array}\end{array}$

Formação acadêmica/Titulação

1994

Livre-docência.

Universidade de São Paulo, USP, Brasil.

Título: , Ano de obtenção: 1994.

$1977-1982$

Doutorado em Saúde Pública (Conceito CAPES 5) .

Universidade de São Paulo, USP, Brasil.

Título: Morbidade Hospitalar no Vale do Paraíba, 1975, Ano de

Obtenção: 1982.

Orientador: Ruy Laurenti. 
